\title{
Simulação numérica de uma função indicadora de fluidos tridimensional empregando refinamento adaptativo de malhas
}

\author{
Daniel Mendes Azerêdo \\ DissertaÇÃo APRESENTADA \\ $\mathrm{AO}$ \\ Instituto de MATEmÁticA E EstatísticA \\ DA \\ UniversidAde DE SÃo PAUlo \\ PARA \\ OBTENÇÃO DO TÍTULO \\ $\mathrm{DE}$ \\ Mestre EM Cî̂nCIAS \\ Área de Concentração: Matemática Aplicada
Orientador: Prof. Dr. Alexandre Megiorin Roma
}

Durante a elaboração deste trabalho o autor recebeu auxílio financeiro da CAPES 


\section{Simulação numérica de uma função indicadora de fluidos tridimensional empregando refinamento adaptativo de malhas}

Este exemplar corresponde à redação final da dissertação devidamente corrigida e defendida por Daniel Mendes Azerêdo e aprovada pela Comissão Julgadora.

Banca Examinadora:

- Prof. Dr. Alexandre Megiorin Roma - IME USP

- Prof. Dr. Antônio Castelo Filho - ICMC USP

- Prof. Dr. Antônio Elias Fabris - IME USP 


\section{Agradecimentos}

Antes de mais nada, agradeço à toda minha família pelo carinho, dedicação e amor que sempre me ofereceram. Agradeço especialmente à minha mãe, uma mulher extraordinária, uma incansável trabalhadora e um exemplo de vida. Minha gratidão especial também às minhas queridas avós (Maria e Cleusa), à minha tia Ivete e à minha amorosa namorada Fabíola, por toda atenção, carinho e incentivo.

Agradeço de maneira muito especial ao meu dedicado orientador, professor Alexandre Megiorin Roma, por toda a paciência, dedicação, incentivo e incalculável ensinamento durante nossas inúmeras reuniões ao longo desses mais de dois anos de trabalho juntos.

Minha gratidão também aos incomparáveis docentes e funcionários do Instituto de Matemática e Estatística da Universidade de São Paulo, por toda a dedicação, atenção, apoio e pelos ensinamentos espetaculares.

Pela generosa ajuda nos momentos de dúvida e dificuldade durante a elaboração desse trabalho, gostaria de agradecer aos amigos Erasmo de Souza Dias, Alessandro Alves Santana, Rudimar Nós, Archibald Silva, Olga Saito, Francisco Moreira, Millena Villar, Diane

Rizzotto Rossetto, Priscila Cardoso Calegari e, em especial, aos meus amigos do peito Giselle Schimidt Ragazzo e Marlon Wisner Valgas.

Não tenho como expressar minha gratidão para com todo o corpo docente e os funcionários do Instituto de Matemática e Estatística da Universidade Federal de Goiás, por me tolerarem pacientemente durante os quatro anos da graduação e por toda a dedicação na arte de ensinar Matemática e formar professores e pesquisadores nessa área. Em especial aos professores e amigos Geci José Pereira da Silva e Rosely Maria Barbosa 
Goes.

Não poderia deixar de agradecer a todos os amigos que tive o imenso prazer de conhecer na UFG, que prefiro não tentar colocar os nomes deles aqui porque tenho certeza que vou esquecer de citar alguém, por toda a ajuda, apoio e torcida. Entre eles, agradeço imensamente aos onze amigos que terminaram o curso de bacharelado em Matemática comigo, pelo companherismo e amizade durante os momentos difíceis.

E, por fim, seria um relapso muito grande da minha parte se não agradecesse a CAPES (Coordenação de Aperfeiçoamento de Pessoal de Nível Superior) pela bolsa de mestrado e a FAPESP (Fundação de Amparo a Pesquisa do Estado de São Paulo), projeto 04/13781-1, pelos recursos computacionais que possibilitaram a elaboração desse trabalho. 


\section{Resumo}

O presente trabalho tem como motivação científica a modelagem matemática e a simulação computacional de escoamentos multifásicos. Mais especificamente, partindo-se de uma formulação que combina o Método da Fronteira Imersa com o uso de uma função indicadora de fluidos as equações do movimento de um escoamento incompressível bifásico são descritas.

Adotando-se uma abordagem empregada comumente, assume-se que as equações que regem a dinâmica do fluido estão discretizadas em uma malha estruturada (malha euleriana) que recobre todo o domínio onde ocorre o escoamento e que a interface de separação entre suas fases é discretizada por uma malha não estruturada formada por triângulos (malha lagrangiana). Empregando-se técnicas de Geometria Computacional e de refinamento adaptativo de malhas, o foco aqui é restrito ao cálculo tridimensional eficiente da função indicadora de fluidos em malhas eulerianas bloco-estruturadas com refinamento dinâmico localizado.

O software livre GMSH pode ser empregado para gerar uma malha triangular, bidimensional e não estruturada para representar computacionalmente um "sólido" por meio de sua superfície externa. Aqui, esse software é utilizado para discretizar a interface de separação entre as fases (a fronteira imersa), obtendo-se a malha lagrangiana inicial. Para o armazenamento dos "vértices" (pontos lagrangianos) emprega-se a estrutura de dados Halfedge, amplamente empregada em Computação Gráfica para armazenar superfícies fechadas e orientáveis.

Uma vez que a malha lagrangiana esteja armazenada nesta estrutura de dados, passa- 
se a estudar uma hipotética interação dinâmica entre a fronteira imersa e o escoamento do fluido. Esta interação é estudada apenas em um sentido. Considerando-se apenas a condição de não deslizamento, assume-se que fronteira imersa acompanha passivamente o escoamento representado por um campo de velocidades pré-estabelecido (imposto). Em nenhum momento, a fronteira imersa oferece qualquer resistência ou exerce qualquer tipo de força ou influência sobre tal escoamento. Em particular, as equações de Navier-Stokes não são resolvidas.

A função indicadora de fluidos é determinada pelo cálculo da distância com sinal, numa vizinhança da fronteira imersa, entre pontos da malha euleriana e a interface de separação. Ela é empregada para identificar o interior e o exterior da região limitada e fechada que, supostamente, contém uma das fases em escoamento. Esta distância com sinal é atualizada a cada passo no tempo empregando idéias e métodos de Geometria Computacional, o que torna o custo computacional para calcular essa função ótimo. Este custo independe da complexidade geométrica da interface. Tal metodologia mostrou-se robusta e produz uma definição nítida das distintas fases do fluido em todos os passos no tempo.

Vários exemplos tridimensionais, para os quais considera-se a dinamicidade das malhas euleriana e lagrangiana, são dados com o objetivo de mostrar a eficiência no cálculo da função indicadora de fluidos. 


\section{Abstract}

The scientific motivation of the present work is the mathematical modeling and the computational simulation of multiphase flows. Specifically, the equations of a two-phase flow are written by combining the Immersed Boundary Method with a suitable fluid indicator function.

It is assumed that the fluid equations are discretized on an Eulerian mesh covering completely the flow domain and that the interface between the fluid phases is discretized by a non-structured Lagrangian mesh formed by triangles. In this context, employing tools commonly found in Computational Geometry, the computation of the fluid indicator function is efficiently performed on a block-structured Eulerian mesh bearing dynamical refinement patches.

Formed by a set of triangles, the Lagrangian mesh, which is initally generated employing the free software GMSH, is stored in a Halfedge data structure, a data structure which is widely used in Computer Graphics to represent bounded, orientable closed surfaces.

Once the Lagrangian mesh has been generated, next, one deals with the hipothetical situation of dealing with the one-way dynamical interaction between the immersed boundary and the fluid flow, that is, considering the non-slip condition, only the action of the flow on the interface is studied. No forces arising on the interface affects the flow, the interface passively being advect with the flow under a prescribed, imposed velocity field. In particular, the Navier-Stokes equations are not solved.

The fluid indicator function is given by a signed distance function in a vicinity of 
the immersed boundary. It is employed to identify interior/exterior points with respect to the bounded, closed region which is assumed to contain one of the fluid phases in its interior. The signed distance is update every time step employing Computational Geometry methods with optimal cost.

Several examples in three dimensions, showing the efficiency and efficacy in the computation of the fluid indicator function, are given which employ the dynamical adaptive properties of the Eurlerian mesh for a moving interface. 


\section{Índice}

Lista de Algoritmos $\quad$ xi

Lista de Figuras $\quad$ xiii

1 Introdução 1

2 Modelo Matemático e Método Numérico 9

2.1 Modelo Matemático . . . . . . . . . . . . . . . . . . . . . . . . . . . . 9

2.2 Discretização . . . . . . . . . . . . . . . . . . . . . . . . . 13

2.2 .1 Discretização da Interface . . . . . . . . . . . . . . . . . . . 13

2.2 .2 Discretização do Domínio . . . . . . . . . . . . . 16

2.2.3 Discretização das Equações no Espaço ........... 19

2.2.4 Discretização das Equações no Tempo . . . . . . . . . . . . . . . 22

3 Refinamento Adaptativo de Malhas $\quad 25$

3.1 Malhas Refinadas Localmente . . . . . . . . . . . . . . . 26

3.2 Malhas Compostas . . . . . . . . . . . . . . . . 26

3.3 Geração de Malhas Compostas . . . . . . . . . . . . . . . . . . . . . 28

3.3 .1 Seleção dos Pontos . . . . . . . . . . . . . . . . . . . . 30

3.3 .2 Agrupamento dos Pontos . . . . . . . . . . . . . . 31

3.4 Mapas Lagrangianos e Eulerianos . . . . . . . . . . . . . . . . . . . 34 
4 Função Indicadora de Fluidos $\quad 37$

4.1 Cálculo da Função Indicadora de Fluidos . . . . . . . . . . . . . . . . . . 38

4.2 CPT para Superfícies Triangularizadas . . . . . . . . . . . . . . 39

4.2 .1 CPT nas Faces . . . . . . . . . . . . . . . . . . 43

4.2 .2 CPT nas Arestas . . . . . . . . . . . . . . . . . 44

4.2 .3 CPT nos Vértices . . . . . . . . . . . . . . . . . . . 46

4.3 CPT em uma Malha Composta Adaptativa . . . . . . . . . . . . . . . . 52

4.4 Implementação . . . . . . . . . . . . . . . . . . . . . . 54

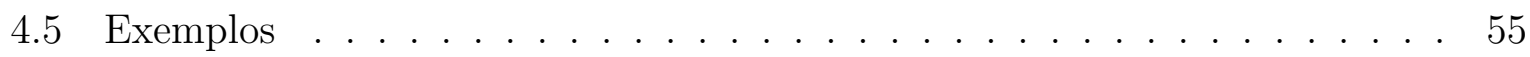

5 Movimento da Fronteira Imersa $\quad 67$

A Máquinas usadas na execução do código computacional $\quad 87$

$\begin{array}{lr}\text { B Estrutura de Dados Halfedge } & 89\end{array}$

C Algoritmos dos mapas eulerianos $\quad 93$

$\begin{array}{ll}\text { Referências Bibliográficas } & 106\end{array}$ 


\section{Lista de Algoritmos}

1 Closest Point Transform Brute . . . . . . . . . . . . . . . . . . 40

2 Closest Point Transform Brute Local . . . . . . . . . . . . . . . . . . . . . 41

3 Closest Point Transform . . . . . . . . . . . . . . . . . . . 42

$4 \quad$ AMR Closest Point Transform . . . . . . . . . . . . . . . . . 53

$5 \quad$ Mapa Euleriano 1.1 . . . . . . . . . . . . . . . . . . . . . . 94

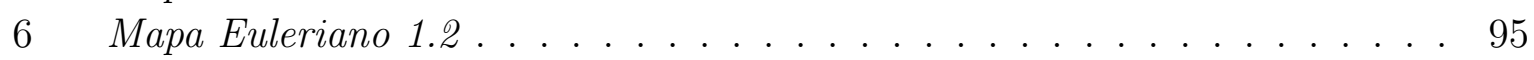

7 Mapa Euleriano 1.3 . . . . . . . . . . . . . . . . . 96

8 Mapa Euleriano 1.4. . . . . . . . . . . . . . . . . . . 97 


\section{Lista de Figuras}

1.1 Regimes de escoamentos de um conduto circular vertical. . . . . . . . . . . 1

1.2 Instabilidade de interface em escoamento anular. . . . . . . . . . . . . . . 2

2.1 Representação esquemática da estrutura de dados Halfedge. . . . . . . . . . 15

2.2 Exemplo da geometria de uma esfera; de uma malha triangular, com 2224 triângulos, gerada pelo software GMSH para representar essa esfera; da geometria de um octaedro e de uma malha triangular, com 2890 triângulos, gerada pelo software GMSH para representar esse octaedro. . . . . . . . . 17

2.3 Definição dos índices nas células computacionais. . . . . . . . . . . . . . . 18

2.4 Representação de uma variável vetorial (Velocidade). . . . . . . . . . . . . 19

2.5 Função bidimensional $\delta_{\Delta}^{2}$ discretizada [57]. . . . . . . . . . . . . . . . . 21

2.6 Vizinhança de um ponto $V q=\mathbf{X}(r, s, t)$ da superfície usada na interpolação da velocidade e Corte paralelo ao plano XZ passando por Vq. . . . . . . . 23

3.1 (a) Malha composta em um domínio computacional $\Omega=[0,1] \times[0,1] \times[0,1]$, com cortes em (b) $x=0.5$, (c) $y=0.3$ e (d) $z=0.5 \ldots \ldots . . . . .27$

3.2 Malhas apropriadamente aninhadas (c) e (d) e não apropriadamente ani-

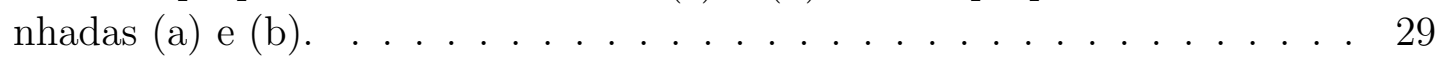

3.3 A maior ponto de inflexão acontece na linha grossa, a qual faz o corte mais eficiente [57]. . . . . . . . . . . . . . . . . . . . . . 33

4.1 Exemplo dos poliedros propostos por Mauch: exemplo de um poliedro construído nas faces, superfície recoberta por todos os poliedros, exemplo de um poliedro construído nas arestas e exemplo de um poliedro construído nos vértices. . . . . . . . . . . . . . . . . . . . 43 
4.2 Prisma triangular reto. . . . . . . . . . . . . . . . . . . . . 44

4.3 Canaleta sobre a superfície triangularizada. . . . . . . . . . . . . . . . 45

4.4 Canaleta construída a partir de uma aresta. . . . . . . . . . . . . . . 46

4.5 Exemplo de um vértice tipo sela. . . . . . . . . . . . . . . . . . . . 46

4.6 Pirâmide invertida sobre a superfície triangularizada. . . . . . . . . . . . . 47

4.7 Construção do vetor pseudonormal. . . . . . . . . . . . . . . . . . . . . . . 48

4.8 Vizinhança formada pela intersecção de $\bar{S}$ e uma bola $B$ centrada em $Q . \quad$. $\quad 50$

4.9 Vizinhança formada pela intersecção de $\bar{S}$ e uma bola $B$ centrada em $Q$. . 51

4.10 Exemplo de uma esfera: superfície triangularizada, isosuperfície, malhas do último nível físico e cortes em $x=1, y=1$ e $z=1 \ldots \ldots$. . . . . 57

4.11 Vista frontal de uma esfera cortada em $y=1$ mostrando a região de transição da função indicadora, a função indicadora coberta pelas arestas das malhas compostas e as malhas compostas utilizadas no refinamento localizado. . . 58

4.12 Exemplo de uma caixa: superfície triangularizada, isosuperfície, malhas do último nível físico e cortes em $x=1, y=1$ e $z=1 \ldots \ldots \ldots$. . . . .

4.13 Visão frontal de uma caixa cortada em $y=1$ mostrando a região de transição da função indicadora, a função indicadora coberta pelas arestas das malhas compostas e as malhas compostas utilizadas no refinamento localizado. . .

4.14 Visão frontal de uma caixa cortada em $z=1$ mostrando a região de transição da função indicadora, a função indicadora coberta pelas arestas das malhas compostas e as malhas compostas utilizadas no refinamento localizado. . .

4.15 Exemplo de três paralelogramos e uma esfera: superfície triangularizada, isosuperfície, malhas do último nível físico e cortes em $x=1, y=1$ e $z=1$.

4.16 Vista frontal de um paralelogramo e uma esfera cortados em $y=1$ mostrando a região de transição da função indicadora, a função indicadora coberta pelas arestas das malhas compostas e as malhas compostas utilizadas no refinamento localizado. . . . . . . . . . . . . . . . . .

4.17 Vista frontal de dois paralelogramos e uma esfera cortados em $z=1$ mostrando a região de transição da função indicadora, a função indicadora coberta pelas arestas das malhas compostas e as malhas compostas utilizadas no refinamento localizado. . . . . . . . . . . . . . . . . .

4.18 Exemplo de um losango: superfície triangularizada, isosuperfície, malhas do último nível físico e cortes em $x=1, y=1$ e $z=1$. 
4.19 Vista frontal de um losango cortado em $y=1$ mostrando a região de transição da função indicadora, a função indicadora coberta pelas arestas das malhas compostas e as malhas compostas utilizadas no refinamento localizado. . . 66

5.1 Exemplo do movimento de uma esfera: isosuperfícies nos passos no tempo $0,45,90,135,180$ e $225 \ldots \ldots \ldots \ldots \ldots$. . . . . . . . . . . 70

5.2 Exemplo do movimento de uma esfera: malhas do nível mais fino e arestas das malhas dos outros níveis nos passos no tempo 0, 45, 90, 135, 180 e 225.

5.3 Exemplo do movimento de uma esfera: corte em $x=1$ da função indicadora de fluidos nos passos no tempo 0, 45, 90, 135, 180 e 225 .

5.4 Exemplo do movimento de uma esfera: corte em $x=1$ das malhas compostas nos passos no tempo $0,45,90,135,180$ e 225 . . . . . . . . . . 73

5.5 Exemplo do movimento de uma esfera: vista frontal de um corte em $y=1$ mostrando a função indicadora de fluidos e as arestas das malhas compostas nos passos no tempo $0,45,90,135,180$ e $225 \ldots \ldots \ldots$. . . . . .

5.6 Exemplo do movimento de uma esfera: vista frontal de um corte em $y=1$ mostrando as malhas compostas nos passos no tempo 0, 45, 90, 135, 180 e 225 .

5.7 Exemplo da deformação de uma esfera: isosuperfícies nos passos no tempo $0,18,36,54,72$ е $90 \ldots \ldots \ldots \ldots \ldots$

5.8 Exemplo da deformação de uma esfera: malhas do nível mais fino e arestas das malhas dos outros níveis nos passos no tempo $0,18,36,54,72$ e 90 . . .

5.9 Exemplo da deformação de uma esfera: corte em $x=0.3$ da função indicadora de fluidos nos passos no tempo $0,18,36,54,72$ e 90 . . . . . . . 78

5.10 Exemplo da deformação de uma esfera: corte em $x=0.3$ das malhas compostas nos passos no tempo $0,18,36,54,72$ e $90 \ldots \ldots$. . . . . .

5.11 Exemplo da deformação de uma esfera: vista frontal de um corte em $x=0.3$ mostrando a função indicadora de fluidos e as arestas das malhas compostas nos passos no tempo $0,18,36,54,72$ e $90 \ldots \ldots \ldots$. . . . . . .

5.12 Exemplo da deformação de uma esfera: vista frontal de um corte em $x=0.3$ mostrando as malhas compostas nos passos no tempo 0, 18, 36, 54, 72 e 90 . 


\section{Introdução}

Escoamentos bifásicos são muito freqüentes em aplicações industriais, notoriamente na área de extração e transporte de petróleo. A Figura 1.1 ilustra alguns regimes comuns e bastante conhecidos de escoamentos bifásicos em tubos. Tais escoamentos podem ser classificados de forma geral nas categorias de escoamento separado ou disperso, dependendo das propriedades e velocidades dos fluidos e da inclinação e do diâmetro do tubo.

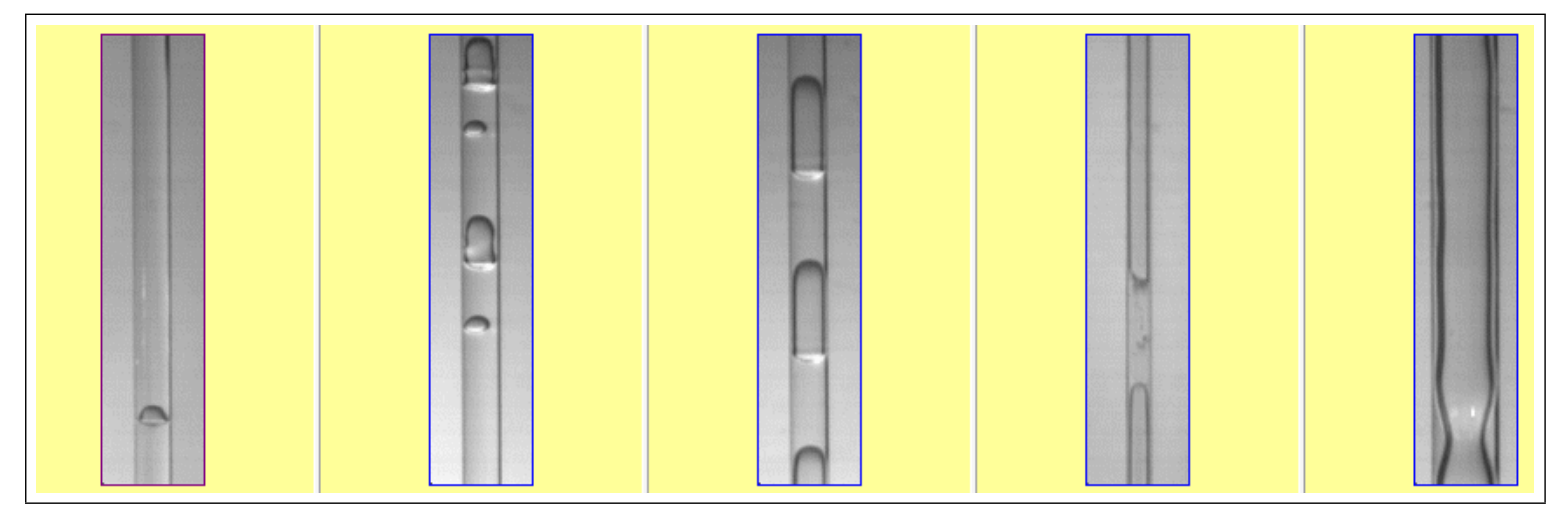

Figura 1.1: Regimes de escoamentos de um conduto circular vertical.

De particular interesse, é o quarto escoamento ilustrado na Figura 1.1. Este padrão é comumente encontrado, por exemplo, no processo de injeção de água para o transporte de óleos pesados, conhecido como método Core Flow. Neste caso, dois fluidos escoam com velocidades diferentes fazendo com que um dos fluidos escoe junto à parede e o outro escoe no centro do conduto circular. Este é o regime anular. Se o fluido junto à parede é menos viscoso, a perda de carga do escoamento global é menor que a perda de carga no caso em que considera-se apenas o fluido do núcleo do escoamento. Dados da literatura 
mostram que a redução da queda de pressão pode chegar a dezenas de vezes quando se utiliza este mecanismo de redução do atrito viscoso e com isto reduzir drasticamente a potência de bombeamento de fluidos.

Até uma certa relação de velocidades o escoamento permanece estável. Após um dado valor desta diferença de velocidades o escoamento torna-se instável, conforme ilustra a Figura 1.2. Caso esta instabilidade venha a se amplificar, o regime de escoamento anular pode ser interrompido e a perda de pressão aumenta bruscamente. As instabilidades podem ser do tipo Rayleigh-Taylor, devido ao efeito combinado da tensão interfacial e/ou gradientes de densidade desfavoráveis nos dois fluidos, e do tipo Kelvin-Helmholtz, devido à um desequilíbrio das velocidades interfaciais dos fluidos.
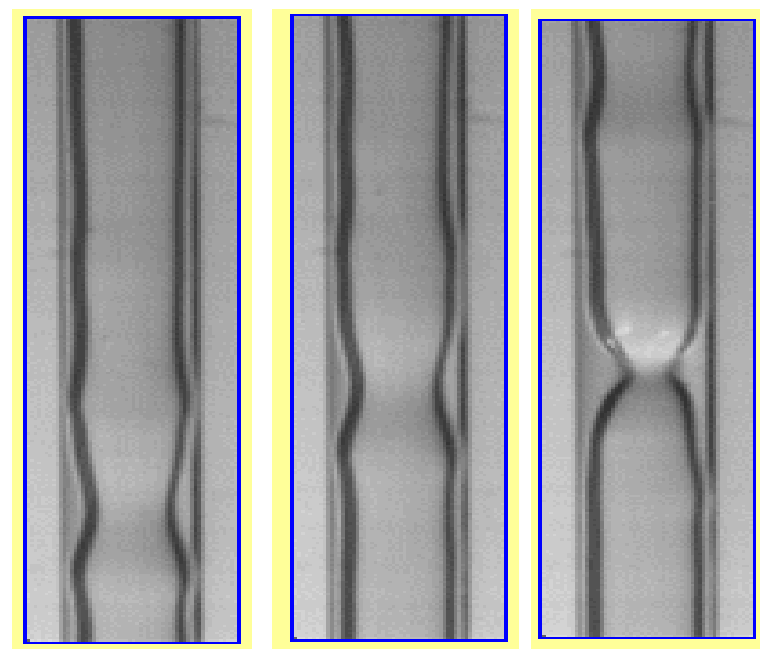

Figura 1.2: Instabilidade de interface em escoamento anular.

Como se nota, o estudo detalhado da formação e do transporte destas instabilidades é de fundamental importância para o domínio desta tecnologia de bombeamento. Devido à grande dificuldade de se estudar experimentalmente os detalhes deste problema, a modelagem matemática e a simulação computacional possibilitam o desenvolvimento de ferramentas com grande potencial para a análise detalhada deste tipo de problema físico.

Vários métodos numéricos têm sido desenvolvidos com o objetivo de determinar com boa precisão propriedades importantes em escoamentos multifásicos. Ao longo do tempo, cada qual tem apresentado vantagens e desvantagens uns com relação aos outros dependendo, por exemplo, da aplicação a ser estudada. Basicamente, existem duas abordagens utilizadas na simulação desse tipo de problema: captura de fronteira (front capturing) e 
acompanhamento de fronteira (front tracking).

As técnicas de captura de fronteira são caracterizadas por tratar a interface como a região que apresenta um gradiente elevado de alguma propriedade (e.g. densidade de massa), sem contar com a presença de outros elementos específicos para representar a interface. Esta metodologia é muito empregada em escoamentos nos quais existem mudanças topológicas na interface (ou interfaces) como, por exemplo, a fragmentação da interface ou a coalescência de interfaces em uma única. Uma desvantagem que pode ser associada a essa técnica é a difusão da interface ao longo de várias células computacionais, resultando em baixa precisão no cálculo de propriedades geométricas tais como a curvatura e a normal. Os principais métodos de captura de fronteira são o Método de Volume de Fluido (Volume-of-Fluid Method - VOF), o Método de Curva de Nível (Level Set Method) e o Método de Campo de Fase (Phase Field Method).

Introduzido por [26, 45], o Método de Volume de Fluido utiliza uma função de "volume fracionado" (volume fraction function) $f$. O valor do volume fracionado em cada célula computacional da malha euleriana é igual à razão entre o volume do fluido contido nessa célula computacional, chamado fluido 1, pelo volume em toda a malha euleriana. Assim, $f$ é unitária em cada célula computacional que está inteiramente contida no fluido 1 e zero se a célula computacional está inteiramente contida no outro fluido, chamado fluido 2. Para as células computacionais que contêm os fluidos 1 e 2, chamadas células interfaciais, $f$ varia entre 0 e 1 . Reciprocamente, dada uma função de volume fracionado definida em cada célula computacional da malha euleriana, pode-se reconstruir uma interface aproximada. Esse processo é chamado de reconstrução da interface. O campo $f$ é transportado pelo escoamento de acordo com a equação

$$
f_{t}+\mathbf{u} \cdot \nabla f=0
$$

A reconstrução da interface é um passo importante do Método de Volume de Fluido o qual tem sido pouco a pouco aprimorado desde sua introdução, desde a chamada Simple Line Interface Reconstruction (SLIC) até Piecewise Linear Interface Reconstruction (PLIC). Uma revisão detalhada dos métodos de reconstrução da interface SLIC e PLIC e suas perspectivas históricas pode ser encontrada em [56]. Outros métodos de reconstrução da interface tais como Piecewise Circle [43], Piecewise Parabolic [53, 54] e Piecewise Spline [22], também têm sido desenvolvidos. 
O Método de Volume de Fluido não requer procedimentos especiais para mudanças topológicas da interface. Algumas implementações recentes têm produzido boa precisão e conservação de massa [35]. Esse método tem sido muito empregado para simular a deformação de gotas $[28,55]$. Uma revisão desse método pode ser encontrada em [59].

No Método de Curva de Nível, introduzido por Osher e Sethian [47], a interface é capturada por uma função curva de nível $\phi$, que vale zero na interface, é positiva em uma das fases e não positiva na outra. A interface é, então, dada implicitamente pela curva de nível zero de $\phi$. Usualmente a função curva de nível é inicializada como sendo a distância com sinal do ponto à interface. Procura-se mantê-la dessa forma ao longo do tempo.

Uma vantagem do Método de Curva de Nível é que este método trabalha com a fragmentação e coalescência da interface automaticamente, pois a interface nunca é reconstruída explicitamente. Como $\phi$ é uma função suave, o vetor normal unitário n e a curvatura $\kappa$ da interface podem ser facilmente calculados por meio das equações

$$
\mathbf{n}=\frac{\nabla \phi}{|\nabla \phi|} \text { e } \kappa=\nabla \cdot \mathbf{n}
$$

Uma desvantagem do Método de Curva de Nível é que, em geral, ele apresenta pouca capacidade de conservar massa (ou equivalentemente, preservar o volume das fases). Por exemplo, na simulação da colisão de gotas a média das variações de volume utilizando este método, descrito em [71], foi de $0.5 \%$ e a média das variações de volume, descrito em [68], foi de 1.3\%. Este método foi fortemente divulgado em dois livros por Sethian [61, 62]. Mais detalhes sobre o Método de Curva de Nível podem ser encontrados em $[48,63,68,69,70]$.

O Método de Campo de Fase tem se mostrado como uma ferramenta viável para a simulação numérica de escoamentos multifásicos. Uma revisão recente desse método pode ser encontrada em [1]. No Método de Campo de Fase, a interface entre os fluidos é substituída por uma região de espessura bem fina, mas não nula, onde as forças interfaciais são suavemente distribuídas. A idéia básica é introduzir um parâmetro de ordem conservativo (por exemplo, concentração de massa) que varia continuamente sobre a interface fina e, em geral, é uniforme em grande parte da fase.

Esse método permite mudanças topológicas na interface [36] e tem muitas vantagens na simulação numérica do movimento da interface [16]. Tal método constitui uma classe 
particular dos Modelos de Interface Difusa. O Método de Campo de Fase pode ser visto como um Método de Curva de Nível motivado fisicamente. Lowengrub e Truskinovsky [36] têm argumentado sobre as vantagens de usar $\phi$ determinada fisicamente em vez de uma função suave artificial para a interface. Mais detalhes sobre o Método de Campo de Fase podem ser encontrados em [3, 4, 14, 17, 27, 29, 31, 32, 46, 75, 76, 77].

Em contraste com os métodos de interface difusa, há o modelo no qual a interface é representada com espessura nula e as propriedades materiais dos fluidos são descontínuas através dela (sharp interface model). Essa forma de representar a interface tem sido empregada com sucesso na simulação de uma grande variedade de escoamentos incompressíveis. Entretanto, o modelo é inapropriado do ponto de vista físico quando a espessura da interface é comparável à escala de comprimento do fenômeno que está sendo analisado [1], o que ocorre quando a interface é submetida a mudanças topológicas, como a ruptura e a coalescência de gotas, ou quando a interface intercepta a si mesma.

As técnicas de acompanhamento de fronteira são caracterizadas por representar explicitamente a interface que se move de forma independente sobre a malha euleriana a qual está inserida. Esta técnica oferece melhor precisão do que as técnicas de captura de fronteira no que diz respeito ao cálculo de propriedades geométricas mas há, entretanto, um maior custo computacional envolvido.

O primeiro método utilizando as técnicas de captura de fronteira foi o Método da Fronteira Imersa, proposto por Peskin [50, 51]. Esse método foi introduzido para estudar escoamentos em torno da válvula mitral natural do coração. Em contraste com outros autores, Peskin não fez qualquer hipótese particular acerca da geometria deste escoamento para observar o movimento da válvula. Partindo apenas das leis de Newton e de características físicas e fisiológicas do fluido, da musculatura e da válvula cardíaca, deduziu as equações dinâmicas do movimento, as quais descrevem a forte interação entre a válvula e o escoamento sangüíneo. O Método de Fronteira Imersa fornece tanto um modelo matemático quanto esquema numérico. A formulação matemática envolve uma mistura das formulações euleriana e lagrangiana as quais se relacionam por equações de interação em que a função delta de Dirac tem um papel importante. No esquema numérico, as equações do fluido são resolvidas em uma malha estruturada "fixa" e as equações que descrevem a interação entre a interface e o fluido são resolvidas em uma malha não estruturada curvilínea que move livremente sobre toda malha euleriana. A comunicação entre as duas 
malhas é feita empregando-se uma versão suavizada da função Delta de Dirac.

No Método da Fronteira Imersa a interface está acoplada ao movimento do fluido exercendo sobre ele uma força singular cuja intensidade é grande nas vizinhanças da interface e zero em todos os outro lugares, além de estar se movendo com a velocidade local do fluido. Comumente, em cada passo no tempo, o método usa o posicionamento da fronteira no início desse passo no tempo para calcular as forças definidas pela fronteira. Essas forças são, então, distribuídas numa vizinhança da fronteira, nos pontos da malha euleriana. Se o fluido for incomprenssível, o espalhamento dos efeitos dessa força pelo fluido, por ação do campo de pressão, é imediato. A nova velocidade do fluido é usada para mover a fronteira, completando assim um passo no tempo. O Método da Fronteira Imersa foi recentemente revisado por Peskin em [52]. Resultados mais recentes sobre o Método da Fronteira Imersa podem ser encontrados em [23, 33, 34, 38, 44, 74, 78, 80].

Freqüentemente, há fenômenos os quais, apesar da natureza local, afetam o escoamento globalmente (e.g. camadas limites, regiões de alta vorticidade ou de alta turbulência, geometria das fronteiras imersas). Surge então a necessidade de um refinamento localizado a fim de captar tais fenômenos físicos locais ou de definir com maior precisão regiões com elevadas curvaturas ou ângulos estreitos. Existem diversas estratégias para se abordar o problema de se incrementar localmente e de forma dinâmica a resolução de uma malha de integração espacial.

Em que se pesem a eficiência resultante e a perícia e habilidade em computação requeridos de quem a implementa, dentre as possibilidades (e.g. malhas não estruturadas, uso de estruturas de dados de árvores, etc.) optou-se nesse trabalho pelo uso da técnica de refinamento adaptativo de malhas (adaptive mesh refinement - AMR) introduzida por Berger e Oliger [7]. Nessa abordagem, a malha é composta por uma seqüência de níveis hierárquicos devidamente aninhados. Mais especificamente, o refinamento é dado pela união de malhas retangulares orientadas nas direções dos eixos coordenados cujos espaçamentos são progressivamente menores. Cada uma dessas malhas é formada basicamente por pontos do domínio onde o erro da solução na malha é maior devido a fenômenos localizados. Trabalhos posteriores os quais visaram estender esta técnica são apresentados em $[8,9,10,11,12,13]$. Roma $[57,58]$ estendeu essa técnica de refinamento adaptativo ao redor de geometrias complexas utilizando o Método da Fronteira Imersa. Recentemente, Griffith [23] paralelizou essa metodologia e a aplicou para estudar o escoamento 
tridimensional do sangue dentro das cavidades cardíacas e sua interação com as válvulas.

Na abordagem via captura de interface, Sussman et al. [70] utilizaram refinamento adaptativo de malhas no contexto do Método de Curva de Nível (Level Set) para calcular a solução de escoamentos bifásicos objetivando o estudo da dinâmica de bolhas ascendentes e a coalescência de bolhas.

No presente trabalho, o refinamento adaptativo de malhas foi implementado empregandose o algoritmo desenvolvido inicialmente por Berger e Oliger [7]. Este algoritmo foi escolhido por ser eficiente computacionalmente (tomando, num vasto espectro de aplicações, tipicamente menos de $5 \%$ do tempo total computacional) e por ser de implementação relativamente simples já que sua implementação envolve estruturas de dados básicas como listas ligadas, vetores e matrizes [9]. Além disso, a discretizações das equações são exatamente as mesmas que se empregaria numa malha uniforme uma vez que as malhas compostas são formadas por uma união de blocos deste tipo.

Basicamente a construção de uma malha refinada localmente pode ser dividida em três passos independentes:

- Seleção dos pontos: A seleção dos pontos que necessitam de melhor resolução é feita utilizando-se algum critério de seleção previamente determinado.

- Geração das malhas: A algoritmo de geração das malhas deve ser capaz de criar malhas finas que cubram todas as regiões que necessitem de refinamento de acordo com algum critério de eficiência.

- Armazenamento dos dados: A estrutura de dados utilizada deve permitir, de forma rápida e com baixo consumo de memória computacional, que as informações das malhas refinadas possam ser acessadas. Essa estrutura deve ser eficiente também para fazer as atualizações das malhas, isto é, incluir e remover malhas.

No presente trabalho, foi implementada uma função indicadora de fluidos utilizando as idéias de Geometria Computacional propostas por Mauch [42], sendo esta implementação o foco. As principais vantagens dessa técnica são que a função indicadora de fluidos é atualizada somente numa vizinhança da fronteira imersa, isto é, não é necessário atualizar a função indicadora de fluidos em toda a malha euleriana e, além disso, a alta resolução 
obtida por esta técnica no cálculo da distância com sinal. Aqui, o cálculo da função indicadora é feito em malhas com refinamento localizado como as mencionadas anteriormente $[6,7,8,9,10,11,12,13]$.

O movimento da fronteira imersa é obtido integrando-se a equação de evolução no tempo. Para garantir que a fronteira imersa esteja sempre recoberta por malhas do nível mais fino, é feita uma remalhagem da malha euleriana, por meio do algoritmo AMR, toda vez que algum ponto da malha lagrangiana está próximo da fronteira do conjunto formado pelas malhas refinadas do nível mais fino (interface de nível).

Em trabalhos futuros, pretende-se resolver simultaneamemte a equação de NavierStokes, fazer uma remalhagem dos pontos da malha lagrangiana sempre que a fronteira imersa se distorcer, calcular as forças interfaciais (vetor normal e curvatura) para que haja a interação plena entre o fluido e a interface (estrutura). 


\section{Modelo Matemático e Método}

\section{Numérico}

Simulações computacionais em dinâmica de fluidos têm importantes aplicações práticas, notoriamente, na indústria. Na indústria petroquímica, por exemplo, há escoamentos especialmente importantes em dutos e em centrífugas. Na sua simulação computacional, comumente são empregadas as equações de Navier-Stokes para modelar esses escoamentos, sendo a formulação lagrangiana empregada para modelar o movimento da interface de separação entre as diversas fases do fluido.

No Método da Fronteira Imersa, a dinâmica do fluido é representada pela formulação euleriana a qual é discretizada numa malha regular e a interface é representada por uma malha triangular não estruturada (domínio lagrangiano).

Neste Capítulo, é descrita a formulação matemática de escoamentos incompressíveis envolvendo interação entre fluidos com propriedades físicas distintas. Tal formulação é fundamentada na mecânica do contínuo e é expressa pelas leis de conservação da massa (equação da continuidade) e de balanço da quantidade de movimento (segunda lei de Newton).

\subsection{Modelo Matemático}

O escoamento de um fluido bifásico viscoso, incompressível, pode ser modelado pelas equações de Navier-Stokes [15], as quais compõem um sistema acoplado de equações 
diferenciais parciais. Empregando a formulação euleriana, tais equações são dadas por

$$
\begin{gathered}
\rho(\phi)\left(\mathbf{u}_{t}+\mathbf{u} \cdot \nabla \mathbf{u}\right)=-\nabla p+\nabla \cdot \mu(\phi)\left(\nabla \mathbf{u}+\nabla \mathbf{u}^{t}\right)+\rho(\phi) \mathbf{g}+\mathbf{f}, \\
\nabla \cdot \mathbf{u}=0,
\end{gathered}
$$

onde $\phi$ é uma função indicadora de fluidos (isto é, $\phi>0 \mathrm{em}$ um dos fluidos e $\phi<=0$ no outro fluido), $\rho$ é a densidade de massa do fluido (suposta constante em cada fase), $\mu$ é o coeficiente de viscosidade do fluido (também constante em cada fase), $p$ é a pressão, u é o vetor velocidade, $\mathbf{g}$ é a aceleração da gravidade e f é o vetor campo de força externa que atua sobre o escoamento. O termo forçante $\mathbf{f}$ é responsável pela influência da interface no movimento dos fluidos.

Para representar a interface de separação entre as diferentes fases, utiliza-se uma superfície bidimensional fechada e orientável definida no espaço tridimensioal. Se $(r, s)$ são as coordenadas curvilíneas que descrevem essa superfície então a cada $(r, s)$ fixo está associado um único ponto material da interface. A posição de um ponto da superfície no instante de tempo $t$ em coordenadas cartesianas, $\mathbf{X}(r, s, t)$, se escreve como

$$
\mathbf{X}(r, s, t)=\left(X_{1}(r, s, t), X_{2}(r, s, t), X_{3}(r, s, t)\right), \forall(r, s) \in U
$$

Observe que as coordenadas curvilíneas $r$ e $s$ podem ser interpretadas como paramêtros lagrangianos.

Se $\mathbf{F}(r, s, t)$ é a força que age sobre os pontos da fronteira imersa na ausência de outras forças internas, a resultante das forças que agem em uma região arbitrária $R$ do domínio é dada por

$$
\begin{aligned}
\int_{R} \mathbf{f}(\mathbf{x}, t) d \mathbf{x} & =\int_{\{(r, s) ; \mathbf{X}(r, s, t) \in R\}} \mathbf{F}(r, s, t) d r d s \\
& =\int_{S} \mathbf{F}(r, s, t) \omega_{R} \mathbf{X}(r, s, t) d r d s \\
& =\int_{S} \mathbf{F}(r, s, t)\left[\int_{R} \delta(\mathbf{x}-\mathbf{X}(r, s, t) d \mathbf{x})\right] d r d s \\
& =\int_{R} \int_{S} \mathbf{F}(r, s, t) \delta(\mathbf{x}-\mathbf{X}(r, s, t)) d r d s d \mathbf{x}
\end{aligned}
$$


onde $\delta$ é a função Delta de Dirac tridimensional e $\omega_{R}(\mathbf{x})=1$ se $\mathbf{x} \in R$ e $\omega_{R}(\mathbf{x})=0$ caso contrário.

Embora essas manipulações sejam formais, elas motivam uma expressão para a densidade de força euleriana $\mathbf{f}$ que age no fluido. Como $R$ é uma região arbitrária, tal expressão é dada por

$$
\mathbf{f}(\mathbf{x}, t)=\int_{S} \mathbf{F}(r, s, t) \delta(\mathbf{x}-\mathbf{X}(r, s, t)) d r d s .
$$

Como se pode observar em (2.4), a densidade de força euleriana $\mathbf{f}$ é singular, tendo suporte apenas sobre a superfície, isto é, ela vale zero em todos os pontos do domínio, excetuando-se os pontos da superfície. Outro fato importante que deve ser observado é que, uma vez que o Delta de Dirac tridimensional é integrado sobre um domínio bidimensional, f tem o mesmo tipo de singularidade definida para uma função Delta de Dirac unidimensional.

No presente trabalho, a interação entre o fluido e a interface é considerada somente no sentido do fluido para a interface; tudo se passa como se os pontos lagrangianos que representam a interface fossem apenas partículas marcadoras e se movessem passivamente ao sabor do escoamento $(\mathbf{F}=0)$.

Para o cálculo das propriedades materiais (densidade de massa e viscosidade) utilizase a função indicadora de fluidos $\phi$, descrita mais a frente, no Capítulo 4. A imagem da função indicadora de fluidos é o intervalo $[-1,1]$ e essa função é positiva em uma das fases e não positiva na outra. A densidade e a viscosidade de cada fase podem ser obtidas pelas relações

$$
\begin{gathered}
\rho(\phi)=\rho_{1}+\left(\rho_{2}-\rho_{1}\right) H(\phi) \\
\mu(\phi)=\mu_{1}+\left(\mu_{2}-\mu_{1}\right) H(\phi)
\end{gathered}
$$

onde $\rho_{1}, \rho_{2}, \mu_{1}$ e $\mu_{2}$ são as densidades de massa e as viscosidades, respectivamente, de cada uma das fases e $H(\phi)$ é a função de Heaviside definida por

$$
H(\phi)=\left\{\begin{array}{l}
0 \text { se } \phi<0 \\
1 \text { se } \phi \geq 0
\end{array}\right.
$$


Sendo o fluido viscoso, os pontos da interface aderem às partículas de fluido e, ambos, acabam por se mover com a mesma velocidade (nonslip condition). Matematicamente, esta condição pode ser expressa em termos do campo de velocidades como

$$
\frac{\partial \mathbf{X}(r, s, t)}{\partial t}=\mathbf{u}(\mathbf{X}(r, s, t), t)
$$

Para encontrar uma expressão para a velocidade dos pontos lagrangianos da interface em termos do campo de velocidades euleriano do fluido, pode-se empregar (formalmente) as propriedades da função Delta de Dirac em três dimensões, chegando-se a

$$
\mathbf{u}(\mathbf{X}(r, s, t), t)=\int_{\Omega} \mathbf{u}(\mathbf{x}, t) \delta(\mathbf{x}-\mathbf{X}(r, s, t)) d \mathbf{x}
$$

onde $\Omega$ representa todo o domínio do escoamento.

As igualdades (2.4) e (2.9) descrevem a interação entre o fluido e a superfície. Elas utilizam a função Delta de Dirac para alternar entre a formulação euleriana, usada para o fluido, e a lagrangiana, usada para as superfícies; (2.4) "espalha" as tensões que agem sobre a superfície para o resto do domínio sendo, por esta razão, comumente denominada como passo de espalhamento. Por outro lado, (2.9) "interpola" as velocidades definidas nos pontos da malha euleriana do domínio para os pontos lagrangianos da superfície sendo esse passo, por essa razão, denominado passo de interpolação. Não se considera aqui (2.4). A interpolação de velocidades, dada por (2.9), é abordada na Seção 2.2.3 do presente Capítulo.

É importante ressaltar que por intermédio da manipulação adequada do termo $\mathbf{F}(r, s, t)$, presente em (2.4), é possível se controlar propriedades da superfície. Por exemplo, podese considerar a superfície como sendo uma estrutura rígida ou elástica ou, ainda, como sendo uma interface entre diferentes fases. Esta abordagem permite que uma grande variedade de problemas físicos possam ser modelados e resolvidos utilizando-se o Método da Fronteira Imersa. 


\subsection{Discretização}

Nessa Seção, destacam-se as discretizações das malhas euleriana e lagrangiana, bem como as discretizações espacial e temporal das equações para o movimento da interface.

\subsubsection{Discretização da Interface}

A modelagem de superfícies é uma área da Modelagem Geométrica a qual estuda a composição e a representação computacional de superfícies. Esta representação deve permitir que, de forma rápida e precisa, sejam obtidas tanto informações geométricas quanto informações topológicas sobre a superfície.

As informações geométricas são aquelas que permitem estudar como a superfície se apresenta dentro do espaço que a envolve. Tais informações permitem saber, por exemplo, o número de vértices ou de arestas da superfície, a distância entre dois vértices ou, ainda, o ângulo entre duas arestas.

As informações topológicas são aquelas que permitem estudar as relações de conectividade e adjacência entre os vários elementos de uma superfície. Tais informações permitem saber, por exemplo, quais vértices são vizinhos de um dado vértice, quais arestas são comuns a um dado vértice, ou ainda, quais faces são adjacentes a uma dada aresta.

A representação de uma superfície pode ser feita de forma hierárquica. No primeiro nível hierárquico, encontra-se o conjunto de todas as faces que compõem a superfície. No segundo nível hierárquico, encontram-se as arestas que são as curvas, parametrizadas ou não, que representam as fronteiras externa e/ou interna de cada uma das faces. As arestas são elementos de dimensão um em $\mathbb{R}^{3}$. No terceiro e último nível hierárquico, encontramse os vértices que são elementos de dimensão zero em $\mathbb{R}^{3}$ e estão situados, geralmente, nos extremos de cada uma das arestas.

No presente trabalho, adotou-se a estrutura de dados Halfedge [37, 64, 66] para armazenar a superfície discretizada, isto é, para armazenar a malha triangular, não estruturada e bidimensional que representa a superfície entre os dois fluidos. Essa estrutura de dados foi escolhida por sua rapidez na obtenção das informações topológicas e geométricas da superfície e ser amplamente utilizada em Computação Gráfica para representar superfícies orientáveis. 
Para representar a discretização da superfície por elementos geométricos, a estrutura de dados Halfedge utiliza seis níveis hierárquicos: Solid, Face, Loop, Edge, Halfedge e Vertex.

A esta estrutura básica de níveis hierárquicos, foram acrescentados outros campos necessários ao desenvolvimento do trabalho. A relação completa de todos os campos da estrutura de dados Halfedge, em linguagem FORTRAN 90, é apresentada no Apêndice B.

$\mathrm{Na}$ implementação corrente, os entes dessa hierarquia fazem uso de ponteiros. A figura 2.1 ilustra algumas das relações entre os ponteiros dessa estrutura de dados. Para informações detalhadas da teoria, implementação e exemplos dos níveis hierárquicos da estrutura de dados Halfedge consulte [66].

No primeiro passo no tempo, para gerar uma malha de triângulos para aproximar a geometria da interface foi empregado o software livre GMSH cujos autores são Christophe Geuzaine da Case Western Reserve University em Cheveland, Ohio, e Jean-François Remacle da Catholic University of Louvain em Louvain, Bélgica. Ele pode ser baixado gratuitamente [81].

Este software foi utilizado em vários trabalhos como, por exemplo, no trabalho de CockBurn e Yenikaya [18] que estudam um método adaptativo para encontrar aproximações para a viscosidade nas equações de Hamilton-Jacobi, no trabalho de Bakosi [5], que modela um escoamento turbulento usando uma abordagem probabilística, no trabalho de Kemmler et al [30] que aplica técnicas computacionais de alto desempenho (processamento paralelo) para modelar o escoamento de água através do solo e, um último exemplo, no trabalho de Xunlei e Tendick [79] que simula o comportamento de tecidos finos deformáveis para sistemas de treinamento cirúrgico.

O GSMH é um software que permite, além de construir a geometria de uma superfície e gerar uma malha triangular não estruturada bidimensional para representar esta superfície, resolver equações diferenciais parciais que envolvam esta superfície assim como visualizar os resultados obtidos.

O tutorial do GMSH apresenta um exemplo da construção de um superfície simples e de como é gerada uma malha não estruturada para representar a superfície. O manual de referência do GMSH inclui uma descrição completa de todos os comandos utilizados pelo GMSH. Ambos estão disponíveis gratuitamente em [82]. 


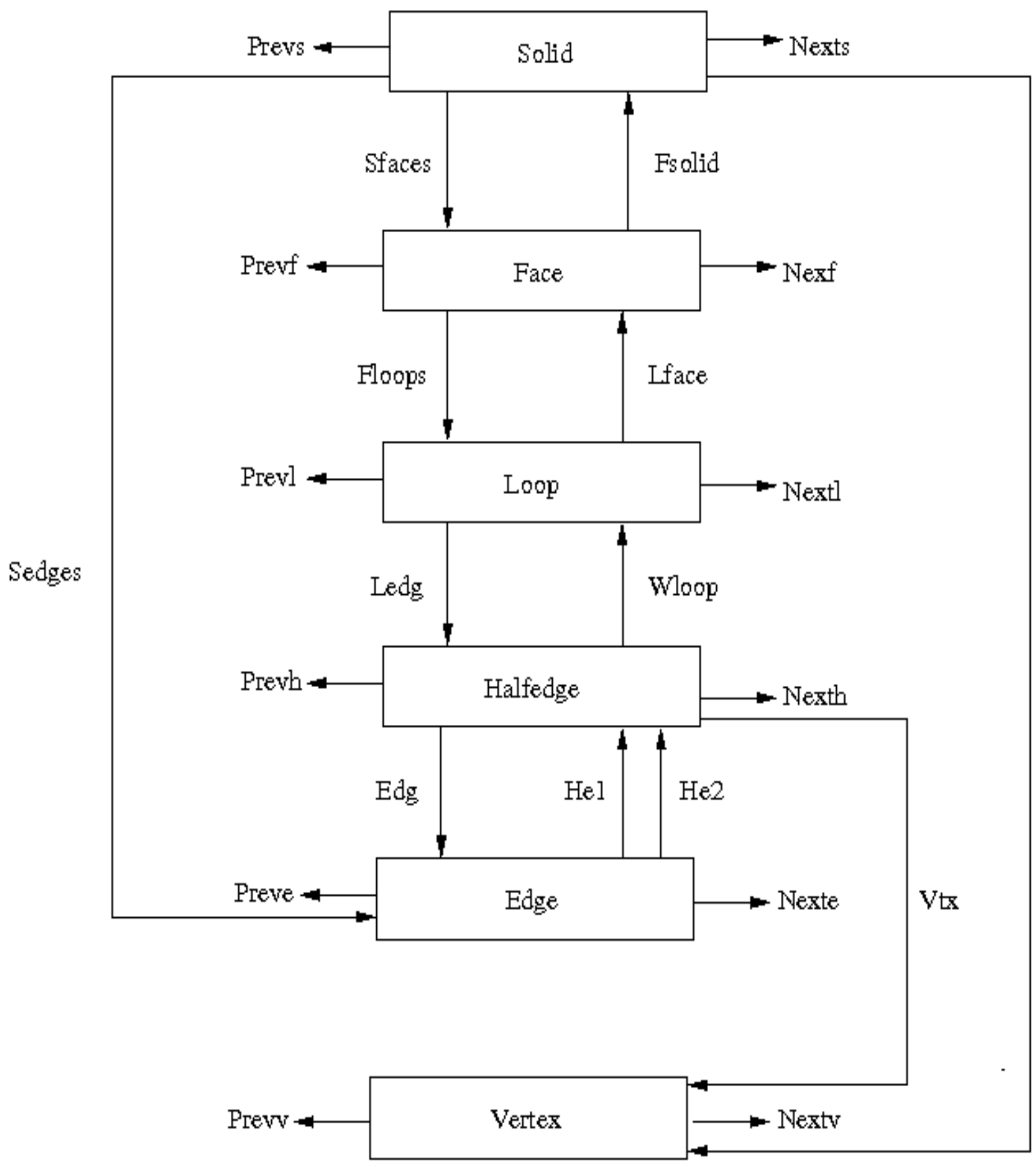

Figura 2.1: Representação esquemática da estrutura de dados Halfedge. 
Um tutorial em língua portuguesa está sendo desenvolvido pelo grupo do Laboratório de Transferência de Calor e Massa e Dinâmica de Fluidos da Faculdade de Engenharia Mecânica da Universidade Federal de Uberlândia (LTCM/FEMEC-UFU). Esse tutorial está disponível gratuitamente em [83].

Exemplos da geometria de uma esfera construída no GMSH, da discretização dessa esfera em uma malha triangularizada, da geometria de um octaedro construída no GMSH e da discretização desse octaedro em uma malha triangularizada pode ser vistos na Figura 2.2 .

Mais informações sobre o GMSH e sua utilização na representação da geometria da superfície e a geração de malhas triangulares não estruturadas para representar superfícies podem ser encontradas em [66].

\subsubsection{Discretização do Domínio}

No presente trabalho, o domínio computacional considerado é o paralelepípedo $\left[A_{x}, B_{x}\right] \times\left[A_{y}, B_{y}\right] \times\left[A_{z}, B_{z}\right]$. Esse domínio é subdividido em diferentes níveis de refinamento, conforme será descrito no Capítulo 3. Cada um desses níveis é composto pela união de paralelepípedos formado por malhas com mesmo espaçamento. Neste ponto, para tornar clara e simples a exposição da discretização das equações do movimento no domínio, considera-se nesta Seção o caso que a malha euleriana é dada por apenas uma malha uniforme que recobre todo o domínio computacional. Posteriormente, a discretização espacial apresentada será estendida sem muito esforço para o contexto de malhas com refinamento localizado pois as malhas refinadas são formadas por união de paralelepípedos.

Neste contexto, considere o domínio computacional discretizado por uma malha regular com $N_{x} \times N_{y} \times N_{z}$ células computacionais, onde $N_{x}, N_{y}$ e $N_{z}$ é o número de células computacionais nas direções $x, y$ e $z$, respectivamente. Os espaçamentos nas direções $x$, $y$ e $z$ são dados, respectivamente, por

$$
\Delta x=\frac{B_{x}-A_{x}}{N_{x}}, \Delta y=\frac{B_{y}-A_{y}}{N_{y}} \text { e } \Delta z=\frac{B_{z}-A_{z}}{N_{z}} .
$$

O centro de cada célula computacional é definido por

$$
x_{i, j, k}=\left(x_{i}, y_{j}, z_{k}\right)=\left(A_{x}+(i-0.5) \Delta x, A_{y}+(j-0.5) \Delta y, A_{z}+(k-0.5) \Delta z\right) .
$$



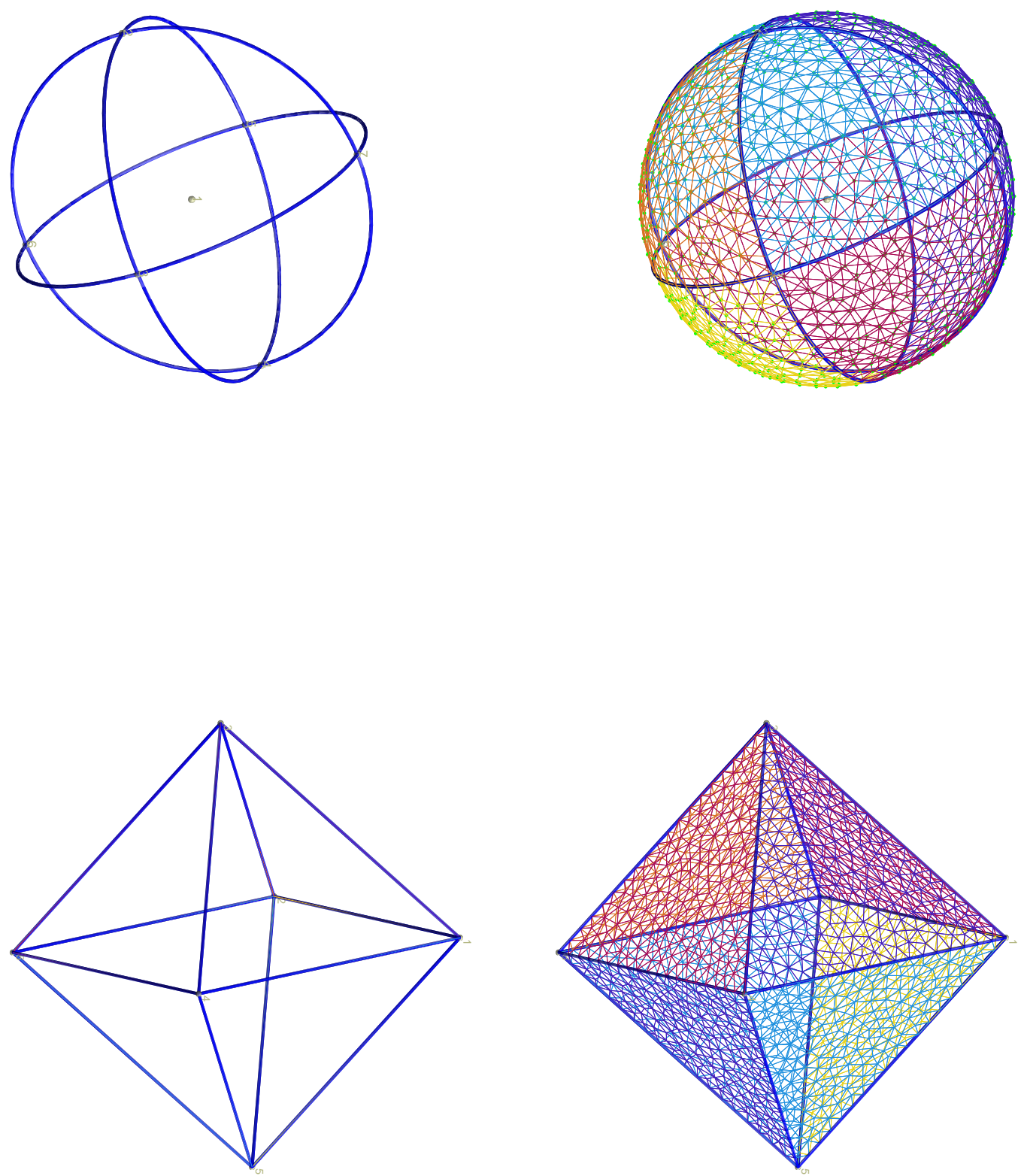

Figura 2.2: Exemplo da geometria de uma esfera; de uma malha triangular, com 2224 triângulos, gerada pelo software GMSH para representar essa esfera; da geometria de um octaedro e de uma malha triangular, com 2890 triângulos, gerada pelo software GMSH para representar esse octaedro. 


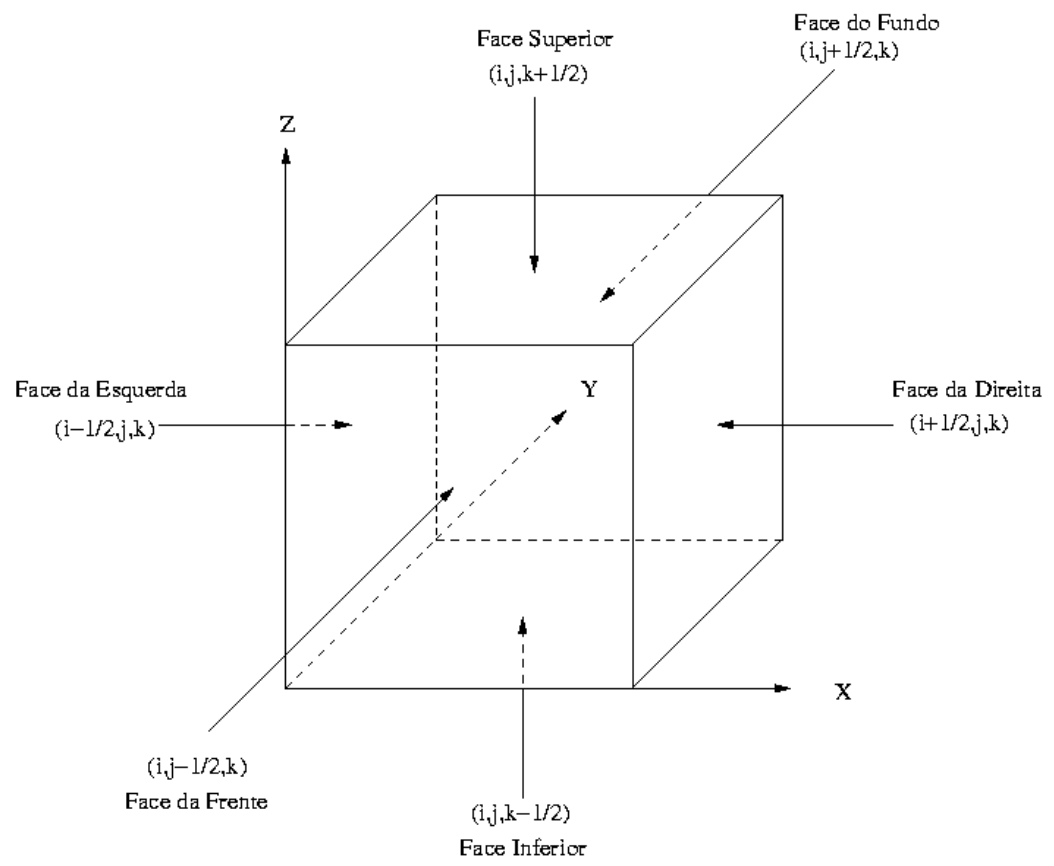

Figura 2.3: Definição dos índices nas células computacionais.

Para comportar as condições de contorno e, no caso de malhas refinadas evitar mudanças nos esquemas numéricos perto do bordo dessa malhas, são adicionadas camadas extras de células computacionais ao redor das malhas (uma "moldura"). Essas células computacionais adicionais são denominadas de células fantasmas.

A indexação utilizada nas células computacionais baseia-se nos índices do centro das células computacionais definidos em (2.11). Dada uma célula computacional de índices $(i, j, k)$, veja Figura 2.3, tem-se que os centros das duas faces paralelas ao plano $Z Y$ (esquerda e direita) têm índices $\left(i-\frac{1}{2}, j, k\right)$ e $\left(i+\frac{1}{2}, j, k\right)$, respectivamente; os centros das duas faces paralelas ao plano $X Z$ (frente e fundo) têm índices $\left(i, j-\frac{1}{2}, k\right)$ e $\left(i, j+\frac{1}{2}, k\right)$, respectivamente; e os centros das duas faces paralelas ao plano $X Y$ (inferior e superior) têm índices $\left(i, j, k-\frac{1}{2}\right)$ e $\left(i, j, k+\frac{1}{2}\right)$, respectivamente.

Uma vez que o domínio computacional com o seu conjunto de células tenha sido estabelecido, falta definir a localização das variáveis vetoriais e das variáveis escalares nas células computacionais. As células deslocadas do esquema MAC (Marker and Cell), introduzidas em Harlow e Welch [25], são adotadas no presente trabalho. Nesta discretização, as variáveis escalares (e.g. pressão, viscosidade, densidade, função indicadora de fluidos, etc.) são definidas no centro das células computacionais e as variáveis vetoriais (e.g. velo- 


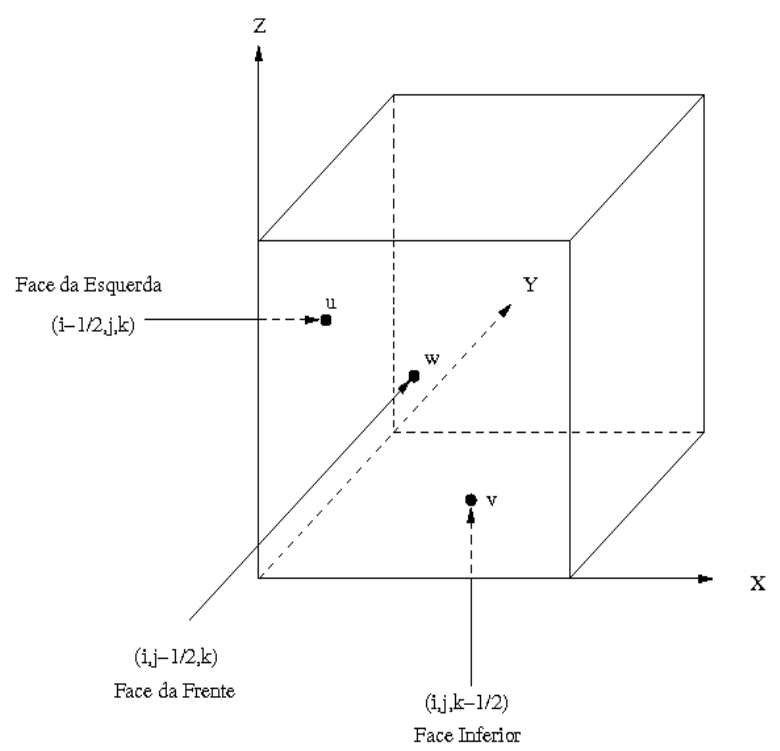

Figura 2.4: Representação de uma variável vetorial (Velocidade).

cidade, termos forçantes, gradiente de pressão, etc.) têm suas componentes definidas no meio das faces das células computacionais.

Por exemplo, a velocidade $\mathbf{u}_{i, j, k}$ definida na célula computacional de índices $(i, j, k)$ (veja Figura 2.4) é dada por

$$
\mathbf{u}_{i, j, k}=\left(u_{i-\frac{1}{2}, j, k}, v_{i, j-\frac{1}{2}, k}, w_{i, j, k-\frac{1}{2}}\right)
$$

\subsubsection{Discretização das Equações no Espaço}

A evolução da posição da superfície no tempo é dada pela resolução da equação

$$
\frac{\partial \mathbf{X}(r, s, t)}{\partial t}=\mathbf{u}(\mathbf{X}(r, s, t), t)=\int_{\Omega} \mathbf{u}(\mathbf{x}, t) \delta(\mathbf{x}-\mathbf{X}(r, s, t)) d \mathbf{x}
$$

onde $\mathbf{u}$, a velocidade do fluido, é suposta conhecida na malha euleriana. Essa velocidade será interpolada para os pontos $\mathbf{X}(r, s, t)$ da interface, utilizando uma aproximação tridimensional da função Delta de Dirac [52].

No presente trabalho, empregar-se-á o produto 


$$
\delta_{\Delta}^{3}(\mathbf{x}-\mathbf{X})=\delta_{\Delta}^{1}\left(x-X_{1}\right) \delta_{\Delta}^{1}\left(y-X_{2}\right) \delta_{\Delta}^{1}\left(z-X_{3}\right)
$$

onde

$$
\begin{aligned}
& \delta_{\Delta}^{1}\left(x-X_{1}\right)=\frac{1}{\Delta x} \phi\left(\frac{x-X_{1}}{\Delta x}\right), \\
& \delta_{\Delta}^{1}\left(y-X_{2}\right)=\frac{1}{\Delta y} \phi\left(\frac{y-X_{2}}{\Delta y}\right), \\
& \delta_{\Delta}^{1}\left(z-X_{3}\right)=\frac{1}{\Delta z} \phi\left(\frac{z-X_{3}}{\Delta z}\right),
\end{aligned}
$$

sendo $\delta_{\Delta}^{1}$ uma aproximação unidimensional da funçaõ Delta e $\phi$ é uma função contínua definida por

$$
\phi(r)= \begin{cases}\frac{1}{6}\left(5-3|r|-\sqrt{-3(1-|r|)^{2}+1}\right), & \text { se } 0.5 \leq|r| \leq 1.5 \\ \frac{1}{3}\left(1+\sqrt{-3 r^{2}+1}\right), & \text { se }|r| \leq 0.5 \\ 0, & \text { caso contrário, }\end{cases}
$$

com $r=\left(x-X_{1}\right) / \Delta x$ ou $r=\left(y-X_{2}\right) / \Delta y$ ou $r=\left(z-X_{3}\right) / \Delta z, \mathbf{X}=\left(X_{1}, X_{2}, X_{3}\right)$, as coordenadas cartesianas de um ponto $Q$ pertencente à superfície e $\mathbf{x}=(x, y, z)$ um ponto da vizinhança de $Q$ situado sobre a malha euleriana e no qual se conhece a velocidade do fluido.

A função $\phi$ acima não foi escolhida arbitrariamente. Na verdade, ela foi determinada por imposição de que um certo conjunto de propriedades as quais devem ser satisfeitas para uma versão discreta da função Delta de Dirac [52]. Em particular, o conjunto de propriedades que serão usadas para determinar esta aproximação são

1. $\phi(r)$ é contínua, $\forall r \in \mathbb{R}$;

2. $\phi(r)=0$, se $|r| \geq 1.5$;

3. $\sum_{i} \phi(r-i)=1, \forall r \in \mathbb{R}$

4. $\sum_{i}[(r-i) \phi(r-i)]=0, \forall r \in \mathbb{R}$;

5. $\sum_{i}[\phi(r-i)]^{2}=\frac{1}{2}, \forall r \in \mathbb{R}$, 
onde todas as somatórias são feitas para os todos os valores inteiros de $i,-\infty<i<+\infty$.

Estas propriedades determinam unicamente a função $\phi$ e, por conseguinte, a função $\delta_{\Delta}$. É interessante observar que a função $\phi$ é continuamente derivável embora está questão não esteja explicitamente imposta [52]. A título ilustrativo, a Figura 2.5, mostra a função bidimensional $\delta_{\Delta}^{2}$ discretizada.

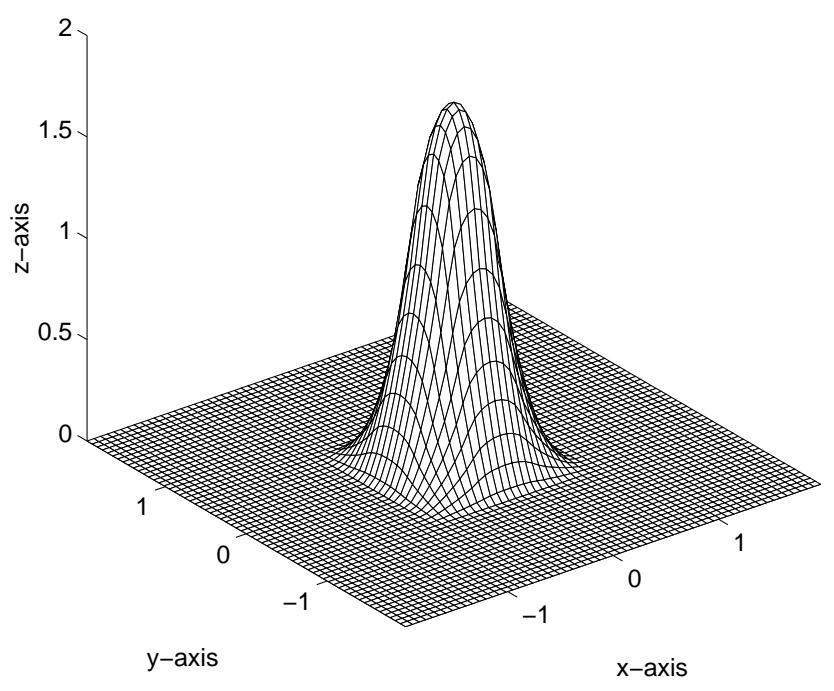

Figura 2.5: Função bidimensional $\delta_{\Delta}^{2}$ discretizada [57].

A propriedade 1, evita saltos nos operadores de interpolação. A propriedade 2 garante que a função delta discretizada tenha suporte finito o qual, no presente trabalho, é formado por três células computacionais. Quando combinadas, as propriedades 3 e 4 garantem que a interpolação das funções lineares sejam exatas. Logo, se funções suaves forem interpoladas, os resultados obtidos terão precisão de segunda ordem.

Finalmente, a propriedade 5 tem sua origem na consideração de que a força de um ponto da superfície influencia o seu próprio movimento e também da imposição de que tal influência é a mesma qualquer que seja a posição deste ponto relativa a malha. Observe que a constante $1 / 2$ na quinta propriedade não é arbitrária, ela pode ser obtida definindose $r=1 / 2$ e por intermédio de algumas manipulações algébricas. 


\subsubsection{Discretização das Equações no Tempo}

Uma vez adotada a discretização tridimensional da função Delta de Dirac (2.14) é possível empregá-la para obter $\mathbf{U}_{r, s}^{n}=\mathbf{u}\left(\mathbf{X}\left(r, s, t^{n}\right), t^{n}\right)$, a velocidade do ponto lagrangiano $\mathbf{X}(r, s, t)$ da interface no instante $t^{n}=t^{n-1}+\Delta t$. Esta velocidade é obtida por interpolação do campo euleriano de velocidades, isto é, o cálculo da velocidade de um ponto $\mathbf{X}(r, s, t)$ da superfície é feita por uma interpolação da velocidade dos pontos do fluido (pertencentes a malha euleriana) numa vizinhança deste ponto (Figura 2.6). Cada componente do vetor velocidade $\mathbf{U}_{\mathrm{r}, \mathrm{s}}^{n}=\left(U_{\mathrm{r}, \mathrm{s}}^{n}, V_{\mathrm{r}, \mathrm{s}}^{n}, W_{\mathrm{r}, \mathrm{s}}^{n}\right)$ de um ponto $\mathbf{X}(r, s, t)$ da interface no instante $t^{n}$ é calculado da seguinte forma

$$
\begin{aligned}
& U_{r, s}^{n}=\left[\sum_{i-2}^{i+2} \sum_{j-2}^{j+2} \sum_{k-2}^{k+2} u_{i-\frac{1}{2}, j, k}^{n} \delta_{\Delta}^{3}\left(\mathbf{x}_{i-\frac{1}{2}, j, k}-\mathbf{X}_{r, s}^{n}\right)\right] \Delta x_{l} \Delta y_{l} \Delta z_{l} \\
& V_{r, s}^{n}=\left[\sum_{i-2}^{i+2} \sum_{j-2}^{j+2} \sum_{k-2}^{k+2} v_{i, j-\frac{1}{2}, k}^{n} \delta_{\Delta}^{3}\left(\mathbf{x}_{i, j-\frac{1}{2}, k}-\mathbf{X}_{r, s}^{n}\right)\right] \Delta x_{l} \Delta y_{l} \Delta z_{l} \\
& W_{r, s}^{n}=\left[\sum_{i-2}^{i+2} \sum_{j-2}^{j+2} \sum_{k-2}^{k+2} w_{i, j, k-\frac{1}{2}}^{n} \delta_{\Delta}^{3}\left(\mathbf{x}_{i, j, k-\frac{1}{2}}-\mathbf{X}_{r, s}^{n}\right)\right] \Delta x_{l} \Delta y_{l} \Delta z_{l}
\end{aligned}
$$

É importante observar que os índices $i, j$ e $k$ utilizados nas somatórias acima se referem aos índices das células computacionais da malha euleriana que se situam nas vizinhanças do ponto lagrangiano $\mathbf{X}(r, s, t)$ da interface.

Embora esquemas numéricos de ordem mais elevadas com propriedades melhores de estabilidade e eficiência possam ser empregados, por simplicidade adotar-se-á aqui a discretização no tempo dada pelo Método de Euler (Explícito)

$$
\mathbf{X}_{r, s}^{n+1}=\mathbf{X}_{r, s}^{n}+\Delta t \mathbf{U}_{r, s}^{n}
$$

Note que a escolha do passo de integração no tempo está sujeita à condição

$$
\Delta t=\min \left\{\Delta t_{1}, \Delta t_{2}\right\}
$$

onde $\Delta t_{1}=\min \left\{\frac{\Delta x_{l}}{\left\|u_{i j k}^{n}\right\|_{\infty}}, \frac{\Delta y_{l}}{\left\|v_{i j k}^{n}\right\|_{\infty}}, \frac{\Delta z_{l}}{\left\|w_{i j k}^{n}\right\|_{\infty}}\right\}$, a qual tem o objetivo de não permitir que os vértices da superfície se movam mais do que uma célula computacional por passo 

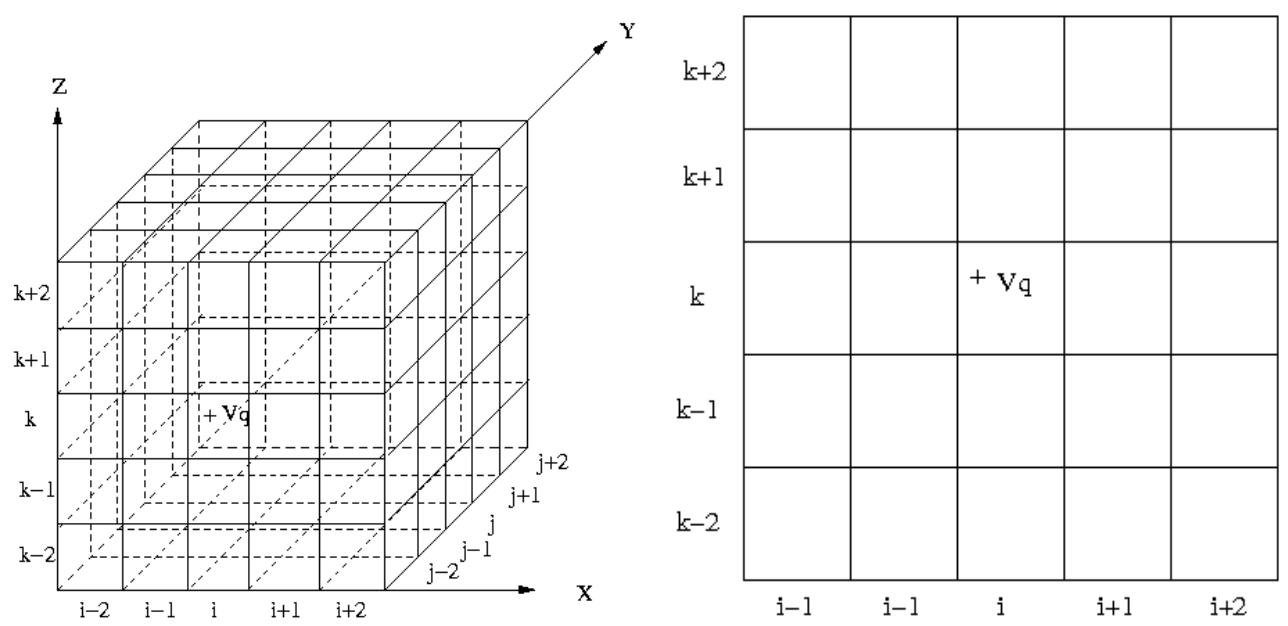

Figura 2.6: Vizinhança de um ponto $V q=\mathbf{X}(r, s, t)$ da superfície usada na interpolação da velocidade e Corte paralelo ao plano XZ passando por Vq.

no tempo e $\Delta t_{2}=\max \left\{0, t_{\text {final }}-t^{n}\right\}$ cujo o objetivo é o de assegurar que o passo no tempo não ultrapasse o tempo final $t_{\text {final }}$. 


\section{Refinamento Adaptativo de Malhas}

Em diversos problemas de dinâmica de fluidos computacional, e de especial interesse aqueles envolvendo escoamentos bifásicos, algumas regiões com propriedades geométricas especiais necessitam de uma resolução que só pode ser encontrada em uma malha euleriana muito fina (e.g. numa vizinhança da interface de separação entre as fases). Para obter a resolução necessária empregando uma malha uniforme é necessário estender essa malha para todo o domínio computacional; assim sendo, neste contexto, a malha resultante pode exceder a memória disponível no computador.

No presente trabalho, são empregadas malhas bloco-estruturas refinadas localmente, denominadas malhas compostas, as quais são obtidas aplicando-se o algoritmo AMR (Adaptative Mesh Refinement) desenvolvido originalmente por Berger e Oliger [7]. Este algoritmo foi escolhido por ser eficiente computacionalmente e por ser de implementação relativamente simples, já que utiliza somente estruturas de dados básicas como listas ligadas, vetores e matrizes como [9]. Além disso, a discretização das equações é a mesma que se usaria numa malha uniforme.

O processo de refinamento permite que regiões importantes do escoamento (e.g. regiões de alta vorticidade, de turbulência, de elevados gradientes de velocidade ou ainda contendo interfaces de separação entre as fases em escoamento) sejam tratadas com maior precisão.

Nesse Capítulo, são descritas as malhas compostas, o algoritmo de geração do refinamento adaptativo de malhas e os mapas utilizados no presente trabalho para otimizar o acesso e a busca de informações nessas malhas compostas. 


\subsection{Malhas Refinadas Localmente}

O domínio físico $\Omega$ onde ocorre o escoamentno é subdividido em diferentes níveis (físicos) de refinamento. Cada nível físico é composto pela união de paralelepípedos formados por malhas com mesmo espaçamento em todas as direções. Denominamos o primeiro nível físico, o mais "grosso", de lbot, isto é, aquele com o maior espaçamento. O último nível físico, o mais "fino", é denominado de ltop - ele tem o menor espaçamento dentre todos os níveis físicos.

A Figura 3.1 mostra uma malha bloco-estruturada tridimensional refinada localmente. A malha é composta por três níveis de refinamento, o primeiro nível físico (lbot) é dado por um único paralelepípedo discretizado por uma malha $16 \times 16 \times 16$ que cobre todo o domínio computacional; o segundo nível físico é dado também por um único paralelepípedo o qual contém $22 \times 24 \times 22$ células computacionais e terceiro nível físico (ltop) é a união de dois paralelepípedos cada um deles contendo $26 \times 12 \times 26$ células computacionais. Dessa forma, a malha composta ilustrada na Figura 3.1 é uma malha com refinamento localizado. Por refinamento, entenda-se a divisão do passo espacial do nível anterior por dois, a razão de refinamento adotada para criar as células computacionais de níveis físicos mais finos.

Antes de descrever o processo de marcação dos pontos do domínio que irão pertencer à malha refinada, é necessário definir as propriedades que a malha composta deve satisfazer para que as equações do movimento possam ser convenientemente discretizadas e integradas nessa estrutura de malha e, além disso, para que o algoritmo de geração de malhas seja simples e eficiente.

\subsection{Malhas Compostas}

Malhas compostas são definidas por meio de uma seqüência hierárquica de malhas aninhadas, progressivamente mais finas, agrupadas em níveis de refinamento $l=$ lbot, lbot $+1, \ldots$, ltop -1 , ltop, com lbot sendo o nível menos refinado. O l-ésimo nível de refinamento $G_{l}$ é dado pela união de um conjunto de malhas cartesianas $G_{l, k}$, as quais não têm pontos internos comuns, isto é, 


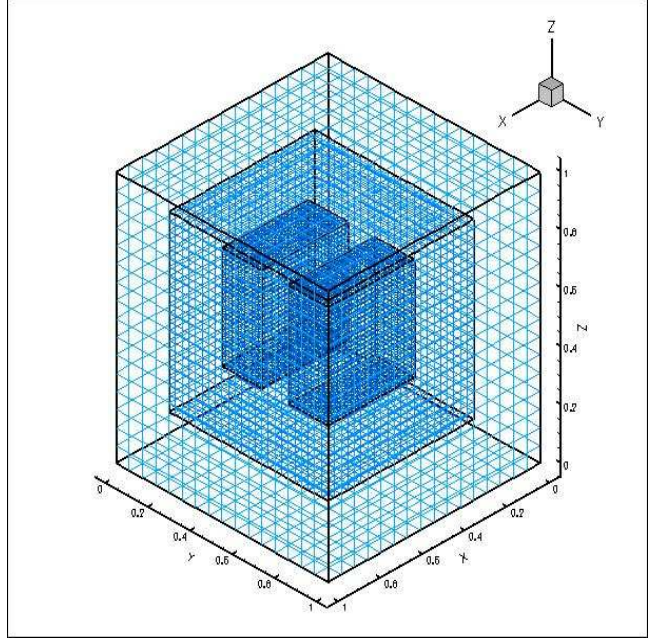

(a)

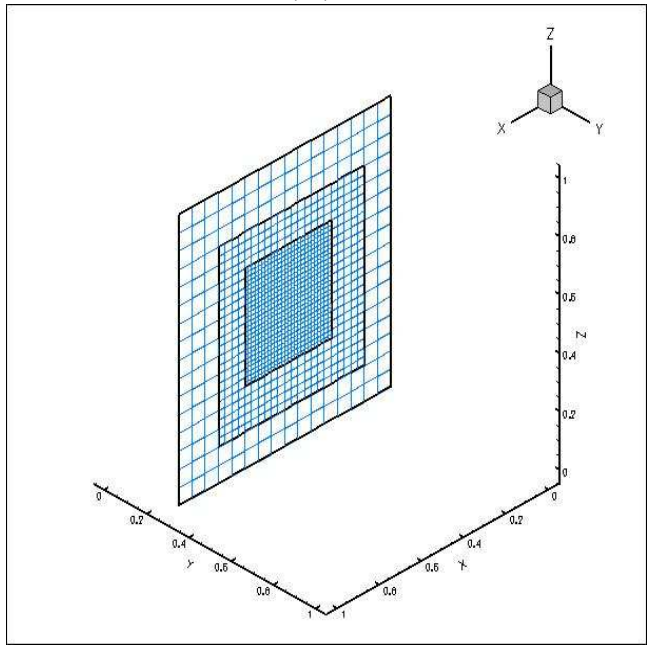

(c)

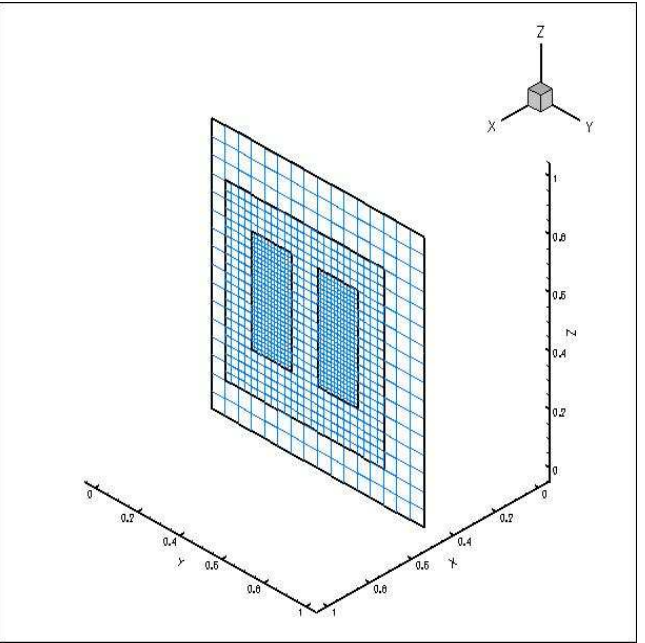

(b)

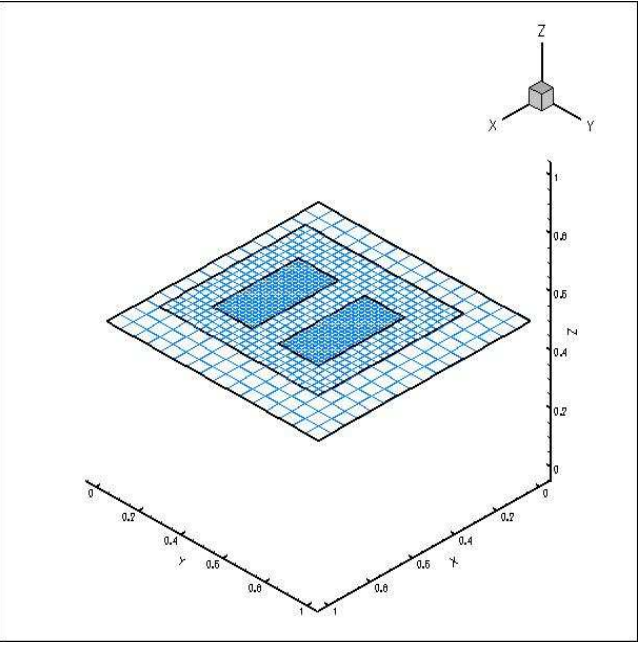

(d)

Figura 3.1: (a) Malha composta em um domínio computacional $\Omega=[0,1] \times[0,1] \times[0,1]$, com cortes em (b) $x=0.5$, (c) $y=0.3$ e (d) $z=0.5$.

$$
G_{l}=\bigcup_{k=1}^{n_{l}} G_{l, k}
$$

$\mathrm{e}$

$$
\stackrel{\circ}{G}_{l, j} \cap \stackrel{\circ}{G}_{l, k}=\emptyset, \forall j \neq k .
$$

É importante observar que, em geral, somente no nível lbot o domínio físico $\Omega$ é completamente recoberto pela união das malhas desse nível. A condição (3.2) garante que 
malhas em um mesmo nível, chamadas malhas irmãs, não estejam sobrepostas.

Malhas pertencentes a um mesmo nível de refinamento $l$ possuem os mesmos espaçamentos $\triangle x_{l}, \triangle y_{l}$ e $\triangle z_{l}$, e tem arestas paralelas aos eixos coordenados. Além disso, elas devem estar apropriadamente aninhadas no nível abaixo, $l-1$, isto é, devem satisfazer as seguintes propriedades:

i) Para todo i, uma malha $G_{l, i}$ deve começar e terminar num canto de uma célula computacional de uma malha $G_{l-1, j}$ do nível de refinamento imediatamente abaixo, para algum $j$;

ii) Deve haver ao menos uma célula computacional no nível $l-1$, pertencente a alguma malha no nível $l-1$, separando cada célula computacional do nível $l$ de uma célula computacional do nível $l-2$ em todas as direções, exceto se esta célula tocar o bordo do domínio físico.

Além das propriedades anteriores, durante a implementação computacional devem ser adicionadas camadas de células fantasmas ao redor de cada malha as quais, entre outras funções, são empregadas para fornecer condições numéricas para os operadores de diferenças finitas utilizados. No presente trabalho, a quantidade de células fantasmas utilizadas foi escolhido em função do espaçamento do nível mais fino e da largura da faixa utilizada para definir a função indicadora de fluidos, descrita do Capítulo 4.

A Figura $3.2(a)-(b)$ exemplifica em duas dimensões malhas superiores que não estão apropriadamente aninhadas segundo as propriedades acima. Na Figura $3.2(c)$, a malha composta mostrada pode ocorrer na prática, apesar da mesma não ser formada por malhas apropriadamente aninhadas. Neste caso, como o bordo das malhas no segundo e terceiro níveis toca a fronteira do domínio $\Omega$, as condições de contorno não periódicas nessas fronteiras devem ser corretamente transferidas. Na Figura $3.2(d)$, a malha composta é formada por malhas apropriadamente aninhadas.

\subsection{Geração de Malhas Compostas}

Inicialmente, somente a malha do primeiro nível físico e o número de níveis físicos são especificados pelo usuário. Depois disso, o único limitante para a geração dos outros níveis passa a ser memória do computador utilizado. 


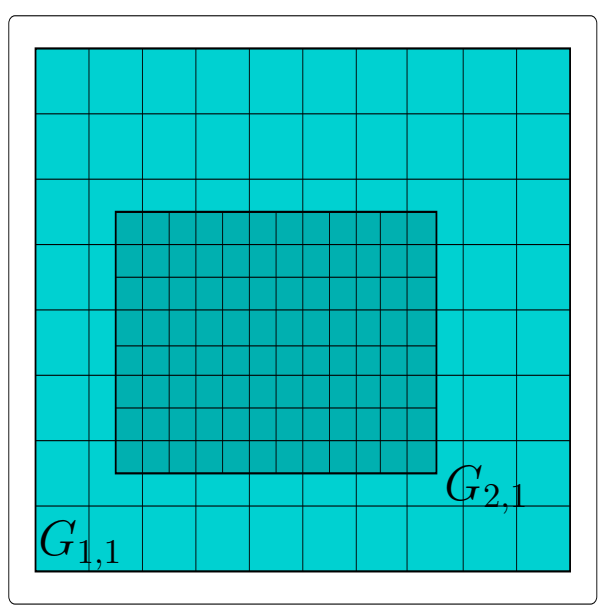

(a)

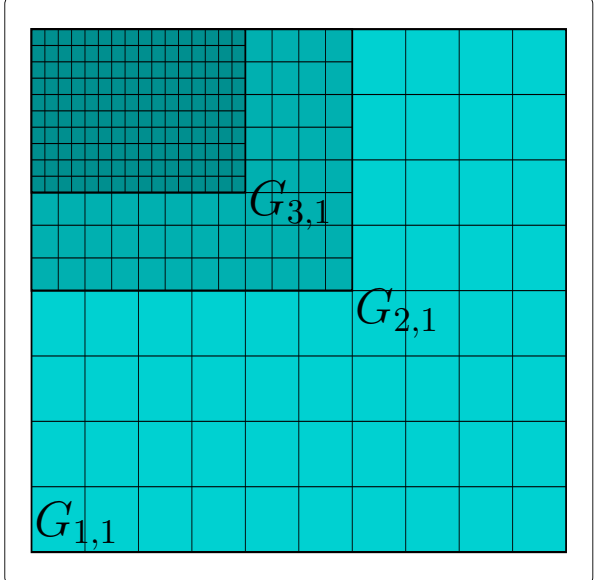

(c)

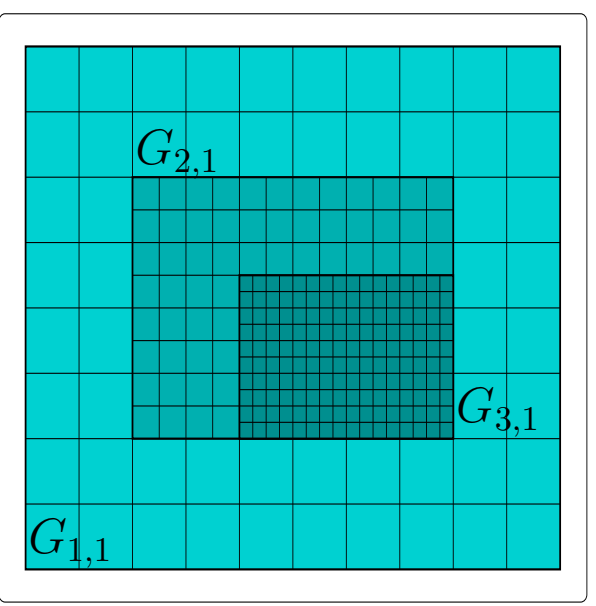

(b)

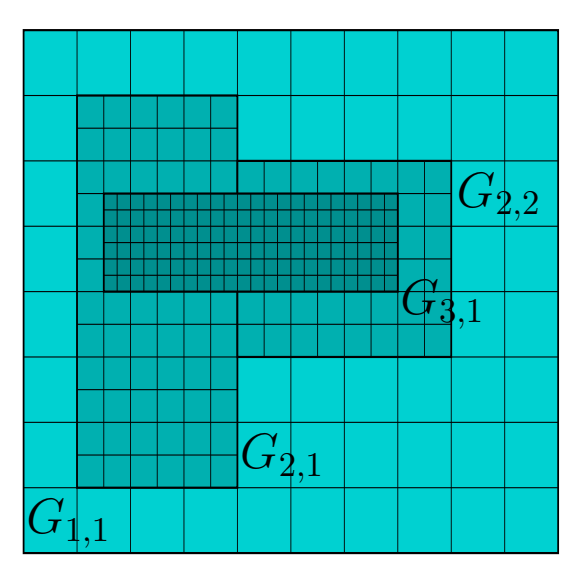

(d)

Figura 3.2: Malhas apropriadamente aninhadas (c) e (d) e não apropriadamente aninhadas (a) e (b).

O processo de geração das malhas consiste de três passos básicos. O primeiro passo do algoritmo é selecionar os pontos do domínio que necessitam de uma melhor resolução; o segundo passo é agrupar os pontos selecionados de forma que eles pertençam a uma união de paralelepípedos satisfazendo algum "critério de eficiência" e o terceiro passo é gerar as malhas dos diversos níveis de refinamento ltop, $\ldots$, lbot -1 de forma que essas malhas satisfaçam as propriedades (i) e (ii). 


\subsubsection{Seleção dos Pontos}

Vários critérios para a seleção dos pontos têm sido propostos. Berger e Oliger [7] utilizam a extrapolação de Richardson para estimar o erro local da solução numérica e selecionam os pontos com as maiores estimativas para colocarem o refinamento. A exemplo de Roma [57], no presente trabalho, são marcados pontos numa vizinhança da interface.

Os níveis de refinamento em uma malha composta são gerados um de cada vez começando pelo nível mais fino, ltop, e finalizando com o nível lbot +1 (o nível físico mais grosso nunca é modificado). Um dos motivos para justificar essa ordem de geração dos níveis de refinamento é garantir que as malhas geradas estejam apropriamente aninhadas.

No presente trabalho, a seleção dos pontos para geração inicial das malhas compostas é feita de maneira diferente da seleção dos pontos para geração das malhas compostas subseqüentes.

Na primeira malha composta, para o nível ltop marcam-se somente as células computacionais no nível ltop - 1 numa vizinhança da interface entre as diferentes fases. Isso é feito utilizando-se uma função de valores inteiros definida em uma malha uniforme com espaçamento equivalente a uma malha do nível ltop - 1 cobrindo o menor paralelepípedo contendo uma vizinhança das interfaces contidas no domínio físico $\Omega$. A utilização dessa função de valores inteiros é necessária para evitar redundâncias na marcação dos pontos, evitando assim utilização de um algoritmo de "limpeza" dos pontos marcados mais de uma vez e otimizando a geração das malhas compostas.

A geração das malhas compostas subseqüentes é feita marcando-se as células computacionais numa vizinhança da interface utilizando-se uma função de valores inteiros definida no nível ltop - 1 da última malha refinada gerada.

Para gerar os outros níveis $l$, lbot $+1<l<l$ top, são marcadas células computacionais no nível $l-1$ de forma a garantir que todos os pontos das malhas do nível $l$ sejam marcados e além desses pontos são marcados pontos numa vizinhança das malhas do nível $l$ para garantir que as malhas do nível $l-1$ estejam apropriadamente aninhadas com as malhas do nível $l$. 


\subsubsection{Agrupamento dos Pontos}

Depois de selecionados os pontos para refinamento, o problema da geração automática de malhas torna-se um problema de otimizar um conjunto de paralelepípedos que contenha todos esses pontos: deseja-se o menor número de paralelepípedos que contenha a região marcada. Certos fatores exercem grande influência sobre a escolha desses paralelepípedos. São eles:

a) O algoritmo deve determinar a menor região refinada possível: como o custo computacional para realizar operações é proporcional ao volume do paralelepípedo, quanto menor for a região recoberta por esses paralelepípedos menor será o uso de memória e o tempo computacional (note que a inclusão de células computacionais não marcadas em alguns paralelepípedos é inevitável pois o algoritmo se restringe à construção de paralelepípedos). Além disso, por razões de implementação computacional, os paralelepípedos são construídos com os lados paralelos aos eixos coordenados. Isso é verdade mesmo se os pontos marcados estão em uma diagonal da malha grossa.

b) O algoritmo deve gerar o menor número de paralelepípedos possível para minimizar a sobrecarga ocasionada pela varredura das estrutura de malhas (pois todas elas exigem o cálculo de valores nas células fantasmas) sem, no entanto, incluir um número demasiadamente grande de pontos não marcados na região a ser refinada (pois haveria um "desperdício", nesse caso, de esforço computacional e de memória).

c) O algoritmo deve ser rápido: este algoritmo é repetidos várias vezes durante uma simulação numérica e deve ser relativamente mais rápido que o tempo de resolução das equações que envolvem a malha.

Combinando elementos de Visão Computacional e Teoria de Reconhecimento de Padrões, dado um conjunto de células computacionais selecionadas o Algoritmo de Berger e Rigoutsos [12] retorna um conjunto de paralelepípedos que não se sobrepõem satisfazendo a um dado critério de eficiência. Em termos gerais, este algoritmo detecta a transição entre uma região selecionada e uma região com células computacionais não selecionadas, detectando o melhor lugar para se aplicar a divisão das malhas.

Assim, o algoritmo determina um conjunto de paralelepípedos que contém não só todos os pontos marcados como também um certo número de células computacionais ao seu redor (cada parelelepípedo é uma espécie de "casco convexo" que tem arestas paralelas 
aos eixos cartesianos). Para isso, recorre-se a técnica de sinalização [12] a qual detecta as transições entre regiões marcadas e regiões não marcadas e encontra o "melhor" lugar para cortar a malha. As funções de sinalização de uma matriz $A$, com $M \times N \times L$ pontos definida somente com as entradas 0 e 1 (0 para os pontos não selelecionados e 1 para os pontos selecionados) são dadas por

$$
\begin{aligned}
& S_{x}(i)=\sum_{j=1}^{N} \sum_{k=1}^{L} A(i, j, k) \\
& S_{y}(j)=\sum_{i=1}^{M} \sum_{k=1}^{L} A(i, j, k) \\
& S_{z}(k)=\sum_{i=1}^{M} \sum_{j=1}^{N} A(i, j, k)
\end{aligned}
$$

que retornam o número de entradas não nulas em cada um dos planos paralelos aos planos cartesianos.

A aresta "mais importante", aquela que irá receber o corte, é aquela responsável pelo maior ponto de inflexão das funções [41]. Mais especificamente, nesse sentido, a aresta mais importante está localizada onde há a maior transição de valores, passando por zero, da segunda derivada da função sinalizadora da matriz $A$.

A Figura 3.3 mostra um exemplo bidimensional de como essa técnica é usada para identificar a aresta mais importante em uma determinada região marcada. O símbolo $\Delta$ corresponde à discretização da segunda derivada associada a função sinalizadora, a qual é aproximada por diferenças centradas.

A técnica de sinalização pode ser usada para gerar vários "retalhos" retangulares pertencentes à certo nível $l$, cuja união contém todas as células computacionais marcadas. A construção de um nível $l$ de refinamento começa com a construção de uma única malha espalhada pela região inteira das células computacionais marcadas. Esta malha é chamada de fecho retangular, que por definição, é o menor paralelepípedo com arestas paralelas aos eixos cartesianos que contém um certo grupo de células computacionais.

Como a malha construída pode conter regiões isoladas que contém células computacionais marcadas, é definido um critério de eficiência para limitar a porcentagem de células 


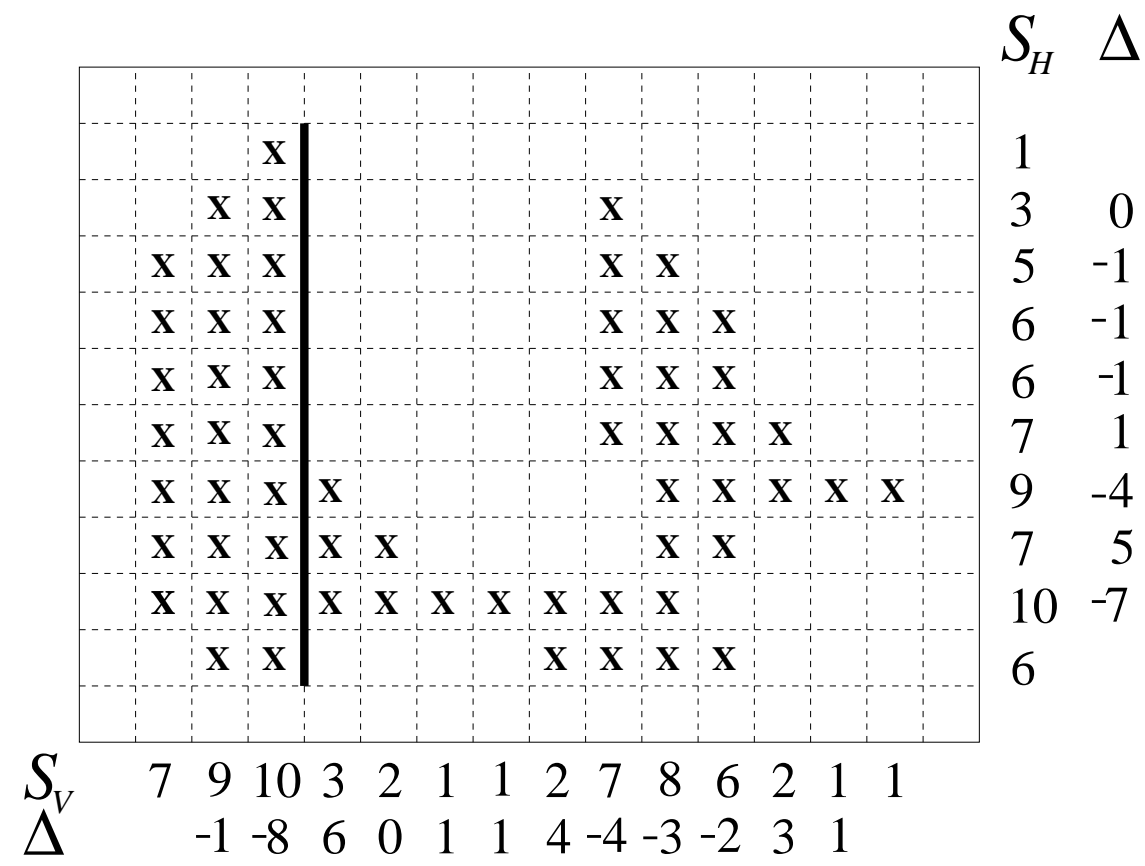

Figura 3.3: A maior ponto de inflexão acontece na linha grossa, a qual faz o corte mais eficiente [57].

computacionais não marcadas que podem estar contidas em cada malha. Esse critério de eficiência é dado por

$$
\frac{\text { número de células computacionais marcadas }}{\text { número total de células computacionais da malha }} \geq \epsilon_{\text {min }}
$$

onde $0<\epsilon_{\min }<1$.

Se uma malha não satisfaz o critério de eficiência, a técnica de sinalização é aplicada novamente para encontrar a aresta mais proeminente onde essa malha deve ser separada em duas (cortada ao meio), obtendo dessa forma uma partição da região original de células computacionais marcadas em duas subregiões. Cada subregião obtida é testada usando o critério de eficiência (3.6); se alguma dessas novas malhas falhar no teste de eficiência a técnica de sinalização é reaplicada. Esse procedimento é feito recursivamente para cada subregião até que todos os fechos retangulares passem no teste de eficiência. A única exceção a esta regra ocorre quando não é possível encontrar nenhuma partição eficiente de um fecho retangular usando a técnica de sinalização [12].

Esse processo de construção de malhas é repetido até que todos os níveis físicos tenham 
sido construídos. No presente trabalho, o processo de remalhagem é feito sempre que a interface se aproxima "demais" de alguma célula computacional do nível mais nível físico mais fino pertencente à fronteira do conjunto de malhas desse nível. A implementação computacional desse critério é feita empregando-se alguns "mapas" eulerianos e lagrangianos os quais serão descritos a seguir.

\subsection{Mapas Lagrangianos e Eulerianos}

Algumas informações sobre as malhas lagrangiana e euleriana precisam ser consultadas várias vezes em cada passo no tempo. Para evitar buscas repetitivas num mesmo passo de tempo para obter essas informações, é computacionalmente vantajoso a construção de algumas estruturas que denominamos de "mapas" para armazenar tais informações.

No presente trabalho, foram construídos dois mapas lagrangianos, dois mapas eulerianos e duas tabelas que associam os índices numéricos das malhas dos níveis ltop e ltop - 1 aos ponteiros dessas malhas.

Os mapas lagrangianos foram construídos para armazenar a relação de pertinência dos pontos lagrangianos em relação às malhas contidas nos níveis ltop e ltop - 1. Esses mapas são definidos no ponteiro da estrutura de dados Halfedge [64, 66] a qual armazena as propriedades dos pontos lagrangianos (vértices). Tais mapas são atualizados a cada passo no tempo após o movimento da interface. Esta estratégia evita que se tenha que fazer uma busca no conjunto de malhas cada vez que for necessário saber a qual malha do nível ltop e ltop - 1 um dado ponto lagrangiano pertence.

Os mapas lagrangianos são reconstruídos e inicializados toda vez que a malha euleriana é substituída. Nos outros passos de tempo, esses mapas são atualizados somente nos pontos que mudam de uma malha para outra do mesmo pertencentes ao mesmo nível de refinamento.

Para atualizar a localização dos pontos lagrangianos quando eles mudam de uma para outra malha, foram implementados dois mapas eulerianos que são funções de valores inteiros definidas no nível ltop - 1: um armazena informações das malhas dos níveis ltop e o outro armazena informações do nível ltop -1 .

Um dos mapas eulerianos foi construído com o objetivo de determinar em que malha 
do nível ltop um dado ponto lagrangiano se encontra. Este mapa euleriano determina também se e quais são as malhas desse mesmo nível que recobrem sua vizinhança. Essas informações são importantes para atualizar os mapas lagrangianos quando os pontos lagrangianos mudam de malha; com isso evita-se uma busca exaustiva sobre todas as malhas e é possível determinar quando é necessário fazer uma remalhagem da malha euleriana. A construção desse mapa foi feita utilizando os Algoritmos 5, 6, 7 e 8 do Apêndice B.

O primeiro passo para a construção desse mapa euleriano é inicializar todas as entradas da função com valor zero. Depois cada uma das malhas do nível ltop é percorrida e para cada uma das faces dessas malhas, a primeira camada de células computacionais vizinha a essa face pelo lado de fora da malha é projetada no nível ltop - 1 e marcada no mapa euleriano com valor $-\infty$. As malhas do nível ltop são então percorridas novamente inicializando as células computacionais internas a cada uma das malhas com um número inteiro positivo associado a cada malha do nível ltop (veja algoritmo 5 do Apêndice B). Assim, é possível identificar no nível ltop - 1 as malhas do nível ltop correspondentes à uma determinada região do domínio computacional.

Para que esse mapa possa também ser usado para identificar quando um ponto está próximo da borda das malhas do nível ltop, uma região próxima da borda foi marcada com sinal negativo no mapa euleriano. A implementação desse algoritmo foi feita percorrendo todas malhas do nível ltop e projetando o sinal das células computacionais, com sinal negativo, exteriores às faces da cada malha para as células computacionais interiores à essa malha. Nessa projeção, o índice da malha foi mantido no mapa euleriano, mudando apenas o sinal do mapa euleriano na célula computacional. Para mais detalhes, consulte os Algoritmos 6, 7 e 8 do Apêndice B.

O outro mapa euleriano construído armazena os índices das malhas do nível ltop - 1 nas células computacionais interiores da malha e nas células fastasmas armazena o índice da malha do nível ltop - 1 que recobre aquela célula fantasma. O objetivo desse mapa é determinar o índice da malha do nível ltop - 1 que o ponto lagrangiano está depois de cada passo no tempo.

Com o objetivo de associar os índices das malhas do nível ltop e ltop - 1 aos ponteiros dessas malhas foram construídas tabelas na forma de vetores de ponteiros que associam a cada índice das malhas dos níveis ltop e ltop - 1 os ponteiros dessas malhas. Com isso, é possível atualizar os mapas lagrangianos sem fazer nenhuma busca nas malhas dos níveis 
ltop e ltop -1 .

Em cada passo no tempo é verificado se cada ponto da malha lagrangiana mudou de malha no nível ltop. Caso isso tenha ocorrido, um dos mapas lagrangianos é consultado para determinar em qual malha do nível ltop - 1 esse ponto lagrangiano estava no passo no tempo anterior e, então, o mapa euleriano que armazena as informações das malhas do nível ltop - 1 é consultado para determinar o índice da malha do nível ltop - 1 a qual este ponto está localizado. Após isso, caso o ponto tenho mudado de malha do nível ltop - 1 , a tabela de ponteiros que associa os índices das malhas do nível ltop -1 ao ponteiro da malha é utilizado para determinar o ponteiro da malha do nível top - 1 que contém esse ponto. O mapa euleriano que armazena as informações das malhas do nível ltop é, então, consulta para determinar o índice da malha do nível ltop em que este ponto está localizado. Finalmente, a tabela de ponteiros que associa os índices das malhas do nível ltop é consultada para determinar o ponteiro da malha do nível ltop que contem o ponto lagrangiano.

Vale ressaltar que os mapas eulerianos e as tabelas de ponteiros são atualizadas somente quando ocorre uma troca da malha euleriana; nos demais passos no tempo, é necessário somente atualizar os mapas lagrangianos. 


\section{Capítulo 4}

\section{Função Indicadora de Fluidos}

Nos problemas de simulação numérica de escoamentos multifásicos, é necessário atualizar as propriedades materiais dos fluidos (viscosidade e densidade de massa) a cada instante do tempo. Como as propriedades materiais são constantes em cada um dos fluidos e, para manter a estabilidade numérica do método, o movimento de suas interfaces de separação é restrito a menos de um espaçamento da malha euleriana em cada passo no tempo, é computacionalmente atraente a idéia de atualizar essas propriedades somente em uma vizinhança das interfaces.

Esta atualização pode ser realizada de forma bastante eficiente por intermédio do uso de uma função distância com sinal atualizada apenas em torno da interface que separa os fluidos (uma superfície fechada). Essa função distância com sinal é empregada para determinar se um ponto pertence ou não ao interior da superfície de separação, por conseguinte, qual é o valor correto das propriedades materiais do fluido no interior e no exterior dessa superfície. Comumente em dinâmica de fluidos computacional, esta função distância com sinal recebe o nome de função indicadora de fluidos, pois usando o sinal determinado por essa função é possível determinar a localização de cada fluido em relação a interface, em cada instante de tempo.

Localizar o interior e o exterior de uma superfície fechada é um problema comum em outras áreas do conhecimento como, por exemplo, Computação Gráfica [20, 21, 24, 67], Geometria Computacional, Visão Computacional [39] e Processamento de Imagens [40], onde o cálculo de distâncias é também necessário.

Neste Capítulo, serão descritos um algoritmo de cálculo e a implementação da função 
indicadora de fluidos utilizando idéias de Geometria Computacional conforme proposto em [42].

\subsection{Cálculo da Função Indicadora de Fluidos}

Sejam $S$ uma superfície fechada em $\mathbb{R}^{3}$ representando a interface entre dois fluidos e $\phi(P)$ uma função indicadora de fluidos que fornece a distância com sinal entre um ponto $P$ da malha euleriana até a superfície $S$. Pode-se então adotar uma convenção para o sinal dessa função nos pontos que estão do lado do vetor normal exterior à $S$ e o sinal oposto para os pontos do lado oposto ao vetor normal à $S$.

Para que a função indicadora de fluidos esteja bem definida, é necessário que a superfície seja orientável. A Garrafa de Klein e a Faixa de Möbius são exemplos de superfícies não-orientáveis.

Na discretização da superfície, foi utilizado o software livre GMSH [66, 82, 83], o qual gera uma malha triangularizada, não estruturada e bidimensional para representar a superfície. Os dados de entrada desse software, foram escolhidos de maneira que o vetor normal a cada uma das faces (elementos triangulares) fosse exterior à superfície. Com essa escolha, a estrutura de dados Halfedge foi implementada e esses vetores normais (unitários) foram armazenados.

No presente trabalho, foi adotada a convenção da função indicadora de fluidos ser negativa nos pontos da malha euleriana que estão no interior da superfície que separa os fluidos e positiva nos pontos que estão no exterior. Esta convenção foi adotada para que a função indicadora de fluidos tenha o mesmo sinal que o produto interno entre o vetor normal à superfície e o vetor projeção do ponto na superfície.

Por questões de eficiência, depois de inicializar a função indicadora de fluidos em todos os pontos da malha euleriana no primeiro passo no tempo, somente informações locais são usadas na atualização da função indicadora ao término de cada passo no tempo, após os pontos lagrangianos (vértices da superfície de separação) terem se movido. Apenas os pontos eulerianos pertencentes à uma vizinhança de tamanho $\epsilon$ da superfície têm a função indicadora atualizada em cada instante do tempo. Dado $\gamma$, tal que $0<\gamma<\epsilon$, a função indicadora é definida com valores variando entre $-\gamma$ e $\gamma$. Fora de uma vizinhança de 
tamanho $\gamma$ da superfície, se o ponto é exterior à superfície o valor da função indicadora é $\gamma$ e se o ponto for interior à superfície o valor da função indicadora é $-\gamma$.

Mais precisamente, dada uma triangularização que representa a superfície $S$, definese a função indicadora de fluidos em $S_{\gamma}$, uma faixa estreita centrada em $S$ com largura $2 \gamma>0$. Fora dessa faixa, a função indicadora $\phi$ é continuamente definida igual a $\pm \gamma$. Assim,

$$
\phi(P)=\left\{\begin{array}{rrrr}
-\gamma & \text { se } & d(P) & <-\gamma \\
d(P) & \text { se } & |d(P)| & \leq+\gamma \\
+\gamma & \text { se } & d(P) & <+\gamma
\end{array}\right.
$$

onde $d(P)$ é a distância euclidiana com sinal do ponto $P$ até a superfície $S$ e o sinal é escolhido de acordo com a direção do versor normal.

Para que a função indicadora de fluidos seja atualizada corretamente a cada passo no tempo os valores de $\epsilon$ e $\gamma$ devem ser escolhidos tais que a variação dos pontos da malha euleriana a cada passo no tempo seja menor do que $(\epsilon-\gamma)$. Essa condição é necessária para garantir que a função indicadora de fluidos seja atualizada em alguns pontos os quais a função indicadora de fluidos tinha valor menor que $\gamma$ e que depois da atualização da posição da malha lagrangiana a distância desse ponto até a superfície passou a ser maior do que $\gamma$.

Para atualizar a função indicadora de fluidos no fim de cada passo no tempo, utilizamos um algoritmo intitulado Closest Point Transform (CPT) desenvolvido por Mauch [42].

\subsection{CPT para Superfícies Triangularizadas}

Nesta Seção, será descrito um algoritmo para calcular eficientemente a função indicadora de fluidos nos pontos da malha euleriana estruturada na vizinhança de superfícies triangularizadas.

Pode-se calcular a função indicadora de fluidos, de maneira rudimentar, ao percorrer cada um dos elementos geométricos da superfície triangularizada (faces, arestas e vértices) e calcular a distância de cada um desses elementos geométricos até cada um dos pontos da malha euleriana. Neste caso, se a triangularização da superfície tiver $M$ elementos 
geométricos e a malha euleriana tiver $N$ pontos, então a complexidade computacional desse algoritmo é $O(M N)$. O Algoritmo 1, intitulado Closest Point Transform Brute por Mauch [42], a seguir, supõe que $S$ é a superfície triangularizada, $\phi$ é a função indicadora de fluidos e $q$ é um dos elementos geométricos da superfície triangularizada (face, aresta ou vértice).

$\overline{\text { Algoritmo } 1 \text { Closest Point Transform Brute }}$

para cada $i j k$ faça

$\phi(i, j, k)=\infty$

fim para

para cada $q \in S$ faça

para cada ponto $P_{i j k}$ da malha euleriana faça

$d=$ distância com sinal do ponto $P_{i j k}$ à $q$

se $|d|<|\phi(i, j, k)|$ então

$\phi(i, j, k)=d$

fim se

fim para

fim para

Observe que no Algoritmo 1, a função indicadora de fluidos é atualizada em todos os pontos da malha euleriana em cada passo no tempo. No presente trabalho como, para preservar a estabilidade do método numérico, o movimento da superfície que representa a interface de separação entre os fluidos é limitado a menos de um espaçamento da malha euleriana por passo no tempo, é necessário atualizar a função indicadora somente numa vizinhança pequena dessa superfície. Assim, o laço interno do Algoritmo 1 pode ser substituído por um laço sobre todos os pontos da malha euleriana que estão numa vizinhança de cada elemento geométrico da superfície. Para isso, define-se uma constante $\epsilon>0$ e atualiza-se a função indicadora somente numa vizinhança de tamanho $\epsilon$ da superfície por meio do Algoritmo 2, a seguir, intitulado Closest Point Transform Brute Local: 


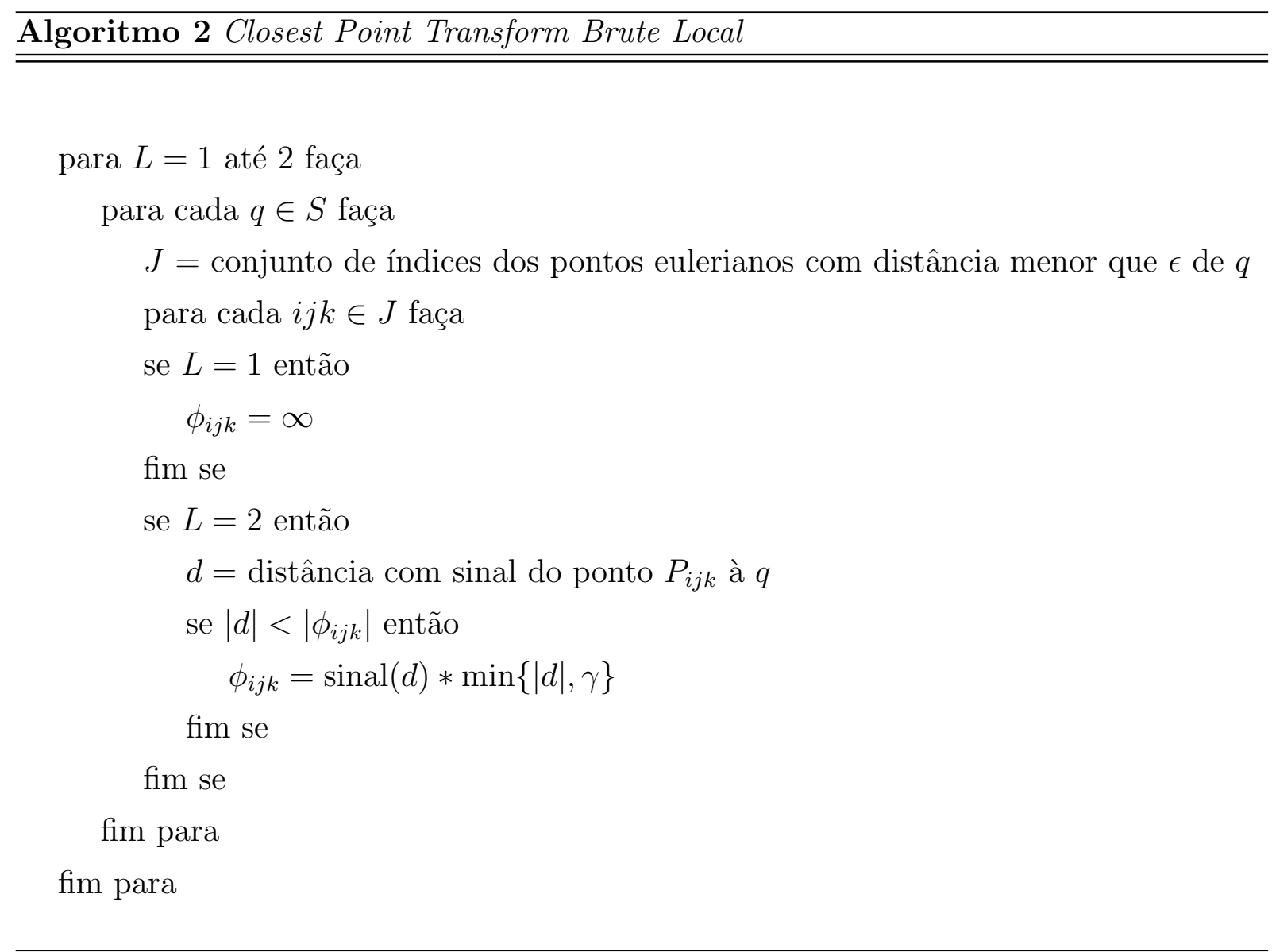

Na literatura, existem vários algoritmos para determinar os pontos da malha euleriana que estão numa vizinhança de tamanho $\epsilon$ dos elementos geométricos da superfície.

O Algoritmo 3, Closest Point Transform proposto por Mauch [42] consiste em percorrer cada um dos entes geométricos da superfície (face, aresta e vértice) e, para cada um desses entes, usar idéias de geometria computacional para construir um poliedro limitante que contém todos os pontos $P$ da malha euleriana que estão a uma distância menor ou igual a $\epsilon$ desse elemento geométrico. Para tratar regiões onde esses poliedros coincidem, é suficiente tomar o mínimo das distâncias calculadas.

Para a construção desses poliedros, Peikert e Sigg [49] propuseram uma nova metodologia que minimiza a região onde os poliedros propostos por Mauch se interseccionam. Entretanto, essa nova metodologia necessita de um complicado cálculo para a distância entre o ponto e a superfície, melhor detalhado por Sigg, Peikert e Gross [65], e deixa "lacunas" próximas de alguns vértices da superfície. Por esses motivos, no presente trabalho, 
a construção desses poliedros foi feita utilizando as idéias propostas por Mauch [42] no Algoritmo 3, Closest Point Transform, descrito a seguir.

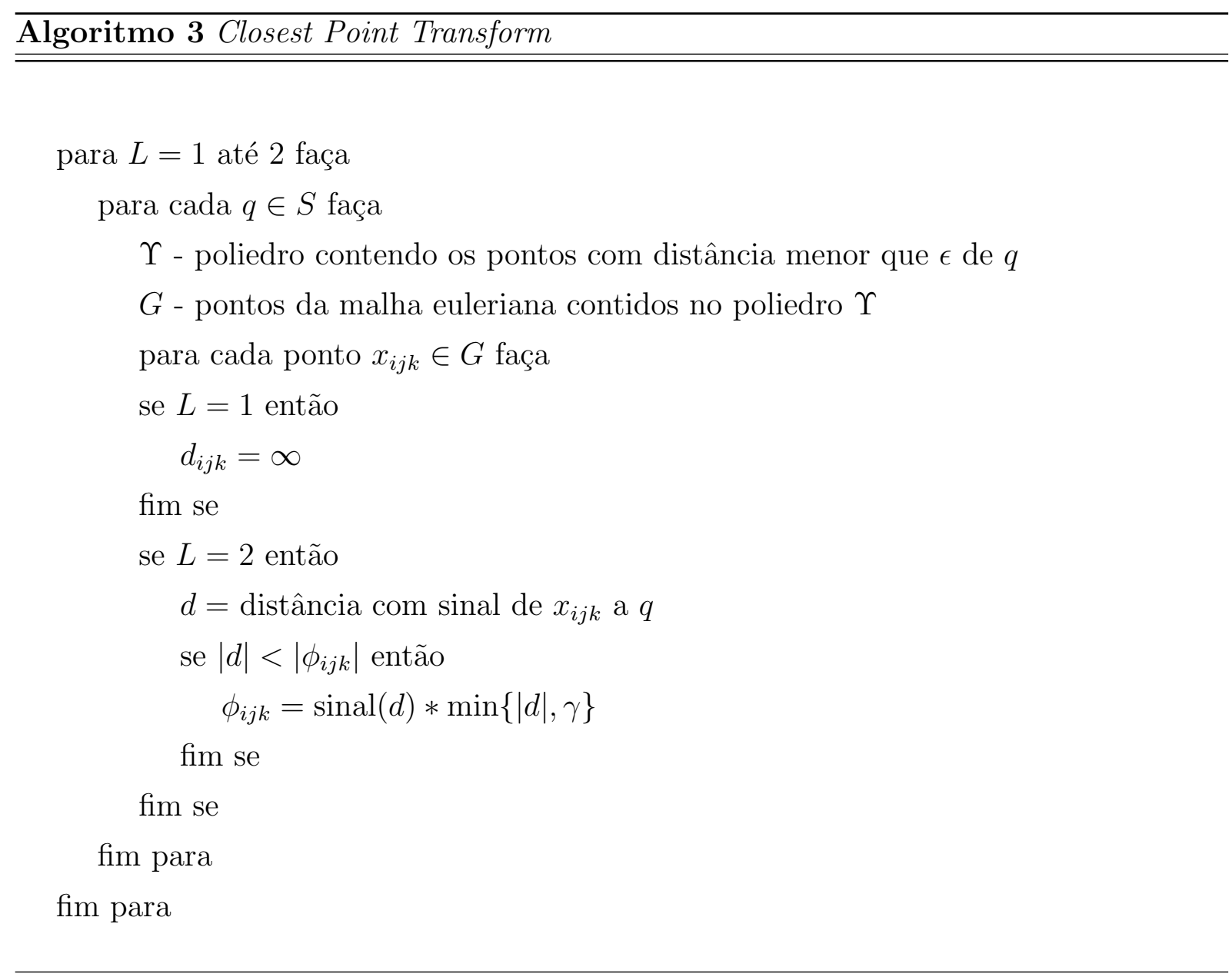

Se $Q$ é um ponto da superfície $S$ que minimiza a distância entre um ponto $P$ até esta superfície, então a distância de $S$ a $P$ é dada por $\|P-Q\|$. Se $S$ é suave então o segmento de reta ligando $Q$ a $P$ é ortogonal ao plano tangente à superfície passando por $Q$. Se a superfície não é suave, então $P$ está "entre" os vetores normais das partes suaves da superfície em torno de $Q$.

Como a superfície triangularizada é composta por faces, arestas e vértices, dado um ponto $P$ pertencente a malha euleriana, o ponto $Q \in S$ que minimiza a distância euclideana entre $P$ a $S$ está em uma face, em uma aresta ou em um vértice de $S$. Nas próximas seções, será discutido detalhadamente o Algoritmo 3, Closest Point Transform, para cada um dos seguintes três casos: $Q$ em uma das faces de $S, Q$ em uma das arestas de $S$ e $Q$ 

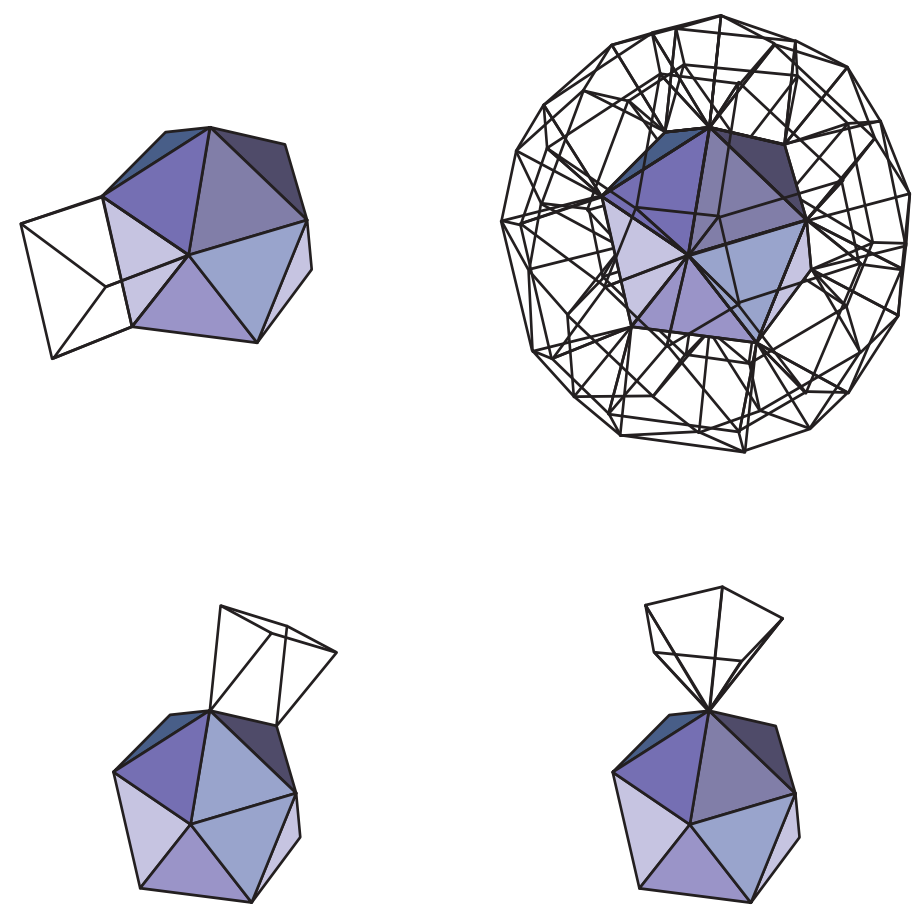

Figura 4.1: Exemplo dos poliedros propostos por Mauch: exemplo de um poliedro construído nas faces, superfície recoberta por todos os poliedros, exemplo de um poliedro construído nas arestas e exemplo de um poliedro construído nos vértices.

em um dos vértices de $S$.

\subsubsection{CPT nas Faces}

Dado um ponto $P$ da malha euleriana, se o ponto $Q$ que minimiza a distância de $P$ à superfície $S$ estiver em uma das faces de $S$ então o vetor $(P-Q)$ é ortogonal a esta face. Assim, $P$ pertence a um prisma reto de base triangular (veja Figura 4.2), determinado pelo vetor normal e pelos vértices $A, B$ e $C$ da face. Esse prisma de base triangular contém pontos da malha euleriana que podem estar na região externa ou na região interna à superfície $S$. A função indicadora de fluidos tem sinal positivo se o ponto estiver na região externa à superfície e sinal negativo se o ponto estiver na região interna à superfície. Obviamente, se o ponto estiver sobre a superfície, a função indicadora vale zero.

No trabalho presente, para construir esse prisma foram utilizadas as propriedades 
da estrutura de dados Halfedge que permitem, a partir do ponteiro da face, acessar as coordenadas dos vértices e do vetor normal unitário externo à face em tempo constante.

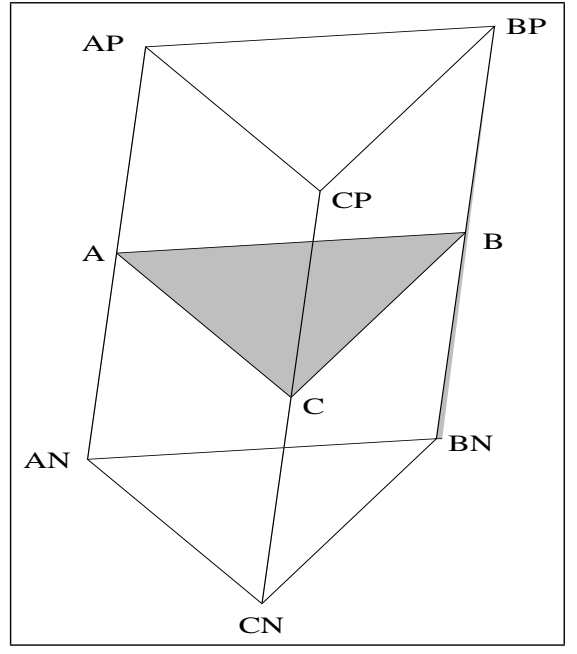

Figura 4.2: Prisma triangular reto.

Depois de construído o prisma reto de base triangular, determina-se o menor paralelepípedo que tem pontos eulerianos como vértices e cujas arestas estão nas direções dos eixos coordenados que contém esse prisma. Para fazer isso, tomam-se os valores máximo e mínimo em cada uma das três coordenadas dos vértices do prisma e, a partir disso, determina-se os índices dos vértices desse paralelepípedo na malha euleriana.

Depois de determinado esse paralelepípedo, emprega-se um algoritmo análogo ao descrito no Apêndice A de [15] para determinar quais pontos do paralelepípedo pertencem ao prisma. Se o ponto $P$ estiver contido no prisma, calcula-se a distância de $P$ até a face por meio do produto interno $<\mathbf{n}, P-A>$, pois $<\mathbf{n}, P-A>=\|\mathbf{n}\|\|P-A\| \cos \theta$, onde $A$ é um dos vértices da face, $\mathbf{n}$ é o versor normal externo à face e $\theta$ é o ângulo entre os vetores $\mathbf{n}$ e $P-A$. Note que calcular a distância utilizando esse produto interno é vantajoso computacionalmente pois evita o cálculo de uma raiz quadrada em cada ponto da malha euleriana próximo de $S$.

\subsubsection{CPT nas Arestas}

Nas arestas, a superfície triangularizada não é diferenciável e por isso não tem mais a propriedade de possuir um vetor normal definido. Neste caso, utilizam-se os vetores 
normais às duas faces adjacentes à aresta para construir uma "canaleta" que contém todos os pontos da malha euleriana cujo ponto de distância mínima esteja sobre esta aresta (Figura 4.3).

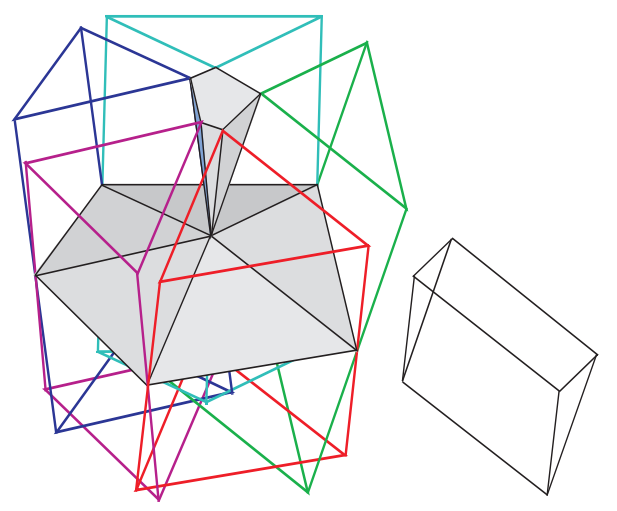

Figura 4.3: Canaleta sobre a superfície triangularizada.

Uma canaleta, como a mostrada na Figura 4.3, pode ser interna ou externa à superfície, dependendo do ângulo externo entre as faces adjacentes. Se esse ângulo externo é maior do que 180 graus, a canaleta é externa à superfície e se o ângulo externo é menor do que 180 graus a canaleta é interna. Obviamente, se o ângulo externo é igual a 180 graus não é necessário a construção da canaleta.

Assim, é computacionalmente vantajoso determinar primeiramente a localização dessa canaleta e, conseqüentemente, o sinal da função indicadora nos pontos pertencentes a ela. Isso evita o cálculo desse sinal separadamente em cada ponto da malha euleriana. $\mathrm{Na}$ construção da canaleta, foram utilizadas as informações dos versores normais às faces adjacentes e as coordenadas dos vértices da canaleta, informações essas que podem ser acessadas em tempo constante na estrutura de dados Halfedge.

Depois de determinado o sinal que será dado aos pontos eulerianos pertencentes à canaleta, ela é construída utilizando-se os vértices $A$ e $B$ da aresta e os versores normais $\mathbf{n}_{1}$ e $\mathbf{n}_{2}$ das faces adjacentes como mostrado na Figura 4.4. Depois de construída a canaleta, procede-se de maneira análoga ao caso das faces para determinar o menor paralelepípedo limitante que contém essa canaleta cujos vértices sejam pontos eulerianos e cujas arestas estejam nas direções dos eixos coordenados. 


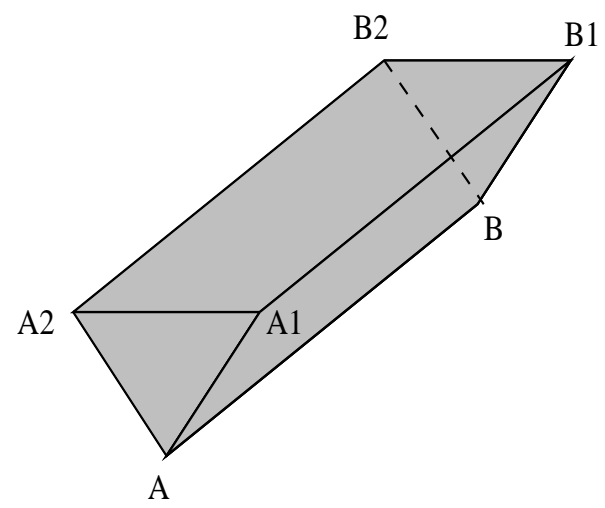

Figura 4.4: Canaleta construída a partir de uma aresta.

\subsubsection{CPT nos Vértices}

Os vértices da superfície podem ser classificados como côncavos, convexos ou de sela, dependendo das arestas adjacentes. Se todas as arestas adjacentes ao vértice possuirem canaleta interna, o vértice é côncavo; se todas as arestas adjacentes possuirem canaleta externa, o vértice é convexo e, se o vértice possuir arestas adjacentes com canaletas de ambos os tipos externas e internas, o vértice é de sela (veja a Figura 4.5).
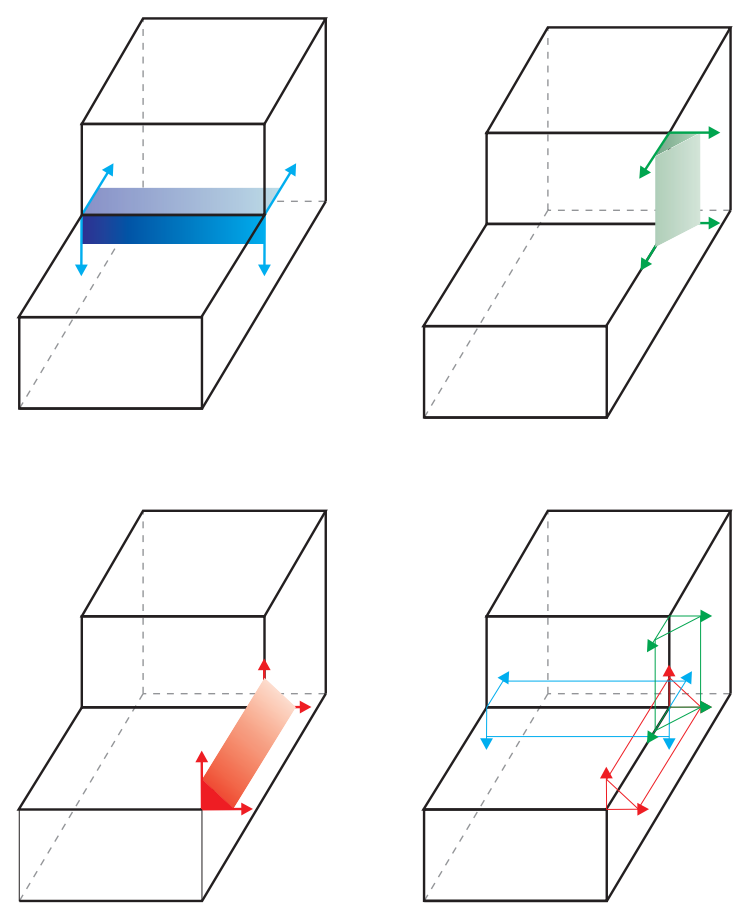

Figura 4.5: Exemplo de um vértice tipo sela. 
Como os vértices côncavos tornam-se convexos e vice-versa quando mudamos a orientação da superfície, eles podem ser tratados de maneira semelhante.

Para vértices de um desses dois tipos (côncavos ou convexos), todos os pontos da malha euleriana, cujo o ponto de distância mínima à superfície for um desses vértices, pertencem a uma pirâmide construída a partir dos versores normais às faces incidentes ao vértice (veja figura 4.6). Assim, a função indicadora de fluidos tem o mesmo sinal em todos os pontos contidos na pirâmide, o qual é o mesmo das canaletas incidentes a este vértice.

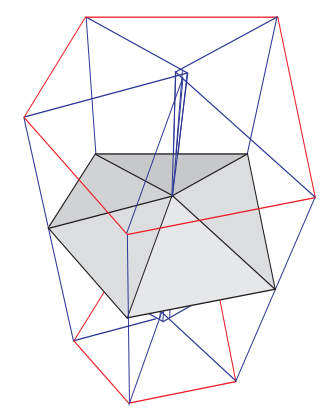

Figura 4.6: Pirâmide invertida sobre a superfície triangularizada.

Diferentemente desses dois tipos de vértices, para os quais só é necessário atualizar a função indicadora de fluidos nos pontos que estão em uma pirâmide interna ou externa à superfície, para os vértices de tipo sela é necessário atualizar a função indicadora de fluidos em pontos que estão no interior da superfície e em pontos que estão no exterior da superfície. Para isso, é necessário determinar a localização de cada ponto da malha euleriana que está numa vizinhança desse vértice em relação à superfície.

Como nos vértices a discretização da superfície não é de classe $C^{1}$, não está definido um vetor normal que possa ser usado para determinar se um ponto está dentro ou fora da superfície. Entretanto, é possível definir vetores nos vértices com algumas propriedades de vetor normal, os quais são denominados de vetores pseudonormais.

Existe uma grande variedade de definições de vetores pseudonormais, cada qual possuindo um subconjunto diferente de propriedades dos vetores normais. No presente trabalho, o interesse está nos vetores pseudonormais que possam ser usados para determinar se um ponto está no interior ou no exterior de uma superfície. Para isso, foi utilizado o vetor angle weighted pseudonormal proposto por Baerentzen e Aanaes [2]. 
Para simplificar a leitura desse trabalho, o vetor angle weighted pseudonormal será referido somente como vetor pseudonormal.

\section{Vetor Pseudonormal}

A idéia de construir um vetor pseudonormal usando a média ponderada dos ângulos das faces adjacentes foi introduzida por Thürmer e Wüthrich [73] e independentemente por Séquin [60] com o objetivo de utilizar esse vetor para determinar a localização de um ponto em relação ao poliedro.

Esta idéia foi melhor desenvolvida por Baerentzen e Aanaes [2], os quais mostraram que uma série de outras definições de vetores pseudonormais não possuem esta propriedade.

Dado um vértice $Q$, o vetor pseudonormal desse vértice é definido por

$$
\mathbf{n}_{Q}=\frac{\sum_{i} \alpha_{i} \mathbf{n}_{i}}{\left\|\sum_{i} \alpha_{i} \mathbf{n}_{i}\right\|}
$$

onde $i$ percorre todas as faces adjacentes ao vértice $Q, \alpha_{i}$ é o ângulo incidente da face e $\mathbf{n}_{i}$ é o vetor normal externo à face (veja a Figura 4.7).

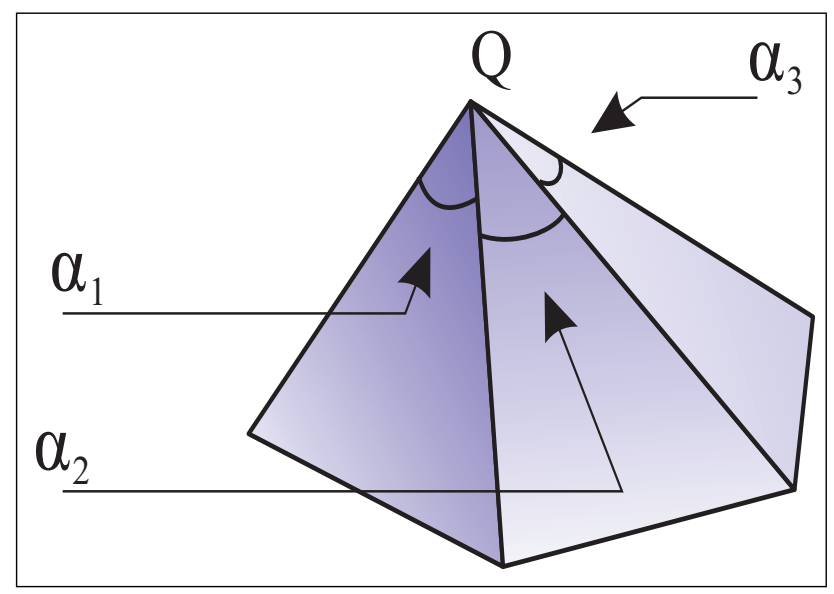

Figura 4.7: Construção do vetor pseudonormal.

Na vizinhança do vértice $Q$, determina-se a localização do ponto $P$ da malha euleriana da seguinte forma

- Se $\left(\mathbf{n}_{Q}, P-Q\right)>0$ então o ponto $P$ está do lado de fora da superfície. 
- Se $\left(\mathbf{n}_{Q}, P-Q\right)<0$ então o ponto $P$ está do lado de dentro da superfície.

- Se $\left(\mathbf{n}_{Q}, P-Q\right)=0$ então o ponto $P$ está sobre a superfície.

Como a proposta do vetor pseudonormal é somente determinar o sinal da função indicadora de fluidos, a normalização desse vetor é omitida e, no presente trabalho, considera-se apenas

$$
\mathbf{n}_{Q}=\sum_{i} \alpha_{i} \mathbf{n}_{i}
$$

Para demonstrar que esse vetor pseudonormal tem, de fato, a propriedade de discernir se um ponto $P$ da malha euleriana está no interior ou no exterior de uma superfície fechada, considere o vértice $Q$ da superfície triangularizada $S$ que minimiza a distância de $S$ a $P$. Seja $V$ a vizinhança de $Q$ formada pela intersecção de $\bar{S}$, a união de $S$ com o sólido delimitado por $S$, e uma bola $B$ centrada em $Q$. O raio de $B$ é escolhido como sendo 1 . Observe que $\partial V$, a fronteira de $V$, é formada por uma parte coincidente com a superfície $\partial V_{S}$ e uma parte coincidente com a bola $\partial V_{B}$ (veja Figura 4.8). Assim, $\partial V=\partial V_{S} \cup \partial V_{B}$ e $\partial V_{S} \cap \partial V_{B}=\emptyset$.

Lema 4.2.1. Para todo ponto $A \in V$, o ângulo $\angle(\overrightarrow{Q A}, \overrightarrow{Q P})$ é maior que ou igual a $\pi / 2$ quando $P \notin \bar{S}$.

\section{Prova.}

Por construção, $Q$ é um ponto estelar em $V$, isto é, o segmento de reta ligando $Q$ a qualquer ponto em $V$ está inteiramente contido em $V$. Assim, se existe um ponto $A \in V$ tal que $\angle(\overrightarrow{Q P}, \overrightarrow{Q A})$ é menor do que $\pi / 2$, então existe um ponto no segmento de reta entre $Q$ e $A$ que está mais próximo de $P$ do que $Q$ (por exemplo, a projeção do ponto $P$ no segmento de reta $A Q)$. Isto pode ser facilmente visto, pois se $\angle(\overrightarrow{Q A}, \overrightarrow{Q P})$ é menor do que $\pi / 2$ então o segmento de reta entre $Q$ e $A$ está contido no interior da bola de raio $r=\|P-Q\| e$ centro em $P$ e para todo ponto $C$ no interior dessa bola tem-se $\|P-C\|<\|P-Q\|$ (veja Figura 4.9). Finalmente, como $S \subset \bar{S}$, isto contradiz a afirmação que $Q$ é o ponto de $S$ mais próximo de $P$. 


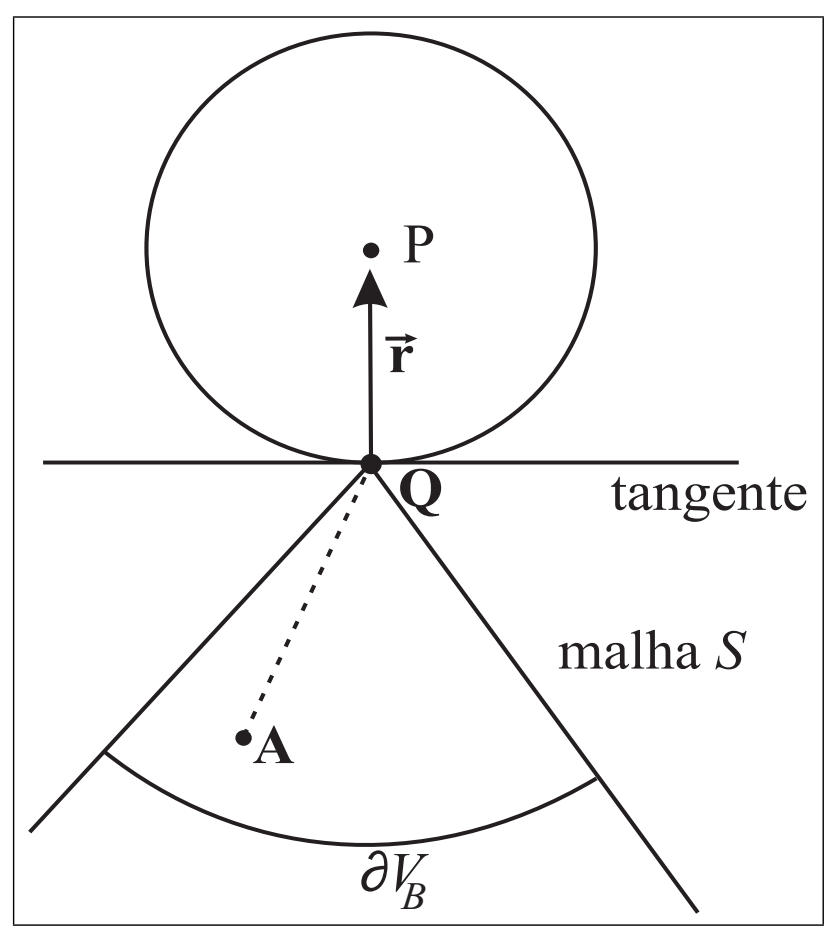

Figura 4.8: Vizinhança formada pela intersecção de $\bar{S}$ e uma bola $B$ centrada em $Q$.

Teorema 4.2.2. Dado um ponto $P$, suponha que $Q$ é o ponto pertencente a superfície $S$ que minimiza a distância de $P$ à $S$, isto é, $d=\inf _{X \in S}\|P-X\|=\|P-Q\|$. Seja $\boldsymbol{n}_{Q}=\sum_{i} \alpha_{i} \boldsymbol{n}_{i}$, onde $i$ percorre todas as faces adjacentes ao vértice $Q, \alpha_{i}$ é o ângulo incidente da face e $\boldsymbol{n}_{i}$ é o vetor normal externo a face; além disso, considere os vetores $\overrightarrow{\boldsymbol{r}}=P-Q$ e $D=\overrightarrow{\boldsymbol{r}} \cdot \boldsymbol{n}_{Q}$. Nesse contexto, $D>0$ se $P$ está no exterior da superfície $e$ $D<0$ se $P$ está no interior da superfície.

\section{Prova.}

Considere primeiro o caso em que $P$ está no exterior da superfície $S$. Seja $\boldsymbol{F}$ um campo de vetores constante definido em cada ponto $A$ como $\boldsymbol{F}(A)=\overrightarrow{\boldsymbol{r}}=P-Q$. Como $\boldsymbol{F}$ é um campo constante tem-se que

$$
\int_{V} \nabla \cdot \boldsymbol{F} d V=0
$$

Pelo Teorema de Gauss, tem-se 


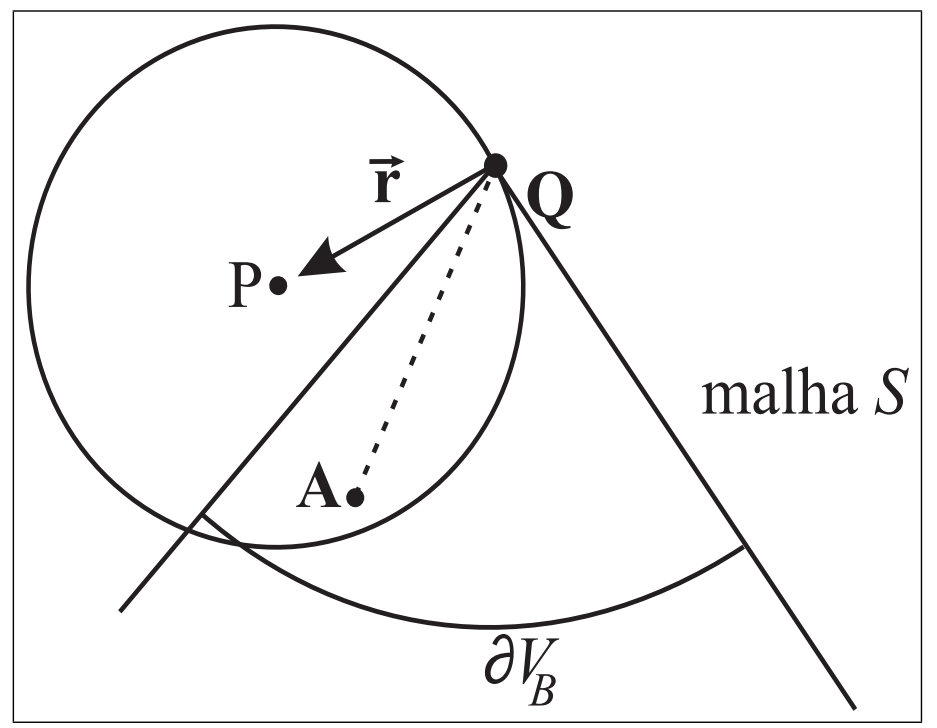

Figura 4.9: Vizinhança formada pela intersecção de $\bar{S}$ e uma bola $B$ centrada em $Q$.

$$
\int_{V} \nabla \cdot \boldsymbol{F} d V=\int_{\partial V} \boldsymbol{F} \cdot \boldsymbol{n}(\tau) d \tau
$$

Como $\boldsymbol{F}(A)=\overrightarrow{\boldsymbol{r}}$ e $\partial V=\partial V_{S} \cup \partial V_{S}$, tem-se

$$
\int_{\partial V} \boldsymbol{F} \cdot \boldsymbol{n}(\tau) d \tau=\int_{\partial V_{S}} \overrightarrow{\boldsymbol{r}} \cdot \boldsymbol{n}(\tau) d \tau+\int_{\partial V_{B}} \overrightarrow{\boldsymbol{r}} \cdot \boldsymbol{n}(\tau) d \tau=0
$$

Para todos os pontos $A \in \partial V_{B}$, a normal $\boldsymbol{n}_{A}$ é dada por $\overrightarrow{A Q}$, pois $B$ é uma esfera centrada em $Q$. Como $\partial V_{B} \subset \bar{S}$, pelo Lema (4.2.1) tem-se que $\overrightarrow{\boldsymbol{r}} \cdot \boldsymbol{n}_{A} \leq 0$ para qualquer ponto $A \in \partial V_{B}$. Assim,

$$
\int_{\partial V_{B}} \overrightarrow{\boldsymbol{r}} \cdot \boldsymbol{n}(\tau) d \tau<0
$$

A desigualdade acima é estrita porque o lado esquerdo dessa desigualdade é zero somente se a área $\partial V_{B}$ é zero e isto só acontece quando há o rompimento da superfície.

Das equações (4.2) e (4.3) segue

$$
\int_{\partial V_{S}} \overrightarrow{\boldsymbol{r}} \cdot \boldsymbol{n}(\tau) d \tau=\sum \overrightarrow{\boldsymbol{r}} \cdot \boldsymbol{n}_{i} \alpha_{i}=\overrightarrow{\boldsymbol{r}} \cdot \boldsymbol{n}_{Q}=D>0
$$


Provando assim o teorema para $P$ exterior à superfície. Se P estiver no interior da superfície, a situação é essencialmente a mesma a menos das normais envolvidas serem as opostas. Isto implica que a integral em $\partial V_{B}$ muda de sinal e $D$ torna-se negativo.

\subsection{CPT em uma Malha Composta Adaptativa}

Para que a função indicadora de fluidos tenha uma boa resolução próximo da interface de separação dos fluidos é necessário que a malha euleriana seja muito fina. Para evitar que essa alta resolução, fruto de uma demanda local, seja estendida para todo o domínio computacional e, portanto, para se poder otimizar a quantidade de memória utilizada, no presente trabalho, a função indicadora de fluidos foi implementada utilizando a estratégia de refinamento adaptativo de malhas, descrita no Capítulo 3.

Como as malhas compostas são construídas recobrindo uma vizinhança da interface de separação entre os fluidos de forma que todos os pontos lagrangianos pertençam a um mesmo nível de refinamento, para atualizar a função indicadora de fluidos é suficiente considerar somente as malhas do nível mais fino, ltop, e depois interpolar os valores da função indicadora de fluidos definida nesse nível para os outros níveis mais grossos.

Ao percorrer cada um dos elementos geométricos da malha lagrangiana é necessário determinar em qual malha composta do nível ltop este elemento geométrico está contido (note que o ente pode pertencer a uma união de malhas no nível mais fino e não necessariamente a apenas uma). Para isso, foi escolhido arbitrariamente um dos vértices desse elemento geométrico e utilizado um mapa lagrangiano, descrito no Capítulo 3, para determinar a qual malha do nível ltop este vértice pertence.

Depois de determinada essa malha do nível ltop, os valores da função indicadora de fluidos são atualizados nessa malha (utilizando, inclusive, as células fantasmas dessa malha quando for necessário). Após percorrer todos os elementos geométricos da superfície, o valor da função indicadora de fluidos nas células fantasmas é comparado com o valor da função indicadora na mesma posição do domínio computacional nas outras malhas do nível ltop vizinhas e o menor valor em módulo é assumido como sendo o valor correto da função indicadora de fluidos. 
A seguir, encontra-se o Algoritmo 4 AMR Closest Point Transform, o qual faz uso do refinamento adaptativo de malhas em torno da superfície que representa a interface de separação entre os fluidos. A notação utilizada no Algoritmo 4 é a mesma utilizada nos demais algoritmos descritos nesse Capítulo.

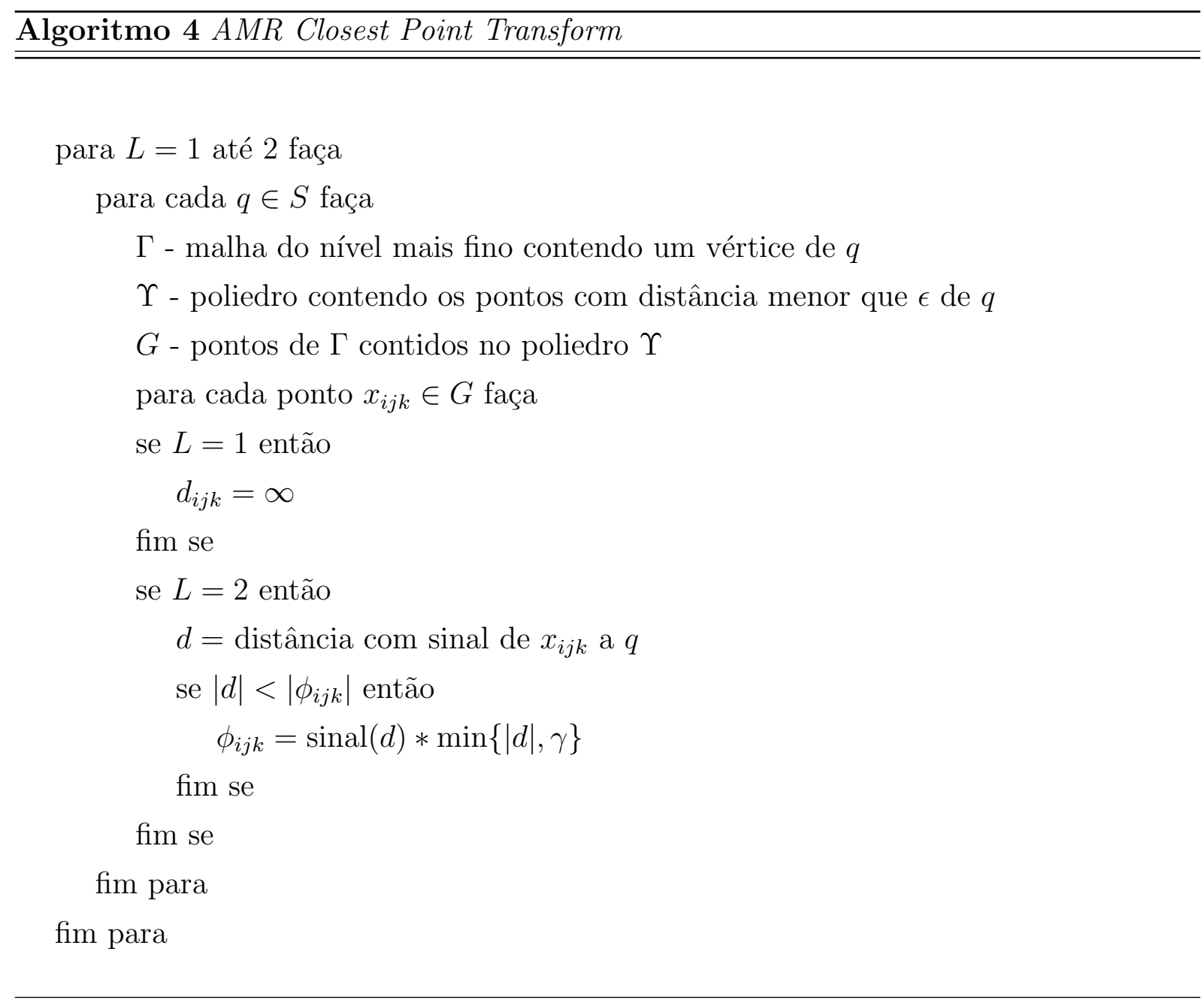

Para garantir que o elemento geométrico e o poliedro construído nesse ente para atualizar a função indicadora de fluidos estejam inteiramente contidos na malha composta do vértice escolhido, as arestas da malha lagrangiana devem ser menores do que a metade do menor espaçamento da malha euleriana e o número de células fantasmas utilizadas ser escolhido proporcional a $\epsilon$. No presente trabalho, foram utilizadas 4 células ao redor de cada malha em cada direção do domínio coordenado e $\epsilon=3 h$, onde $h=\min \{\Delta x, \Delta y, \Delta z\}$ é o menor espaçamento da malha euleriana. 


\subsection{Implementação}

Devido ao uso da aritmética computacional de ponto flutuante no armazenamento de seus dados, é preciso um pequeno aumento no tamanho dos poliedros (aproximadamente $\left.10^{-12}\right)$ na direção do vetor normal para garantir que os pontos da malha euleriana sobre sua fronteira estejam incluídos no poliedro e não sejam deixados de fora quando for calculada a distância até a superfície.

Para armazenar o vetor pseudonormal, foi definido um vetor tridimensional na lista ligada que armazena as propriedades dos vértices na estrutura de dados Halfedge. Antes de percorrer as faces da superfície, esse vetor pseudonormal é alocado e inicializado com valor zero. Ao percorrer cada uma das faces da superfície, é calculado o ângulo interno de cada um dos vértices e multiplicado pelo vetor normal externo à face e o vetor resultante é adicionado ao vetor pseudonormal armazenado no ponteiro do vértice na estrutura Halfedge. Depois de percorrer todas as faces, a estrutura de dados Halfedge já tem armazenado o vetor pseudonormal de cada um dos vértices da superfície.

Como o vetor pseudonormal é utilizado somente para determinar o sinal da função indicadora de fluidos, não é necessário que esse vetor seja unitário. Assim, durante a implementação o vetor pseudonormal não foi dividido por seu módulo.

Para determinar o tipo de cada um dos vértices, foi definido uma variável inteira na lista ligada que armazena as propriedades das arestas na estrutura de dados Halfedge e ao percorrer as arestas o algoritmo calcula os sinais de cada uma delas e armazena esse sinal na lista ligada. Quando se percorre os vértices, para cada um deles o algoritmo percorre os ponteiros das arestas adjacentes à esse vértice e, usando os sinais de cada uma dessas arestas, determina o tipo do vértice.

Como é observado em [2], o tempo computacional adicional para o cálculo do sinal da função indicadora é insignificante quando comparado com o tempo computacional para calcular a função indicadora de fluidos sem o cálculo do sinal. Para determinar o sinal é necessário somente o cálculo de um produto interno a mais.

A distância entre os pontos eulerianos e os vértices da superfície (pontos lagrangianos) é calculada ao quadrado e só é tirada a raiz quadrada quando a menor distância tiver sido calculada. 
No presente trabalho, a função indicadora de fluidos foi primeiro implementada em uma malha uniforme e validada por meio de visualizações utilizando o software Tecplot [84]. Nesses testes, foram empregadas as superfícies utilizadas para gerar os exemplos da próxima Seção.

A validação da função indicadora de fluidos no contexto de malhas compostas com refinamentos localizados foi feita por meio de vários testes os quais empregaram as mesmas superfície utilizadas durante a validação do cálculo da função indicadora numa malha uniforme. Os resultados obtidos nas malhas compostas foram validados comparando-se aos resultados obtidos numa malha uniforme equivalente, isto é, numa malha uniforme cujo espaçamento é aquele do nível ltop da malha composta. Nessa malha uniforme equivalente a função indicadora de fluidos foi calculada diretamente. Em todos os casos testados a diferença entre esses resultados foi igual a zero.

\subsection{Exemplos}

Nesta Seção, são apresentados alguns exemplos de cálculo da função indicadora de fluidos para diversas geometrias da superfície que representa a interface de separação entre os fluidos. O refinamento adaptativo empregado na malha euleriana em torno da interface também é exemplificado nessa Seção.

Em todos os exemplos dessa Seção, o domínio computacional utilizado foi o cubo $[0,2] \times[0,2] \times[0,2]$ e a malha euleriana tem no nível mais grosso (nível de base) 32 células computacionais em cada direção. Foram empregados 4 níveis de refinamento. Nesse contexto, a resolução obtida na vizinhança da interface é equivalente a uma malha com 256 células computacionais em cada direção do domínio computacional.

Na Figura 4.10 e na Figura 4.11, a interface é uma superfície esférica com centro no ponto $(1,1,1)$, raio igual à 0.7 . A discretização dessa superfície esférica contém 13.857 vértices, 41.565 arestas e 27.710 faces.

Nas Figuras 4.12, 4.13 e 4.14 a interface é uma superfície com o formato de uma caixa. A discretização dessa superfície contém 10.174 vértices, 30.516 arestas e 20.344 faces.

Nas Figuras 4.15, 4.16 e 4.17 a interface é composta por uma superfície esférica e 3 superfícies com a forma de paralelepípedos. A superfície esférica tem centro no ponto 
$(1,0.9,0.9)$, raio igual à 0.295 e sua discretização tem 9.851 vértices, 29.547 arestas e 19.698 faces. Uma das superfícies com forma de parelelepípedo tem os lados em $x=0.2$, $x=1.8, y=0.2, y=0.6, z=0.2$ e $z=1.8$ e sua discretização tem 8.861 vértices, 26.577 arestas e 17.718 faces. Uma outra superfície com forma de paralelepípedo tem os lados em $x=0.2, x=1.8, y=0.605, y=1.8, z=0.2$ e $z=0.6$ e sua discretização tem 6.983 vértices, 20.943 arestas e 13.962 faces. E a última superfície com forma de paralelepípedo tem os lados em $x=0.2, x=1.8, y=1.2, y=1.8, z=0.605$ e $z=1.8$ e sua discretização tem 8.277 vértices, 24.825 arestas e 16.550 faces.

Nas Figuras 4.18 e 4.19 a interface é uma superfície com o formato de um losango cujos vértices são os pontos $(1,1,0.5),(1,0.5,1),(0.5,1,1),(1,1.5,1),(1.5,1,1)$ e $(1,1,1.5)$. A sua discretização tem 1.995 vértices, 5.979 arestas e 3.986 faces. 

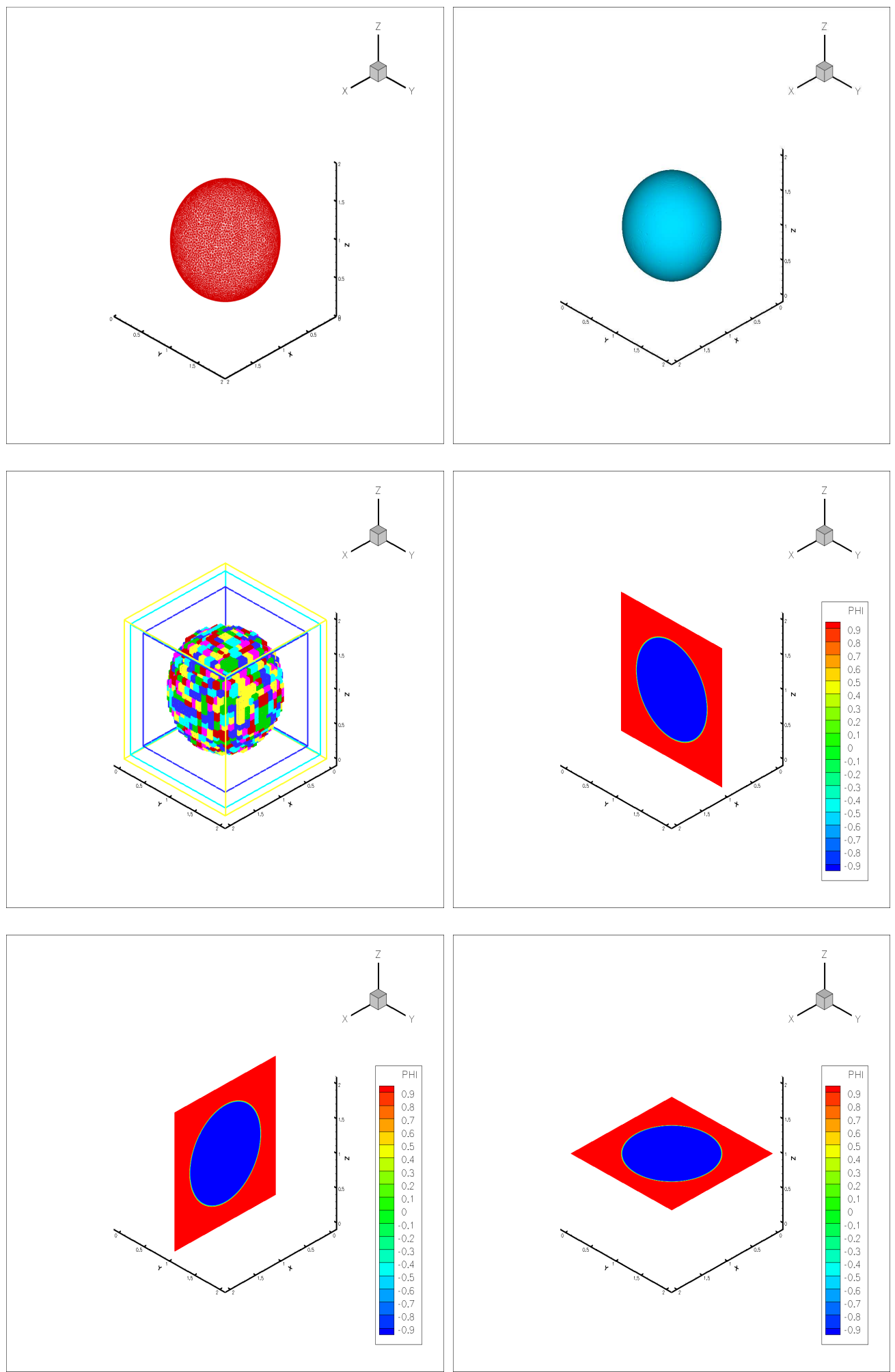

Figura 4.10: Exemplo de uma esfera: superfície triangularizada, isosuperfície, malhas do último nível físico e cortes em $x=1, y=1$ e $z=1$. 

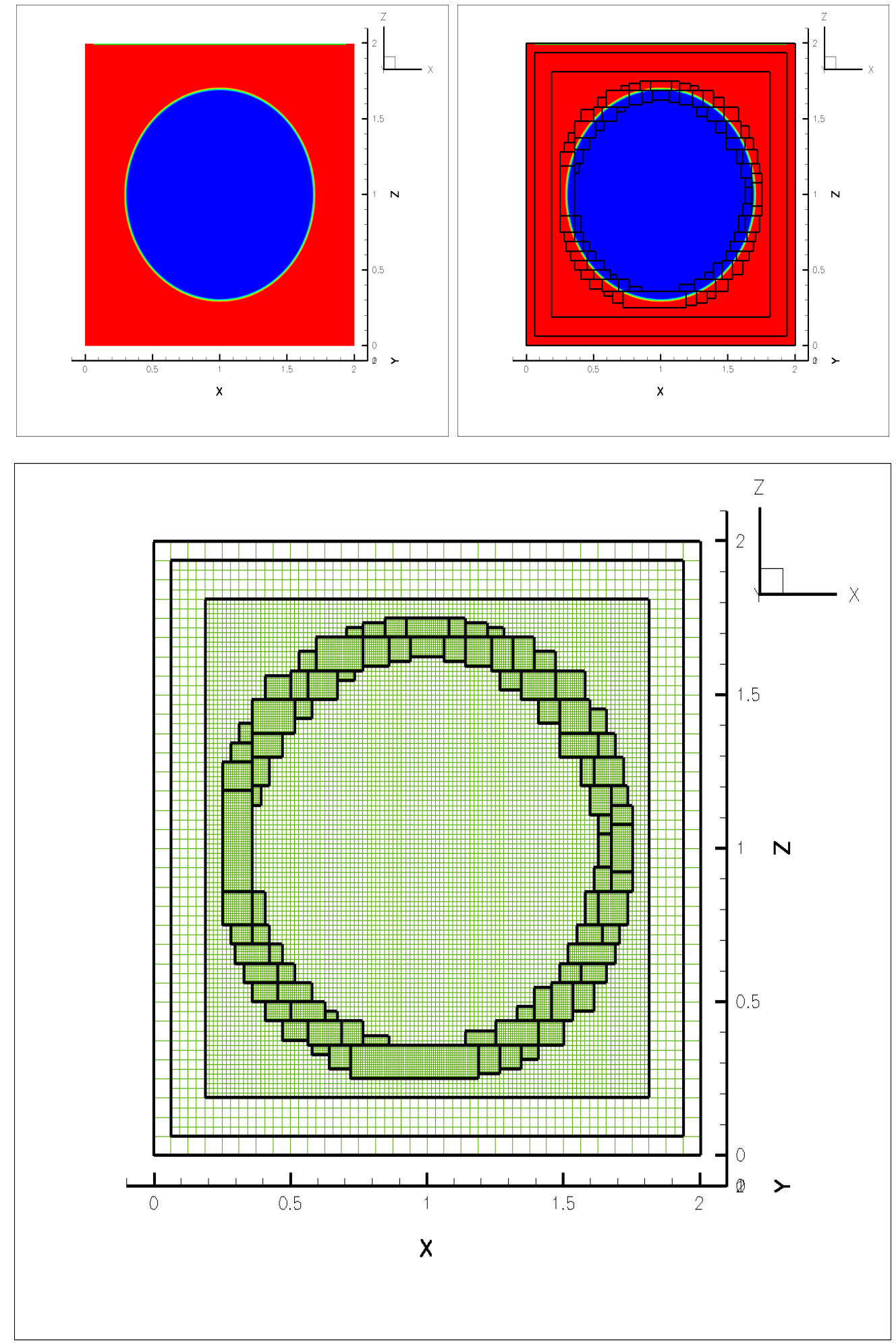

Figura 4.11: Vista frontal de uma esfera cortada em $y=1$ mostrando a região de transição da função indicadora, a função indicadora coberta pelas arestas das malhas compostas e as malhas compostas utilizadas no refinamento localizado. 

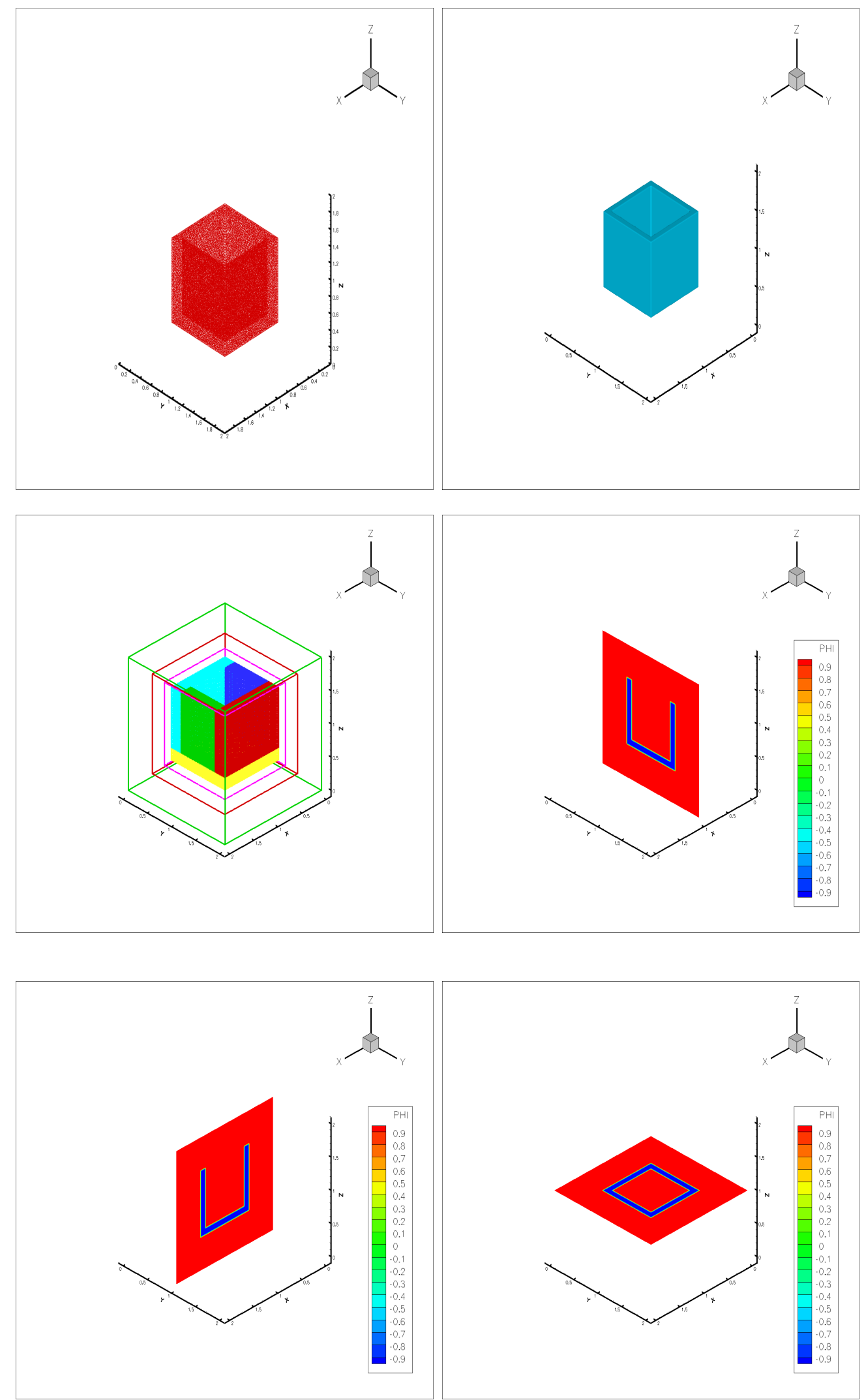

Figura 4.12: Exemplo de uma caixa: superfície triangularizada, isosuperfície, malhas do último nível físico e cortes em $x=1, y=1$ e $z=1$. 

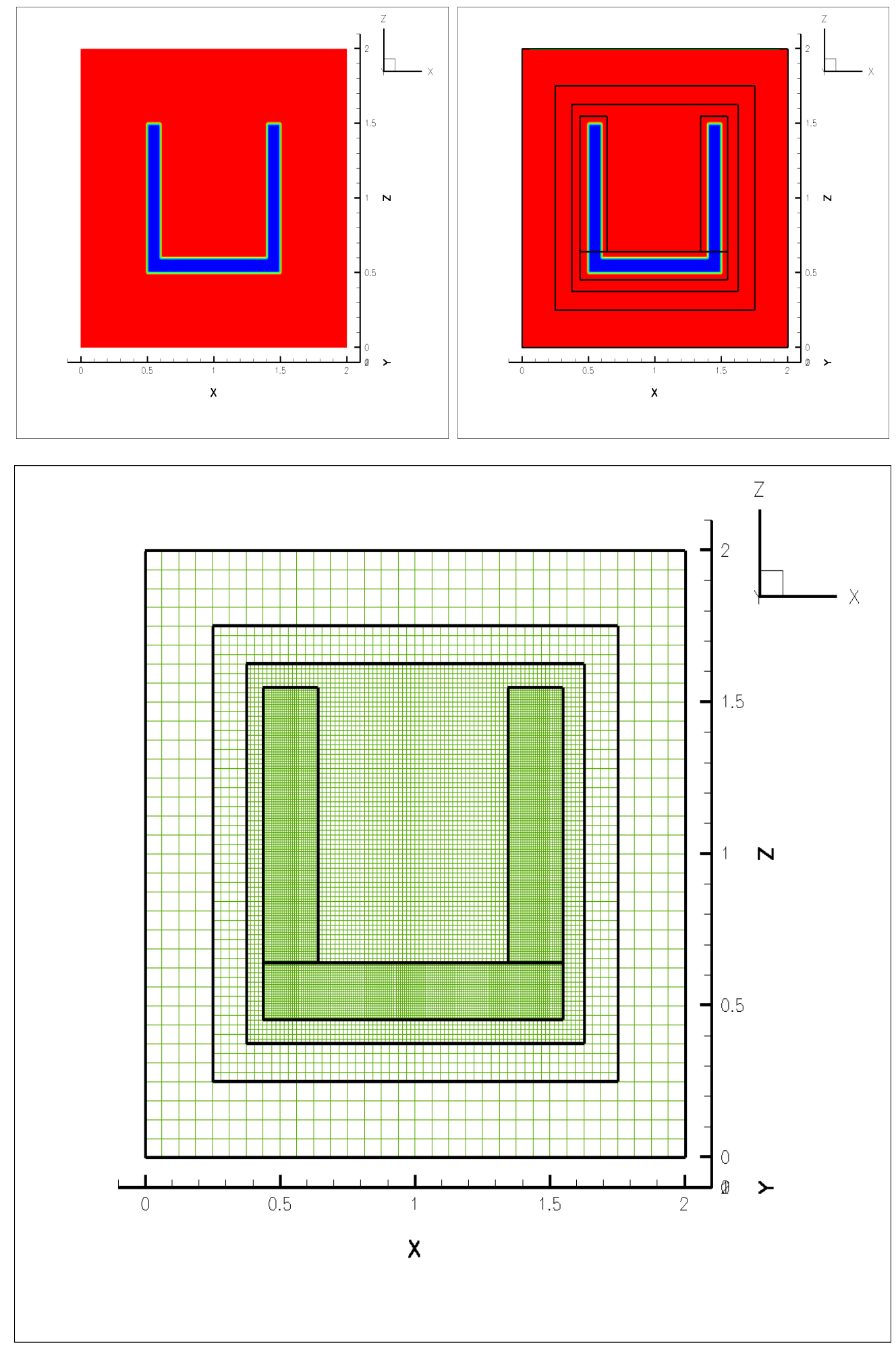

Figura 4.13: Visão frontal de uma caixa cortada em $y=1$ mostrando a região de transição da função indicadora, a função indicadora coberta pelas arestas das malhas compostas e as malhas compostas utilizadas no refinamento localizado. 

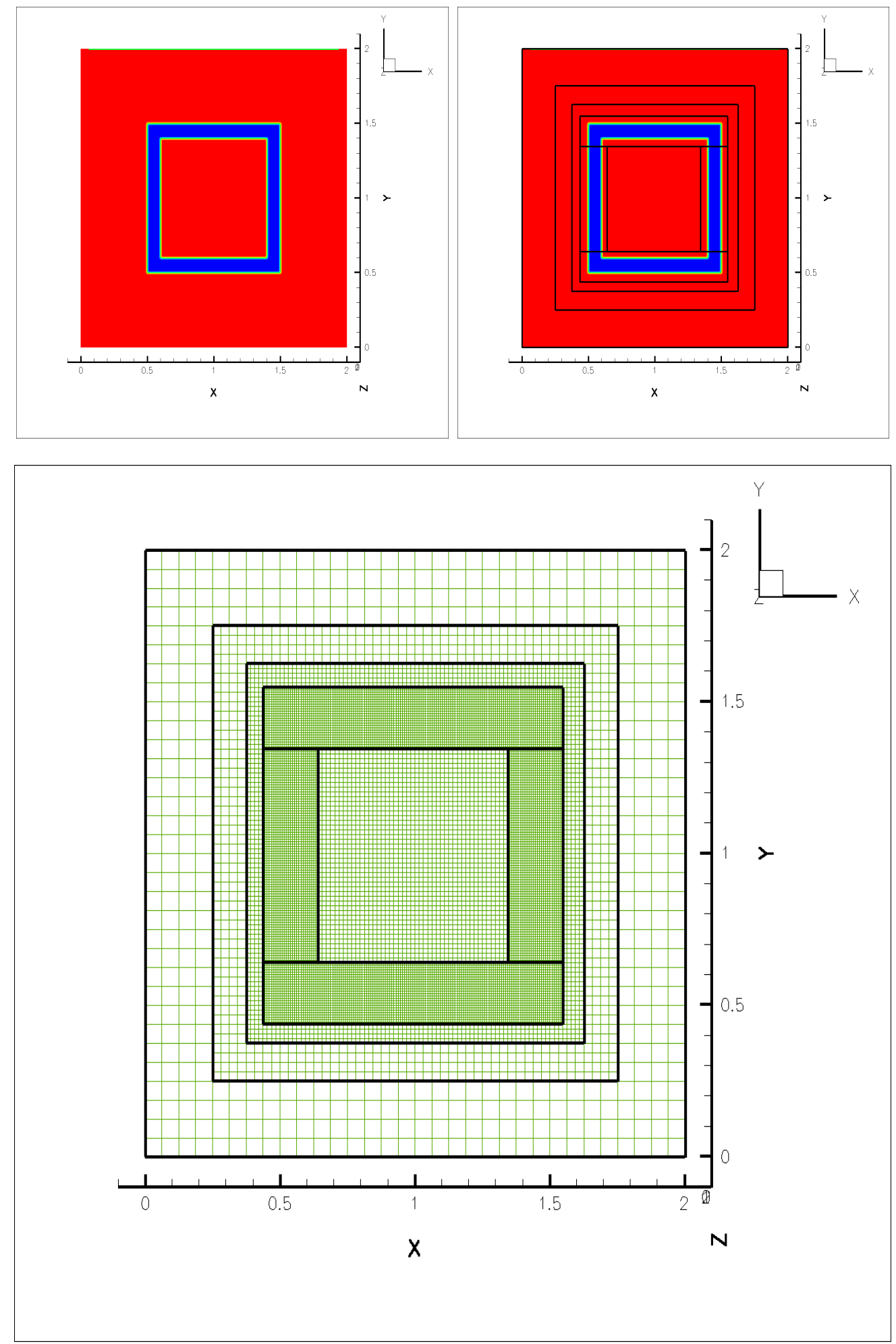

Figura 4.14: Visão frontal de uma caixa cortada em $z=1$ mostrando a região de transição da função indicadora, a função indicadora coberta pelas arestas das malhas compostas e as malhas compostas utilizadas no refinamento localizado. 

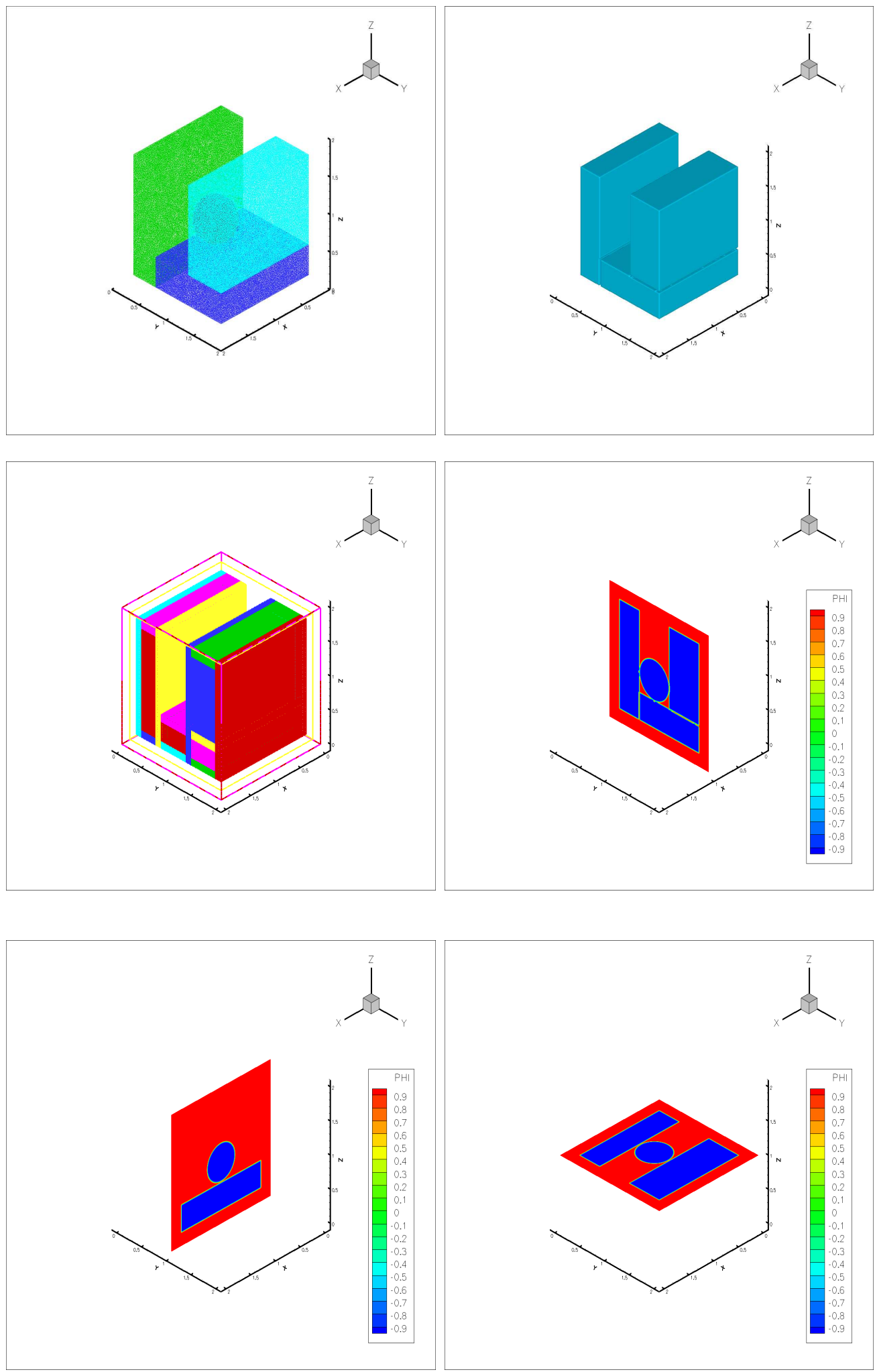

Figura 4.15: Exemplo de três paralelogramos e uma esfera: superfície triangularizada, isosuperfície, malhas do último nível físico e cortes em $x=1, y=1$ e $z=1$. 

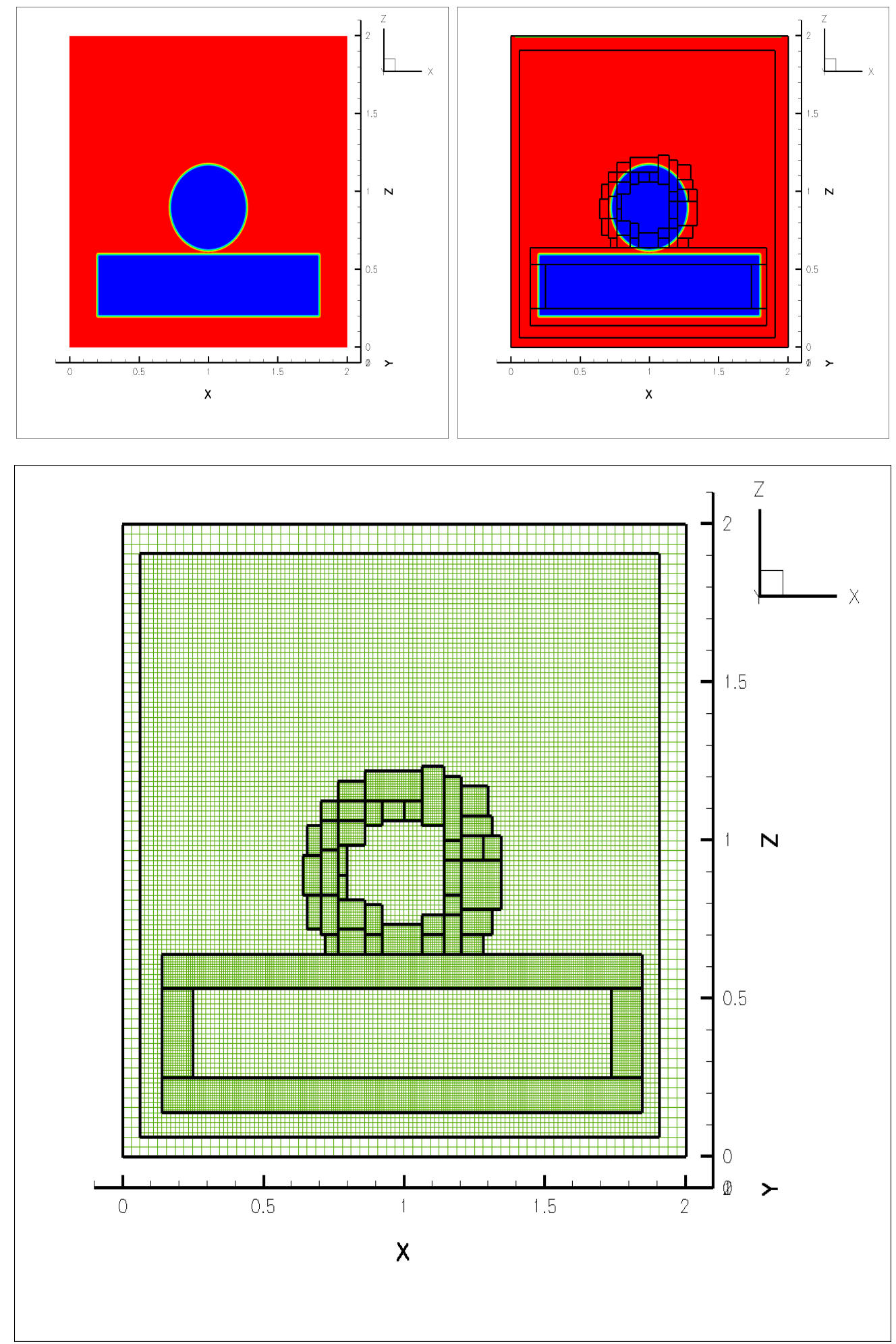

Figura 4.16: Vista frontal de um paralelogramo e uma esfera cortados em $y=1$ mostrando a região de transição da função indicadora, a função indicadora coberta pelas arestas das malhas compostas e as malhas compostas utilizadas no refinamento localizado. 

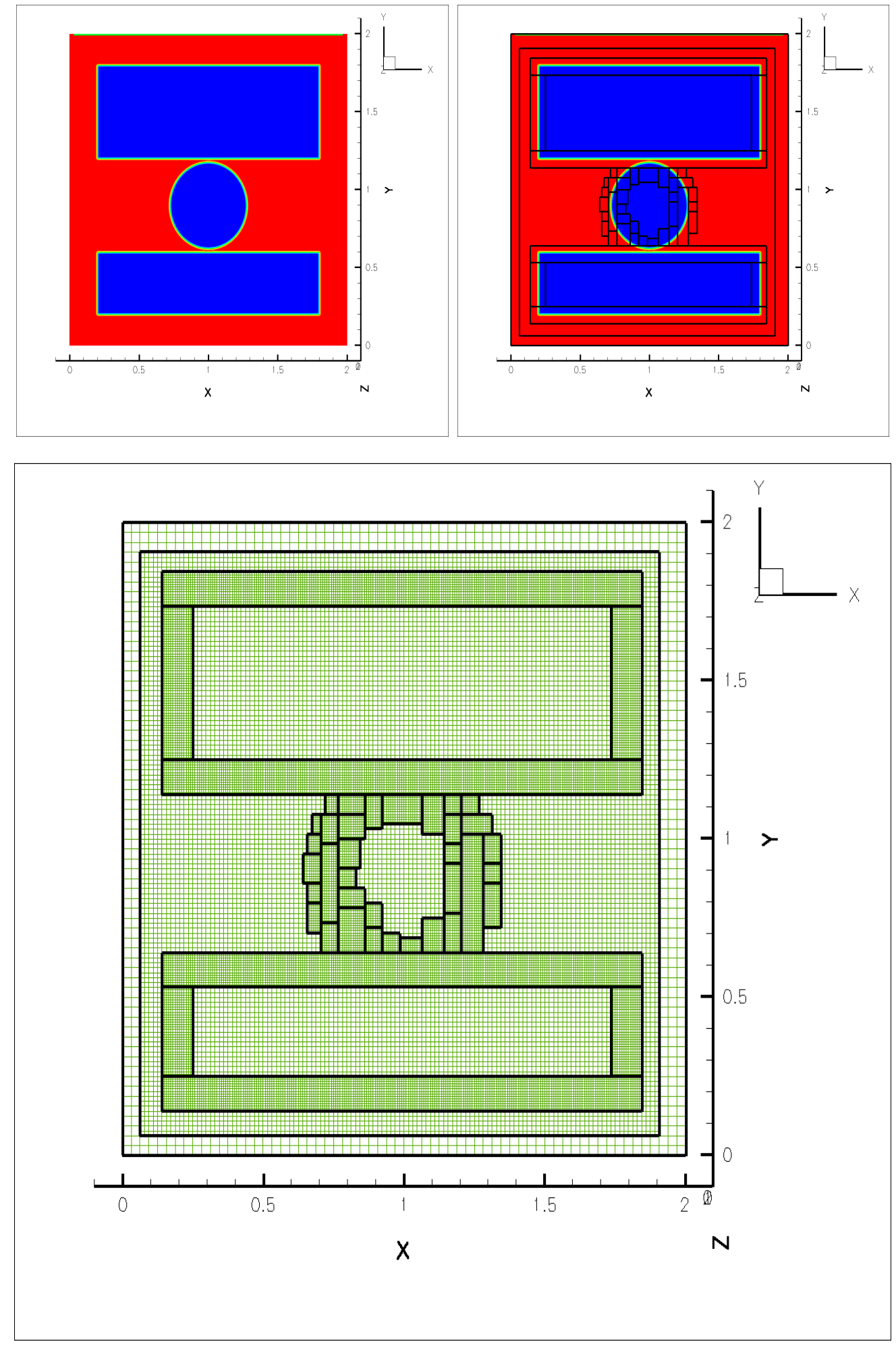

Figura 4.17: Vista frontal de dois paralelogramos e uma esfera cortados em $z=1$ mostrando a região de transição da função indicadora, a função indicadora coberta pelas arestas das malhas compostas e as malhas compostas utilizadas no refinamento localizado. 

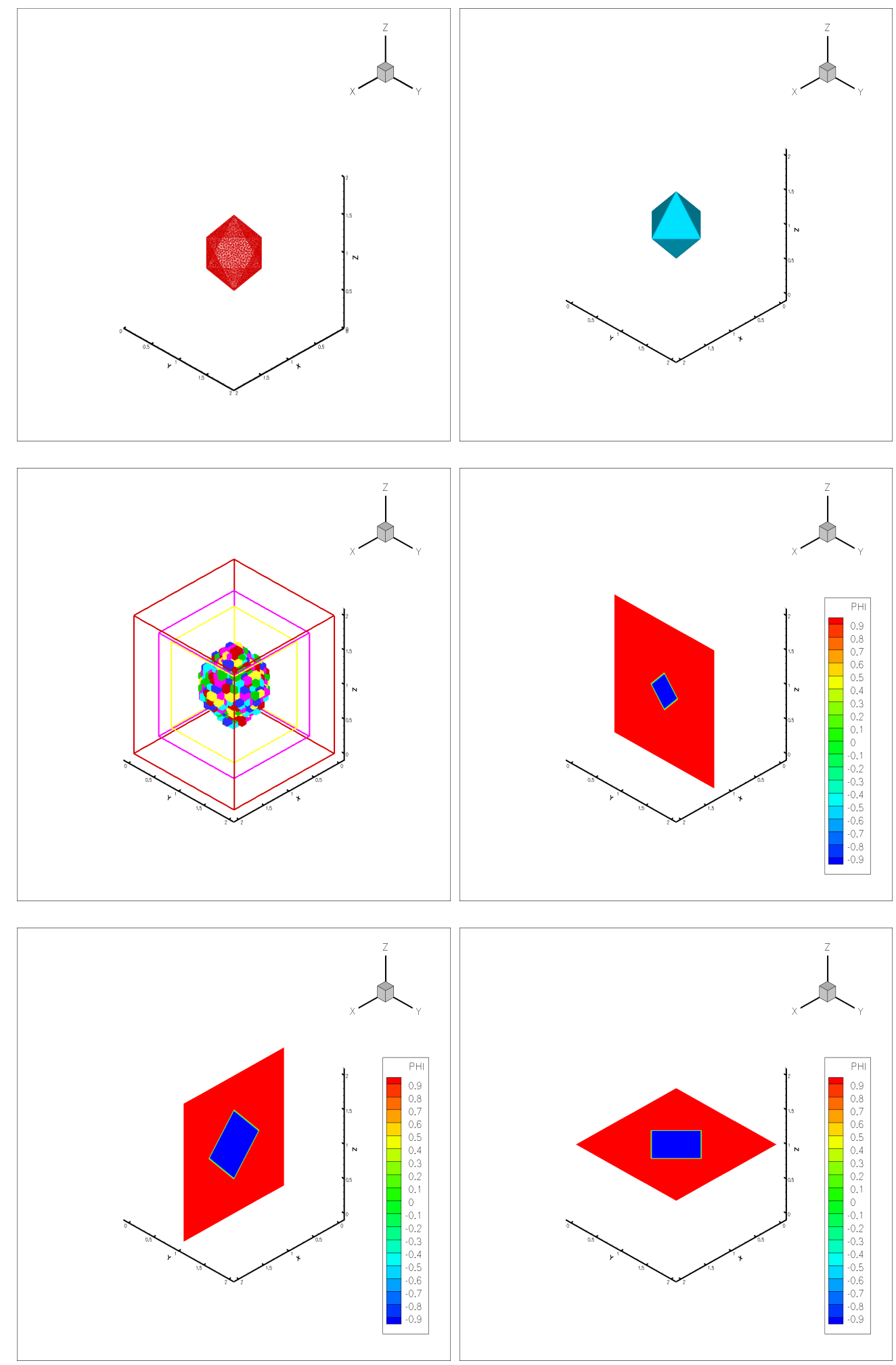

Figura 4.18: Exemplo de um losango: superfície triangularizada, isosuperfície, malhas do último nível físico e cortes em $x=1, y=1$ e $z=1$. 

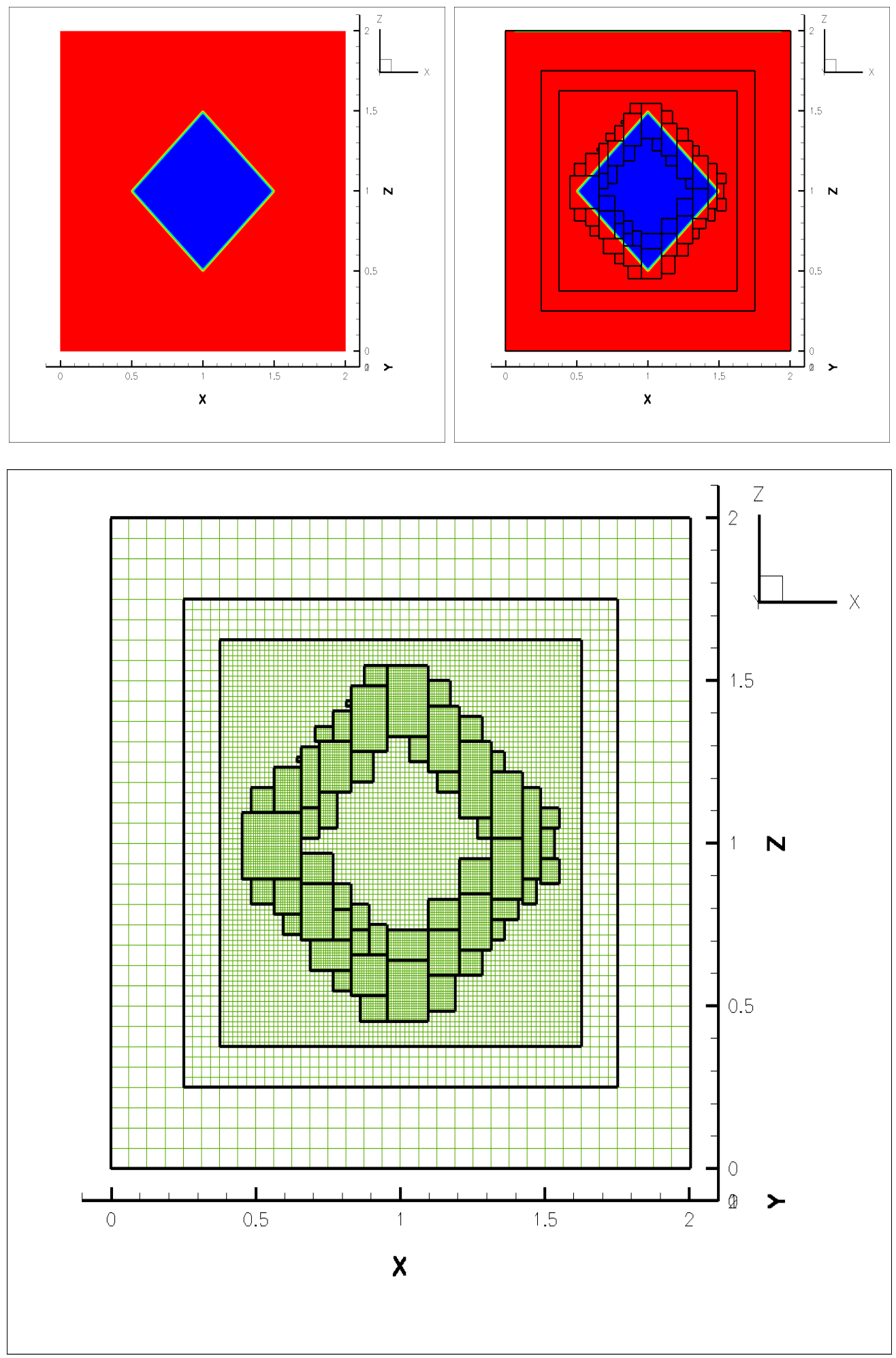

Figura 4.19: Vista frontal de um losango cortado em $y=1$ mostrando a região de transição da função indicadora, a função indicadora coberta pelas arestas das malhas compostas e as malhas compostas utilizadas no refinamento localizado. 


\section{CAPÍtulo 5}

\section{Movimento da Fronteira Imersa}

Neste Capítulo, são apresentados exemplos da função indicadora de fluidos quando a interface de separação entre os fluidos se move ao longo do tempo. Esse movimento da interface é acompanhado pelo refinamento adaptativo de malhas empregado para refinar localmente a malha euleriana em torno da interface, esse processo de acompanhamento do movimento da interface também é exemplificado neste Capítulo.

Vale ressaltar que o objetivo deste capítulo é somente exemplificar a atualização da função indicadora de fluidos quando a interface de separação dos fluidos se move. Os exemplos dados não tem a intenção de simular qualquer fenômeno físico, pois não há a interação estrutura-fluido e o campo de velocidade foi imposto.

Na primeira simulação computacional realizada no presente trabalho, o domínio computacional utilizado foi o paralelepípedo $[0,2] \times[0,2] \times[0.4]$. A malha euleriana é formada por 4 níveis físicos sendo que o nível menos refinado tem $16 \times 16 \times 32$ células computacionais. Disso conclui-se que a resolução obtida na vizinhança da interface é equivalente a resolução obtida em uma malha uniforme com $128 \times 128 \times 256$ células computacionais. Como condição inicial para a malha lagrangiana foi utilizada uma esfera com centro no ponto $(1,1,1)$ e raio 0.7 discretizada por 13.857 vértices, 41.565 arestas e 27.710 faces.

Nessa simulação computacional, foi utilizado o campo de velocidades $\mathbf{u}=(0,0,1)$ para movimentar a interface. Como este campo é constante, a interface se move em uma única direção sem que haja nenhuma deformação da superfície (movimento de corpo rígido). Dado o campo de velocidades, a atualização da posição dos pontos da malha lagrangiana foi feita utilizando o Método de Euler Explicíto, com passo no tempo $\Delta t=0.5 h$, onde 
$h=\min \{\Delta x, \Delta y, \Delta z\}$ sendo $\Delta x, \Delta y$ e $\Delta z$ os espaçamentos do nível mais fino da malha euleriana nas direções $x, y$ e $z$, respectivamente.

A construção das malhas compostas foi feita marcando pontos em uma vizinhança da interface de tamanho $6 h$. A região de segurança marcada para evitar que a interface saísse do nível mais fino da malha composta é formado por duas células computacionais do nível mais fino. Assim, a interface tem quatro células computacionais do nível mais fino de folga para se mover sem que seja necessário fazer uma remalhagem da malha euleriana. Como o passo no tempo utilizado foi $0.5 h$, a remalhagem da malha euleriana é necessária somente a cada 8 passos no tempo.

Na Figura 5.1, podem ser vistas as isosuperfícies da malha lagrangiana nos passos no tempo $0,45,90,135,180$ e 225. Como era de se esperar, a forma da isosuperfície não se altera com o passar do tempo.

Na Figura 5.2, são mostradas as malhas compostas do nível mais fino acompanhando o movimento da interface e as arestas das malhas compostas dos outros níveis físicos nos passos no tempo 0, 45, 90, 135, 180 e 225.

Nas Figuras 5.3 e 5.4, a função indicadora de fluidos e as malhas compostas que acompanham o movimento da interface são mostradas por meio de um corte no plano $x=1$ nos passos no tempo $0,45,90,135,180$ e 225 .

Nas Figuras 5.5 e 5.6, os eixos coordenados foram rotacionados para mostrar uma visão frontal da função indicadora de fluidos com as arestas das malhas compostas e as malhas compostas nos passos no tempo 0, 45, 90, 135, 180 e 225.

As malhas compostas do passo inicial no tempo são formadas por 318 malhas no nível mais fino. Enquanto, nos outros passos no tempo mostrados nas figuras 5.1, 5.2, 5.3, 5.4, 5.5 e 5.6 o nível mais fino das malhas compostas é formado por 352 malhas compostas.

Na segunda simulação computacional realizada no presente trabalho, o domínio computacional utilizado foi o cubo $[0,1] \times[0,1] \times[0,1]$. A malha euleriana tem 4 níveis físicos sendo que o nível menos refinado é formado por $32 \times 32 \times 32$ células computacionais. Assim, a resolução obtida na vizinhança da interface de separação entre os fluidos é equivalente a resolução de uma malha uniforme com $256 \times 256 \times 256$ células computacionais. Como condição inicial para a malha lagrangiana foi utilizada uma esfera com centro no ponto $(0.35,0.35,0.35)$ e raio 0.15 discretizada por 28.208 vértices, 84.618 arestas e 56.412 
faces.

Nessa simulação, o campo de velocidades utilizado para movimentar a interface foi $\mathbf{u}=\left(2 \sin ^{2}(\pi x) \sin ^{2}(2 \pi y),-\sin ^{2}(\pi y) \sin ^{2}(2 \pi z),-\sin ^{2}(\pi z) \sin ^{2}(2 \pi y)\right)$. A atualização da posição dos pontos da malha lagrangiana foi feita utilizando o Método de Euler Explícito, com passo no tempo $\Delta t=0.25 h$, onde $h=\min \{\Delta x, \Delta y, \Delta z\}$ sendo $\Delta x, \Delta y$ e $\Delta z$ os espaçamentos do nível mais fino da malha euleriana nas direções $x, y$ e $z$, respectivamente.

Novamente, a construção das malhas compostas foi feita marcando pontos em uma vizinhança da interface de separação de tamanho 6h. A região de segurança marcada para evitar que a interface saísse do nível mais fino da malha composta é formada por duas células computacionais do nível mais fino. Com isso, a interface tem quatro células computacionais no nível mais fino de folga para se mover sem que seja necessário fazer uma remalhagem euleriana. Como nessa simulação o passo no tempo utilizado foi $0.25 h$, depois de cada remalhagem euleriana, a interface pode se movimentar por pelo menos 16 passos no tempo sem haja a necessidade de uma nova remalhagem euleriana.

A cada passo no tempo foi testado se os poliedros construídos para atualizar a função indicadora de fluidos estavam inteiramente contidos em uma malha composta do nível mais fino com o objetivo de interroper a simulação caso esta condição falhasse. Nessa segunda simulação, este critério falhou depois de 91 passos no tempo devido a distorção dos triângulos da malha lagrangiana.

Na Figura 5.7, podem ser vistas as isosuperfícies da malha lagrangiana nos passos no tempo 0, 18, 36, 54, 72 e 90.

Na Figura 5.8, são mostradas as malhas compostas do nível mais fino acompanhando o movimento da interface e as arestas das malhas compostas dos outros níveis físicos nos passos no tempo 0, 18, 36, 54, 72 e 90.

Nas Figuras 5.9 e 5.10, a função indicadora de fluidos e as malhas compostas que acompanham o movimento da interface são mostradas por meio de um corte no plano $x=0.3$ nos passos no tempo $0,18,36,54,72$ e 90 .

Nas Figuras 5.11 e 5.12, os eixos coordenados foram rotacionados para mostrar uma visão frontal da função indicadora de fluidos com as arestas das malhas compostas e as malhas compostas nos passos no tempo 0, 18, 36, 54, 72 e 90. 

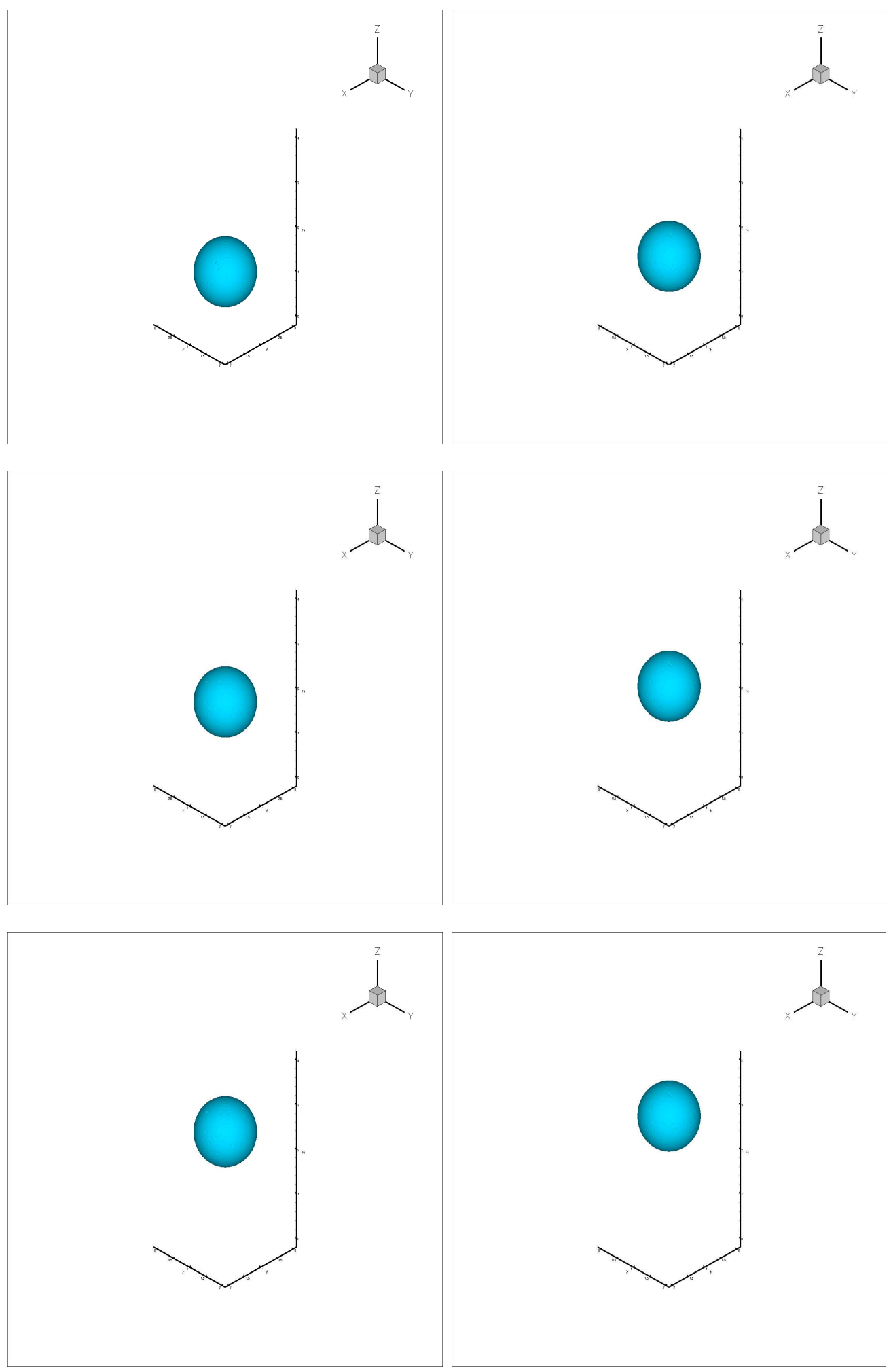

Figura 5.1: Exemplo do movimento de uma esfera: isosuperfícies nos passos no tempo 0, $45,90,135,180$ e 225. 

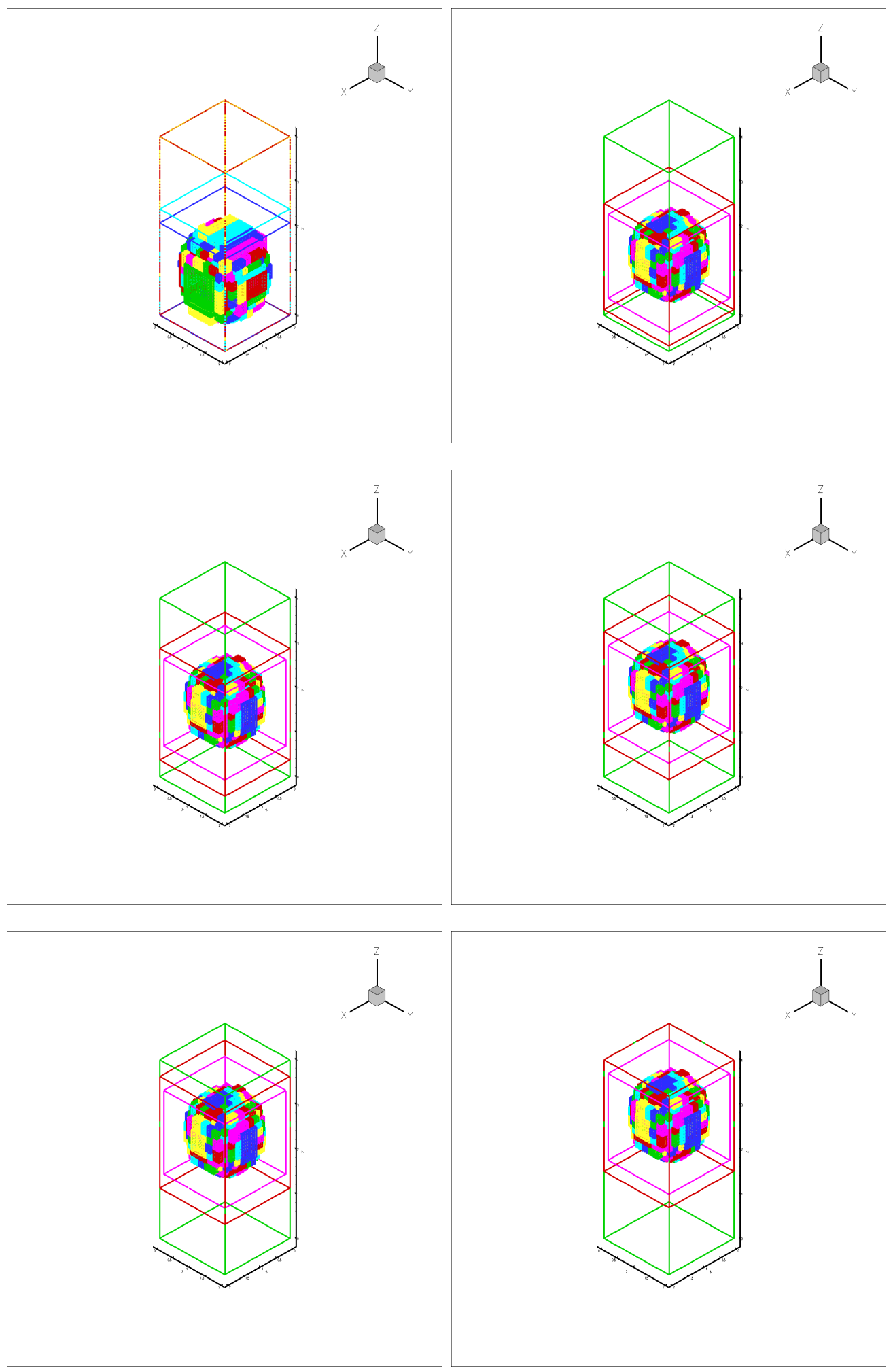

Figura 5.2: Exemplo do movimento de uma esfera: malhas do nível mais fino e arestas das malhas dos outros níveis nos passos no tempo 0, 45, 90, 135, 180 e 225. 

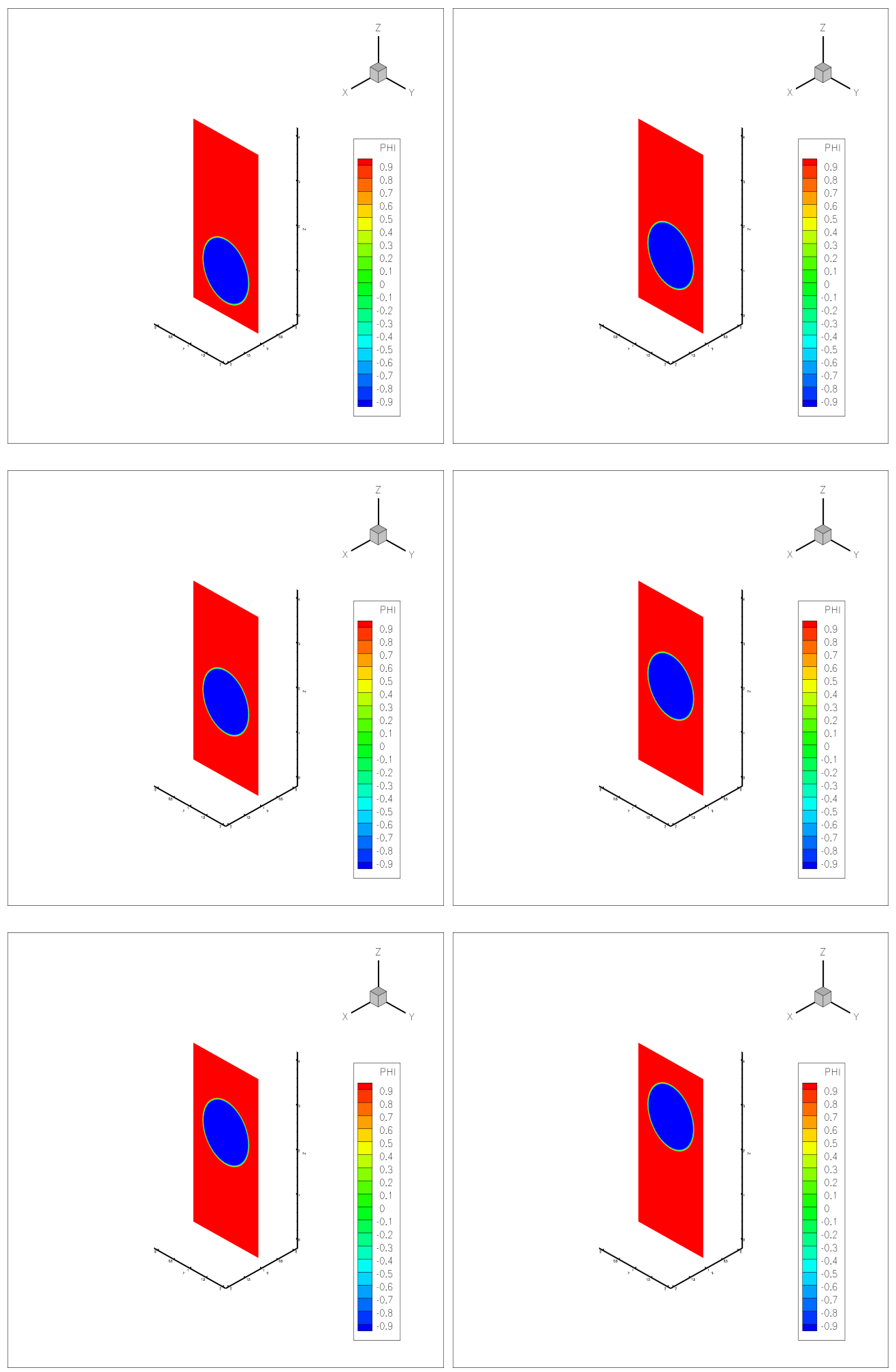

Figura 5.3: Exemplo do movimento de uma esfera: corte em $x=1$ da função indicadora de fluidos nos passos no tempo 0, 45, 90, 135, 180 e 225 . 

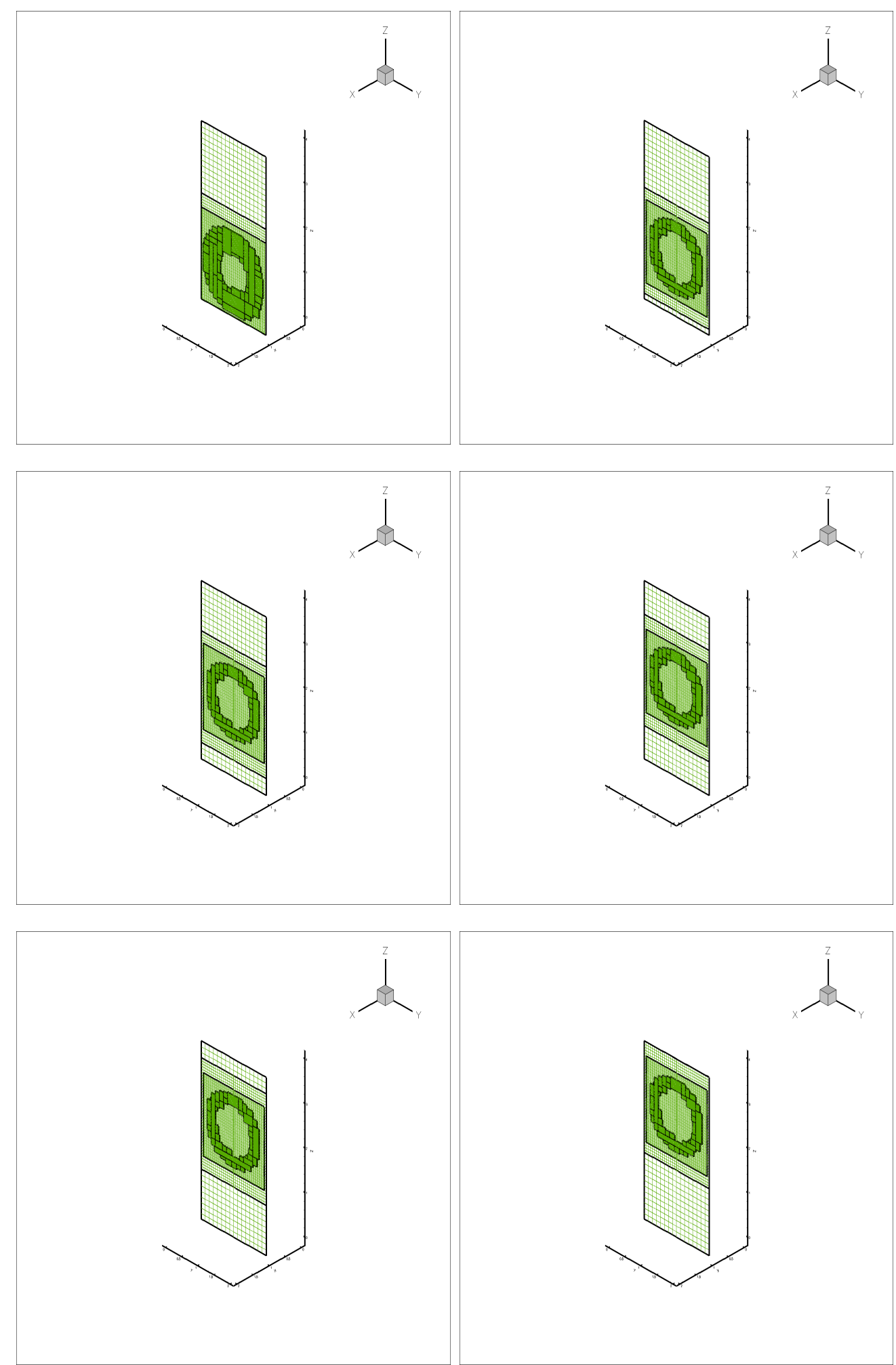

Figura 5.4: Exemplo do movimento de uma esfera: corte em $x=1$ das malhas compostas nos passos no tempo 0, 45, 90, 135, 180 e 225. 

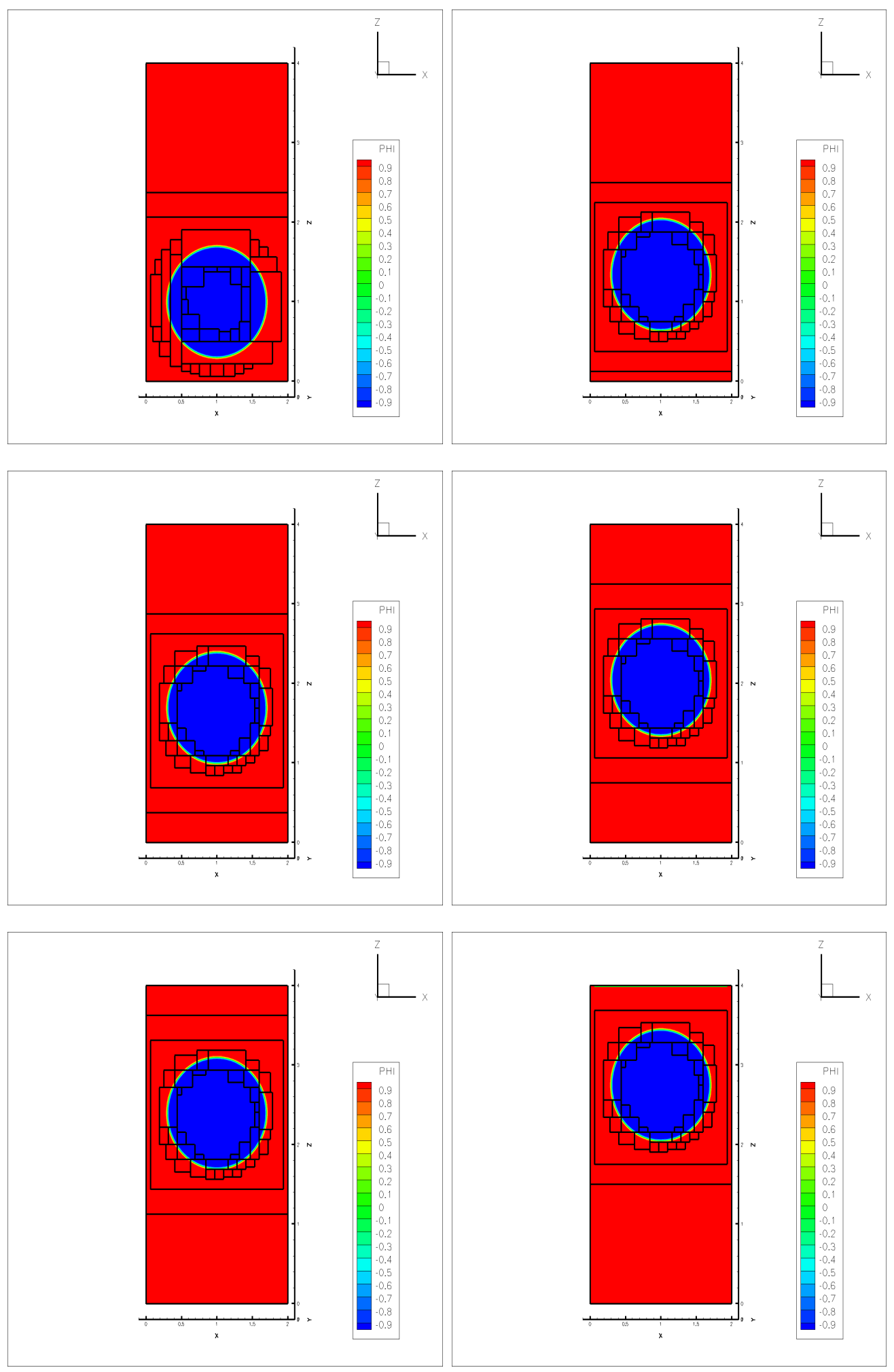

Figura 5.5: Exemplo do movimento de uma esfera: vista frontal de um corte em $y=1$ mostrando a função indicadora de fluidos e as arestas das malhas compostas nos passos no tempo 0, 45, 90, 135, 180 e 225. 

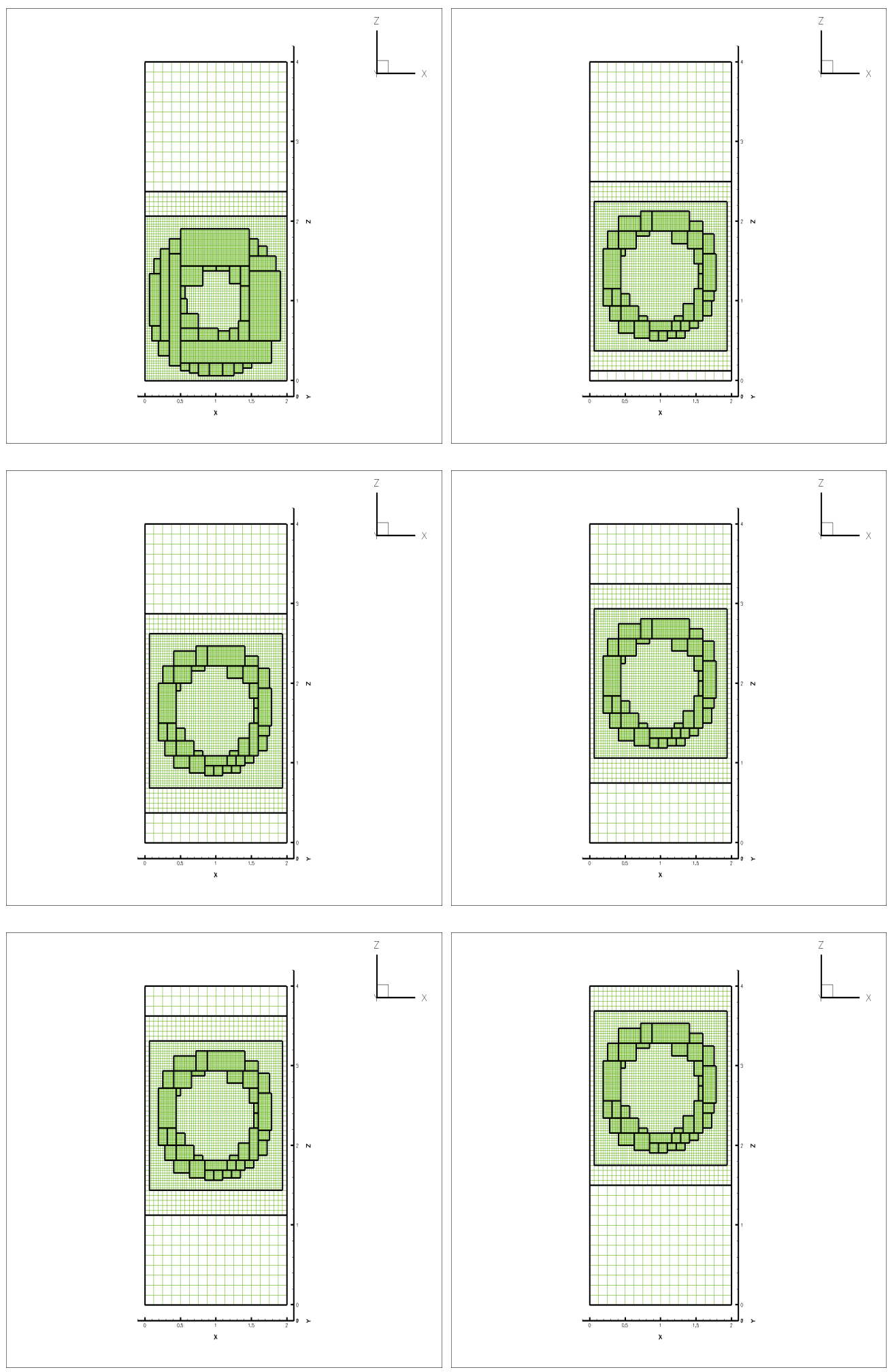

Figura 5.6: Exemplo do movimento de uma esfera: vista frontal de um corte em $y=1$ mostrando as malhas compostas nos passos no tempo 0, 45, 90, 135, 180 e 225 . 

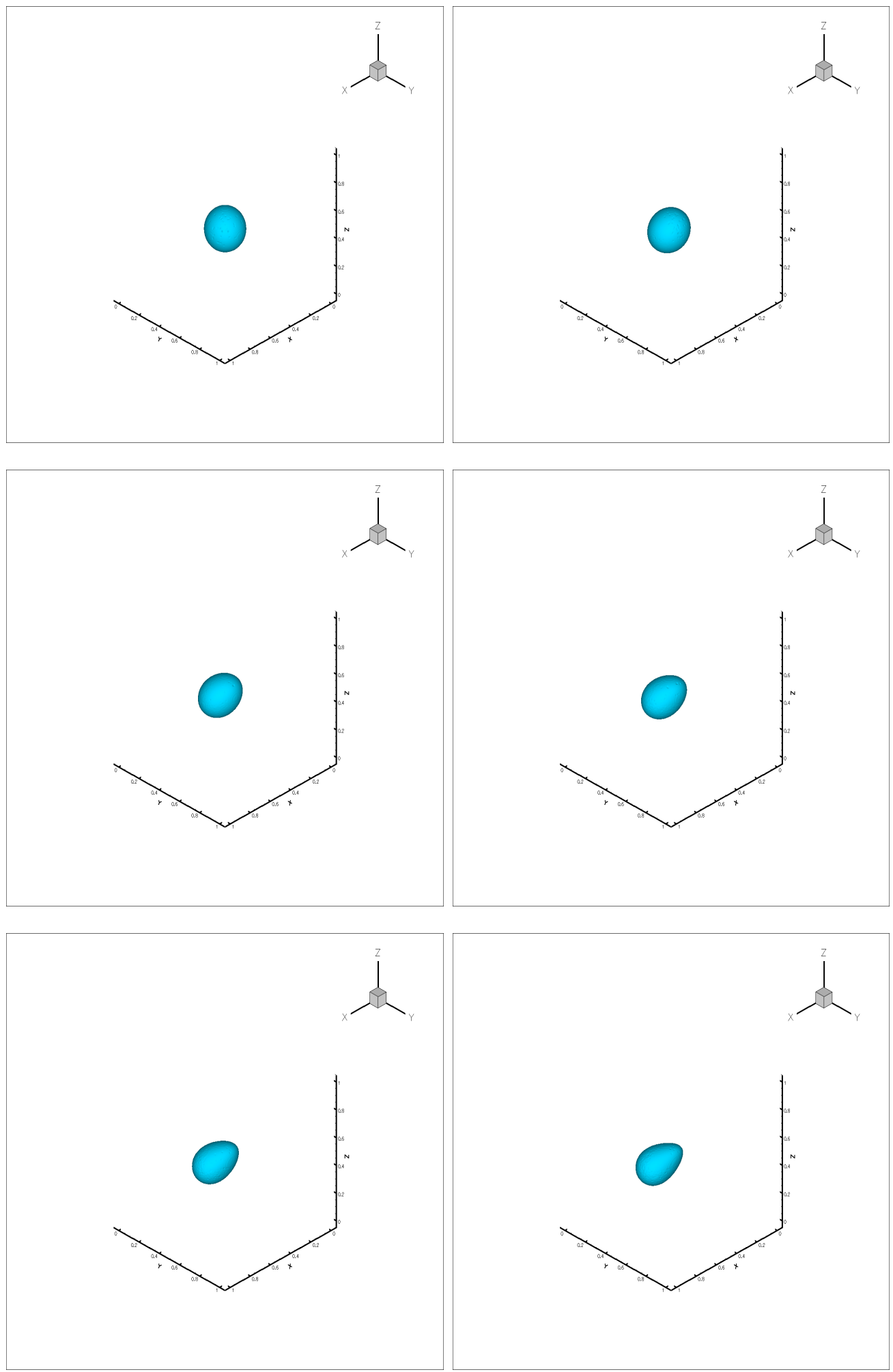

Figura 5.7: Exemplo da deformação de uma esfera: isosuperfícies nos passos no tempo 0, $18,36,54,72$ e 90. 

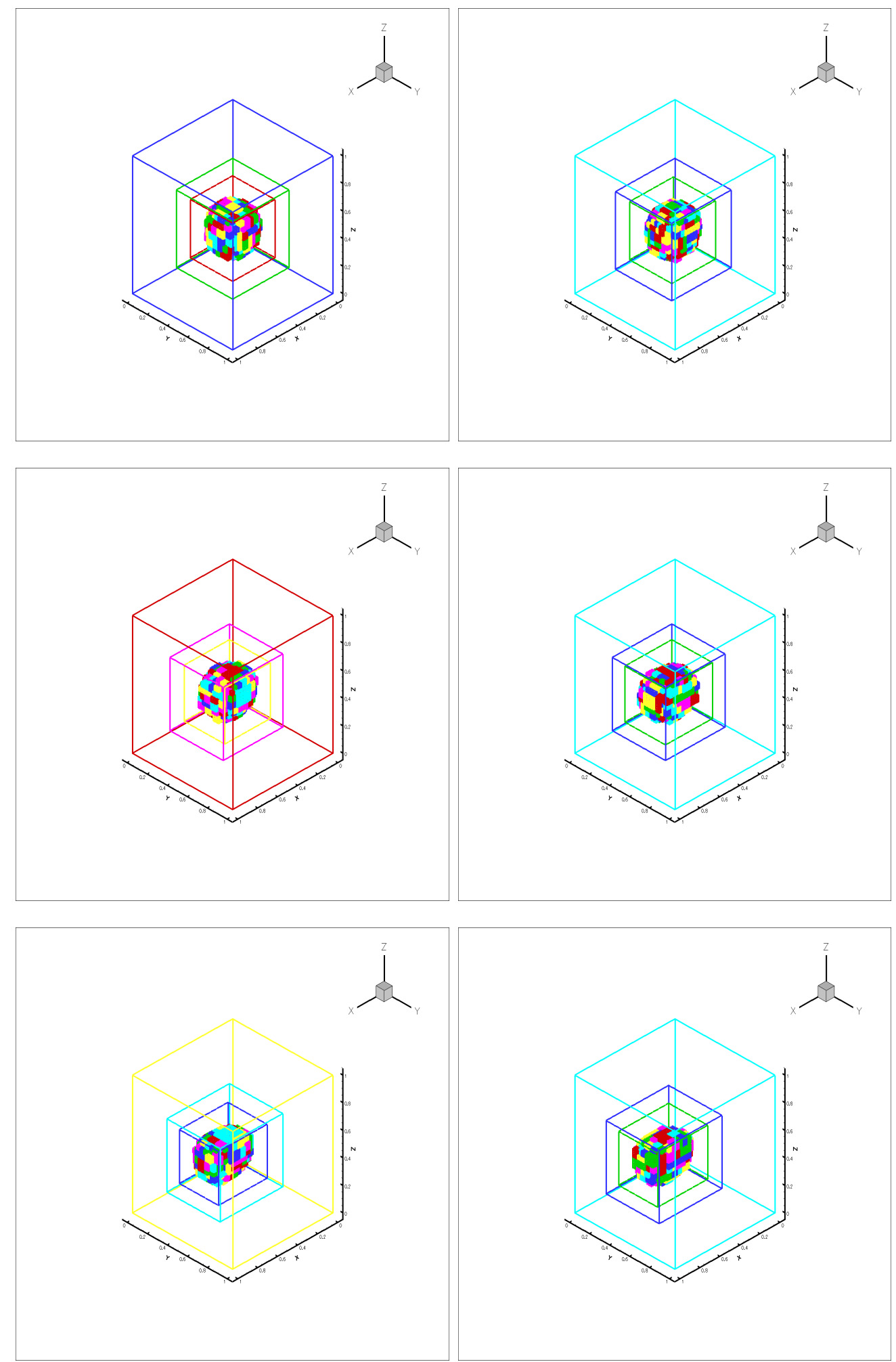

Figura 5.8: Exemplo da deformação de uma esfera: malhas do nível mais fino e arestas das malhas dos outros níveis nos passos no tempo 0, 18, 36, 54, 72 e 90. 

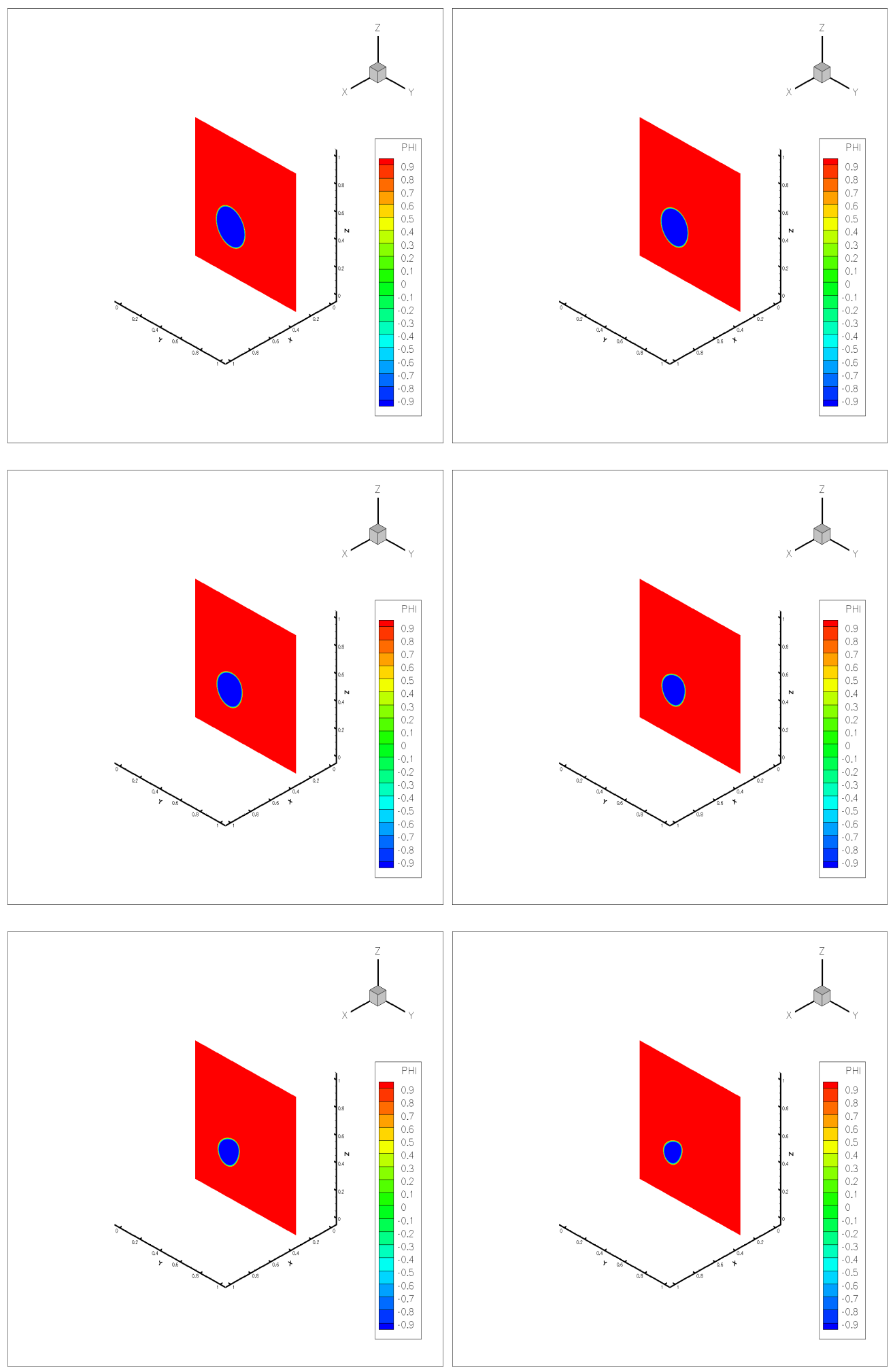

Figura 5.9: Exemplo da deformação de uma esfera: corte em $x=0.3$ da função indicadora de fluidos nos passos no tempo 0, 18, 36, 54, 72 e 90 . 

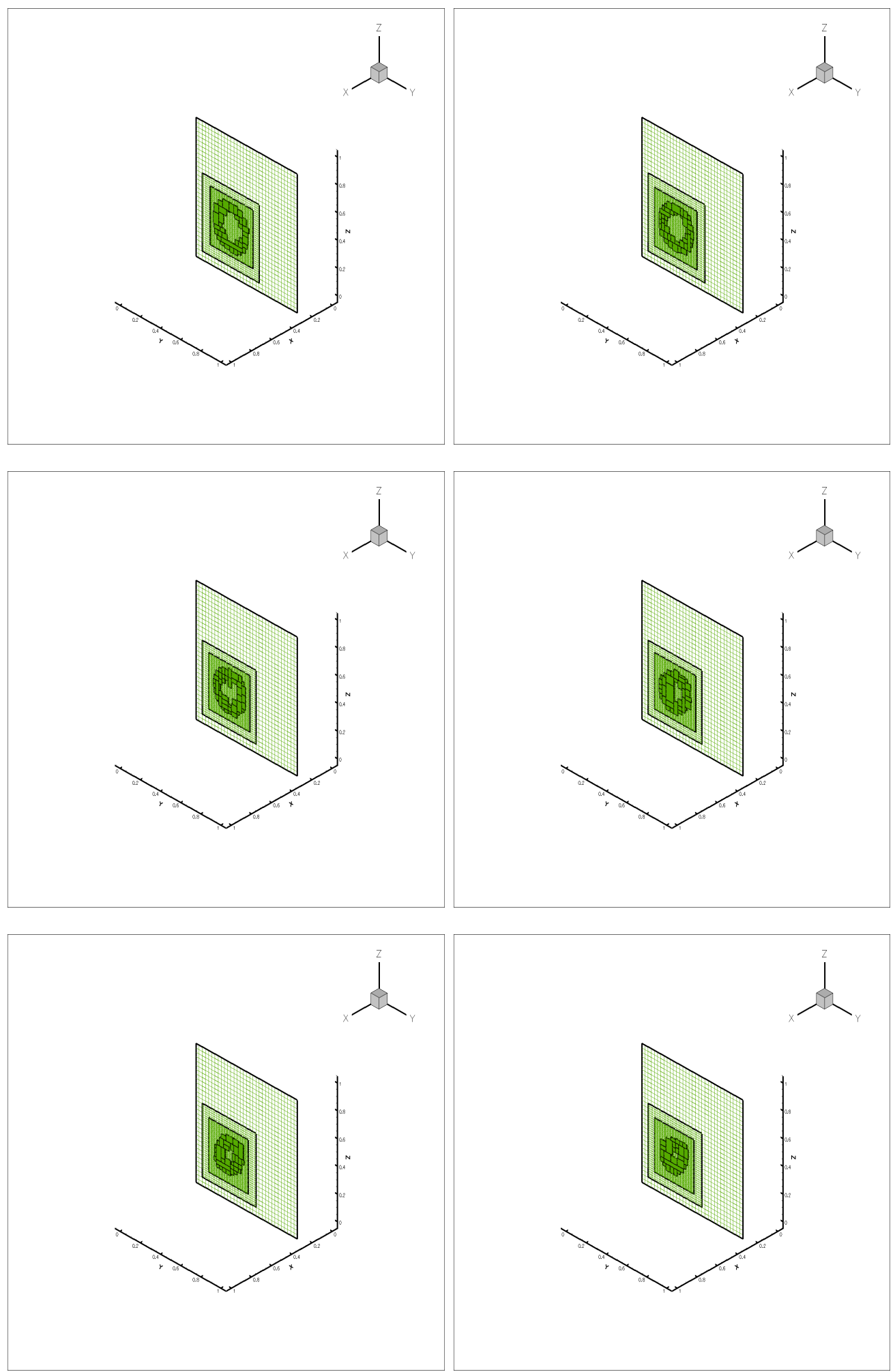

Figura 5.10: Exemplo da deformação de uma esfera: corte em $x=0.3$ das malhas compostas nos passos no tempo $0,18,36,54,72$ e 90 . 

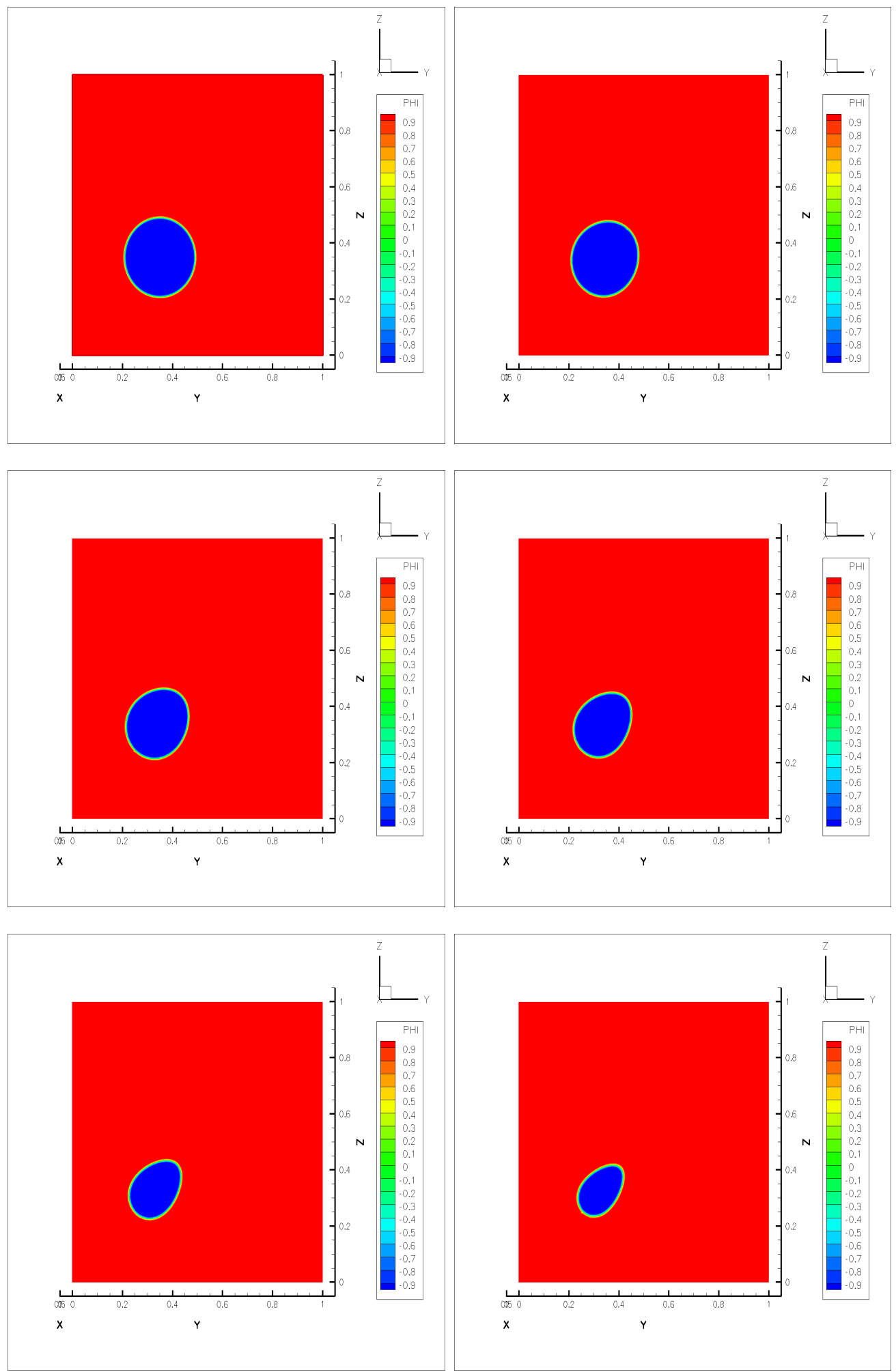

Figura 5.11: Exemplo da deformação de uma esfera: vista frontal de um corte em $x=0.3$ mostrando a função indicadora de fluidos e as arestas das malhas compostas nos passos no tempo $0,18,36,54,72$ e 90. 

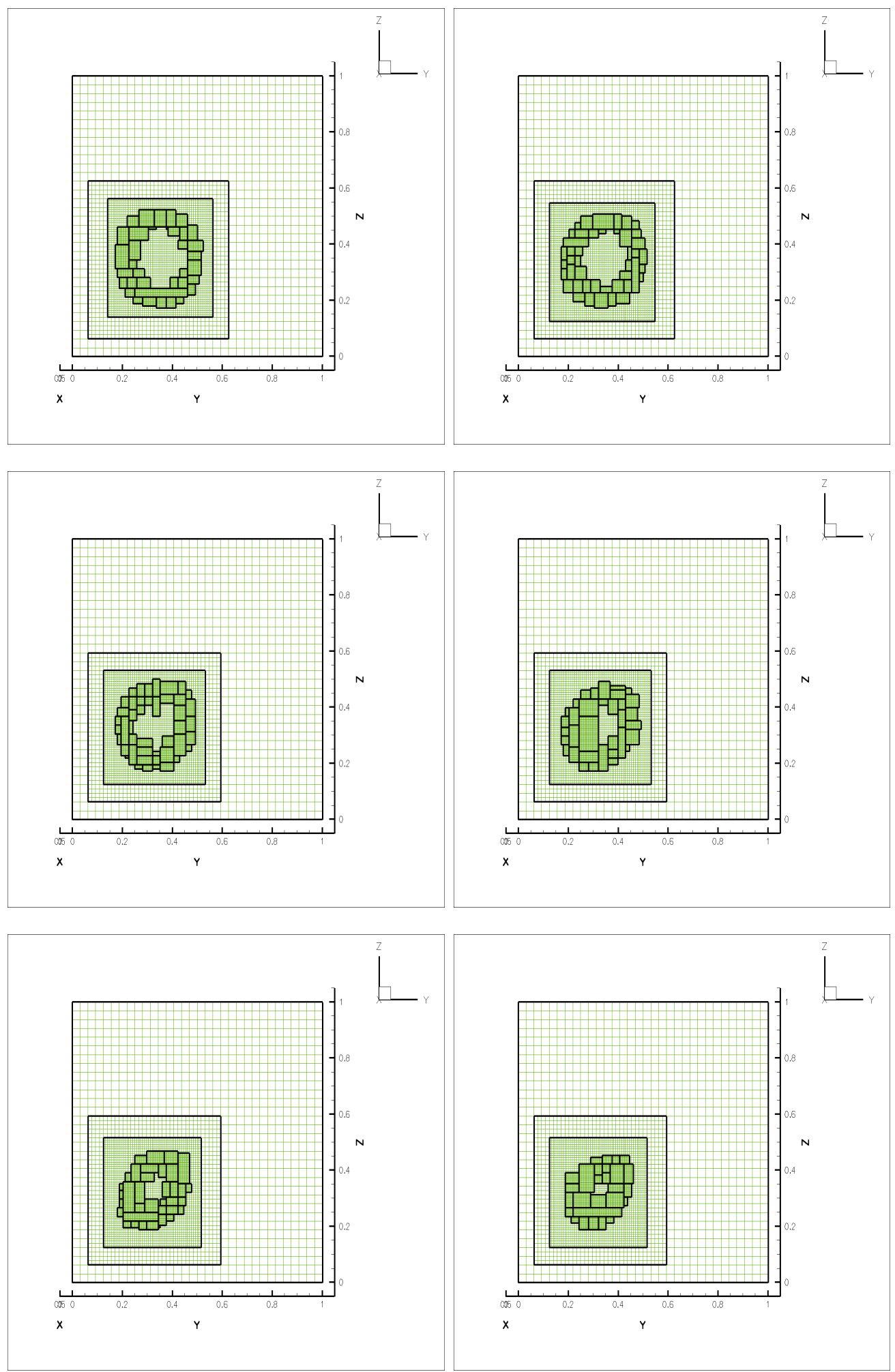

Figura 5.12: Exemplo da deformação de uma esfera: vista frontal de um corte em $x=0.3$ mostrando as malhas compostas nos passos no tempo 0, 18, 36, 54, 72 e 90. 


\section{Conclusão}

O presente trabalho tem como motivação científica a modelagem matemática e a simulação computacional de escoamentos multifásicos. Mais especificamente, partindo-se de uma formulação que combina o Método da Fronteira Imersa com o uso de uma função indicadora de fluidos as equações do movimento de um escoamento incompressível bifásico são escritas.

O objetivo do presente trabalho é calcular uma função indicadora de fluidos tridimensional; essa função é determinada pelo cálculo de uma função distância local com sinal numa vizinhança da fronteira imersa. A função distância com sinal é empregada para identificar a pertinência de pontos com relação à uma superfície fechada e orientada utilizando pouca memória e com baixo custo computacional. Essa função distância é atualizada a cada passo no tempo utilizando idéias de Geometria Computacional, o que torna o custo computacional para calcular essa função ótimo.

Adotando-se uma abordagem empregada comumente, assume-se que as equações que regem a dinâmica do fluido estão discretizadas numa malha euleriana que discretiza o domínio onde ocorre o escoamento e que interface de separação entre suas fases é discretizada por uma malha lagrangiana não estruturada formada por um triângulos.

Para o armazenar os "vértices" da malha lagrangiana utilizou-se a estrutura de dados Halfedge, amplamente empregada em Computação Gráfica para armazenar superfícies fechadas e orientáveis.

Na construção da função distância com sinal utilizou-se o algoritmo Closest Point Transform (CPT) inicialmente em uma malha euleriana uniforme (sem nenhum tipo de 
refinamento) recobrindo todo o domínio computacional para testar a robustez e a eficiência desse algoritmo.

A implementação desse algoritmo requer um teste de inclusão dos pontos próximos aos vértices tipo sela; para solucionar este problema foi utilizado o vetor pseudonormal, proposto em [2]. Esta metodologia mostrou-se robusta e eficiente computacionalmente, o que contribuiu significativamente para a geração computacional de uma nítida interface de separação entre os fluidos.

O algoritmo Closest Point Transform, utilizado na atualização desse campo de distâncias, também mostrou-se robusto e produziu uma definição nítida das distintas fases do fluido em todos os passos no tempo. Vale ressaltar que este algoritmo calcula precisamente a distância entre os pontos da malha euleriana e a superfície triangularizada.

Para obter uma melhor resolução na vizinhança da superfície utilizando pouca memória computacional, foi utilizado o algoritmo de Refinamento Adaptativo de Malhas (AMR) Este algoritmo foi empregado para gerar malhas bloco-estruturadas refinadas localmente em torno da malha euleriana e foi escolhido por ser eficiente computacionalmente (tomando tipicamente menos de $5 \%$ do tempo total computacional) e por ser de implementação relativamente simples, já que utiliza estruturas de dados como listas ligadas, matrizes e vetores.

Para o movimento da fronteira imersa, foi considerada apenas a condição de não deslizamento, assume-se que fronteira imersa acompanha passivamente o escoamento representado por um campo de velocidades pré-estabelecido (imposto) na malha euleriana. Este campo de velocidades é então interpolado para a malha lagrangiana e é feita a integração da equação de evolução no tempo. Para garantir que a fronteira imersa esteja sempre recoberta por malhas do nível mais fino, é feita uma remalhagem da malha euleriana, por meio do algoritmo AMR, quando algum ponto da malha lagrangiana está próximo da fronteira do conjunto formado pelas malhas refinadas do nível mais fino.

Algumas informações da relação entre a malha euleriana e a malha lagrangiana precisam ser consultadas várias vezes em cada passo no tempo. Para evitar buscas repetitivas num mesmo passo no tempo para obter essas informações, foram construídas algumas estruturas denominadas "mapas" para armazenar tais informações.

No presente trabalho, foram construídos mapas lagrangianos e mapas eulerianos. Os 
mapas lagrangianos foram construídos para armazenar a relação de pertinência dos pontos lagrangianos em relação às malhas contidas nos níveis ltop e ltop - 1. Os mapas eulerianos são utilizados para armazenadas informações das malhas adjacentes a cada malha dos níveis ltop e ltop - 1 e para determinar quando deve ser feita uma remalhagem da malha euleriana.

A contribuição do presente trabalho se dá principalmente no contexto do estudo de Dinâmica de Fluidos Computacional servindo de base para a resolução de problemas envolvendo o Método da Fronteira Imersa. Para a solução destes problemas, faz-se necessário o cálculo de uma função indicadora de fluidos que permita ao mesmo tempo utilizar pouca memória e com baixo custo computacional.

Em trabalhos futuros, intenciona-se resolver simultaneamente a equação de NavierStokes, fazer uma remalhagem dos pontos da malha lagrangiana sempre que a fronteira imersa se distorcer, calcular as quantidades geométricas necessárias para o cálculo das forças interfaciais (vetor normal e curvatura) para que haja a interação plena entre o fluido e a interface (estrutura). 


\section{Máquinas usadas na execução do código computacional}

Listamos a seguir as máquinas que foram usadas na execução e validação do código computacional.

1. Máquina 1, uma Power Mac G5 (modelo M9591LL/A) com processador dual de 2.3GHz, 4GB de memória RAM, 250GB de disco rígido, aritmética de 64 bits, compilador absoft para Fortran 90 e sistema operacional Linux (yellow dog linux ydl). Esta máquina está localizada no Departamento de Matemática Aplicada do Instituto de Matemática e Estatística da Universidade de São Paulo.

2. Máquina 2, uma Power Mac G5 (modelo M9592LL/A) com processador quad (duplo dual) de 2.5GHz, 16GB de memória RAM, 250GB de disco rígido, aritmética de 64 bits, compilador absoft para Fortran 90 e sistema operacional Linux (ydl). Esta máquina está localizada no Departamento de Matemática Aplicada do Instituto de Matemática e Estatística da Universidade de São Paulo.

Essas máquinas foram adquiridas com recursos da FAPESP (Fundação de Amparo a Pesquisa do Estado de São Paulo), projeto 04/13781-1. 


\section{Estrutura de Dados Halfedge}

Neste Apêndice são mostrados todos os campos da estrutura de dados Halfedge, escritos em FORTRAN 90, que são utilizados no programa de movimentação da fronteira imersa.

MODULE HALF_EDGE

USE DATA_TYPES

IMPLICIT NONE

SAVE

TYPE VECTOR

DOUBLE PRECISION, DIMENSION(4) : : VEC

END TYPE

TYPE VELOCITY

DOUBLE PRECISION, DIMENSION(3) : : VEL

END TYPE

TYPE GRID_COMPONENTS1

INTEGER

: : IX, IY, IZ, MX, MY, MZ, IU, \&

$\mathrm{BW}, \mathrm{BE}, \mathrm{BS}, \mathrm{BN}, \mathrm{BB}, \mathrm{BT}$

END TYPE GRID_COMPONENTS1 


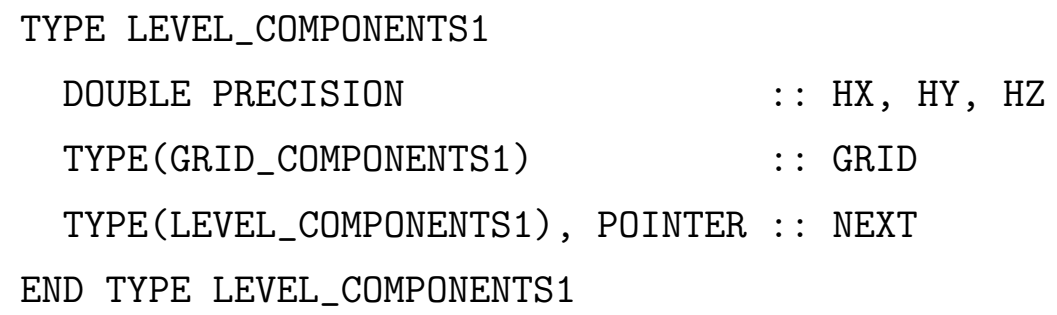

TYPE SOLID

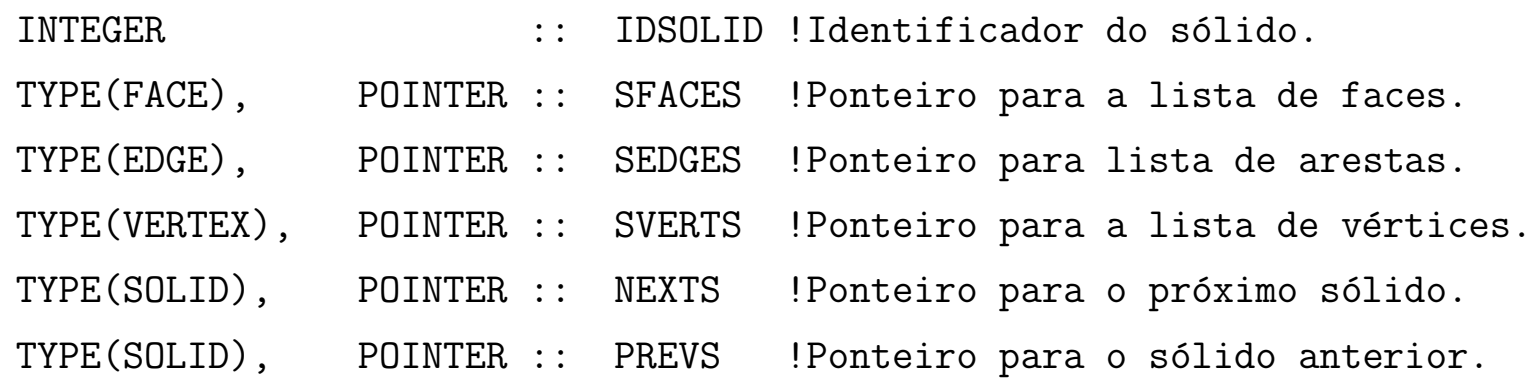

END TYPE SOLID

TYPE FACE

\begin{tabular}{|c|c|c|c|}
\hline INTEGER & & $::$ IDFACE & !Identificador da face. \\
\hline TYPE(SOLID), & POINTER & $::$ FSOLID & $\begin{array}{l}\text { !Ponteiro para o sólido ao qual } \\
\text { !pertence a face. }\end{array}$ \\
\hline TYPE (LOOP), & POINTER & $::$ FLOUT & !Ponteiro para o loop externo da face. \\
\hline TYPE (LOOP) & POINTER & $::$ FLOOPS & !Ponteiro para a lista de loops da face. \\
\hline TYPE (VECTOR) & & $::$ FEQ & !Equação do plano da Face $(a x+b y+c z+d=0)$ \\
\hline TYPE (FACE), & POINTER & $::$ NEXTF & !Ponteiro para a próxima face do sólido. \\
\hline TYPE (FACE) & POINTER & $::$ PREVF & !Ponteiro para a face anterior do sólido. \\
\hline
\end{tabular}

TYPE LOOP

TYPE(HALFEDGE), POINTER :: LEDG !Ponteiro para uma das semi-arestas do Loop. TYPE(FACE), POINTER : : LFACE !Ponteiro para a face ao qual pertence o Loop TYPE(LOOP), POINTER : : NEXTL !Ponteiro para o próximo "loop" da face. 
TYPE(LOOP), POINTER : : PREVL !Ponteiro para o "loop" anterior da face. END TYPE Loop

TYPE HALFEDGE

TYPE(EDGE), POINTER : : EDF !Ponteiro para aresta que é associada à !semi-aresta.

TYPE(VERTEX), POINTER : : VTX !Ponteiro para o vértice final da ! semi-aresta.

TYPE(LOOP), POINTER : : WLOOP !Ponteiro para o Loop ao qual pertence à ! semi-aresta.

TYPE(HALFEDGE), POINTER :: NEXTH !Ponteiro para próxima semi-aresta.

TYPE(HALFEDGE), POINTER : : PREVH !Ponteiro para a semi-aresta anterior. END TYPE HALFEDGE

TYPE EDGE

\begin{tabular}{|c|c|c|}
\hline INTEGER & $:$ IDEDGE & ! Identificador da aresta. \\
\hline TYPE (HALFEDGE), & POINTER : : HE1 & !Ponteiro para semi-aresta direita. \\
\hline TYPE (HALFEDGE), & POINTER : : HE2 & !Ponteiro para a semi-aresta esquerda. \\
\hline TYPE (EDGE) , & POINTER : : NEXTE & !Ponteiro para a próxima aresta. \\
\hline TYPE (EDGE) & POINTER : : PREVE & !Ponteiro para a aresta anterior. \\
\hline TYPE (PROPEDGE), & POINTER : : PROPE & $\begin{array}{l}\text { !Ponteiro para armazenar propriedades da } \\
\text { !aresta. }\end{array}$ \\
\hline
\end{tabular}

END TYPE EDGE

TYPE VERTEX

INTEGER

: : IDVERTEX !Identificador do vértice.

TYPE(HALFEDGE), POINTER :: VEDGE !Ponteiro para a semiaresta que começa !no vértice.

TYPE (VECTOR)

: VCOORD1 !Coordenadas cartesianas do vértice no ! instante t1.

TYPE (VECTOR)

:: VCOORD2 !Coordenadas cartesianas do vértice no 


\begin{tabular}{|c|c|c|}
\hline \multirow{2}{*}{ TYPE(VELOCITY) } & \multicolumn{2}{|r|}{ ! instante t2. } \\
\hline & $::$ VEL01 & !Velocidade do vértice no instante t1. \\
\hline TYPE (VELOCITY) & $::$ VELO2 & !Velocidade do vértice no instante t2. \\
\hline TYPE(VERTEX) & POINTER : : NEXTV & !Ponteiro para próximo vértice. \\
\hline TYPE (VERTEX), & POINTER : : PREVV & !Ponteiro para o vértice anterior. \\
\hline TYPE [LEVEL_COM] & ENTS1], POINTER : & $\begin{array}{c}\text { APLAGRAN1 !Ponteiro para o mapa lagrangeano } \\
\text { !do nível ltop. }\end{array}$ \\
\hline TYPE[LEVEL_COM] & ENTS1], POINTER & $\begin{array}{c}\text { APLAGRAN2 !Ponteiro para o mapa lagrangeano } \\
\text { !do nível ltop-1. }\end{array}$ \\
\hline
\end{tabular}

END TYPE VERTEX

TYPE PROPEDGE

INTEGER

END TYPE PROPEDGE

TYPE PROPVERTEX

DOUBLE PRECISION

END TYPE PROPVERTEX

END MODULE HALF_EDGE
: : SIGNAL

: : PSEUDO_NORMAL (3) 


\section{Algoritmos dos mapas eulerianos}

Listamos a seguir os algoritmos empregados na construção dos mapa euleriano que armazena informações da malhas composto do nível ltop.

Nesses algoritmos, para cada malha composta $G$ pertencente ao nível ltop foram utilizadas as seguintes notações:

- $i_{0}=$ menor índice global, na direção do eixo $x$, da malha $G$ projetado no nível ltop - 1;

- $i_{1}=$ maior índice global, na direção do eixo $x$, da malha $G$ projetado no nível ltop -1 ;

- $j_{0}=$ menor índice global, na direção do eixo $y$, da malha $G$ projetado no nível ltop -1 ;

- $j_{1}=$ maior índice global, na direção do eixo $y$, da malha $G$ projetado no nível ltop - 1;

- $k_{0}=$ menor índice global, na direção do eixo $z$, da malha $G$ projetado no nível ltop -1 ;

- $k_{1}=$ maior índice global, na direção do eixo $z$, da malha $G$ projetado no nível ltop -1 . 


\section{Algoritmo 5 Mapa Euleriano 1.1}

para cada malha $G$ do nível ltop faça

$$
\varphi_{i, j, k}=0
$$

fim para

para cada malha $G$ do nível ltop faça

determinar os índices $i_{0}, i_{1}, j_{0}, j_{1}, k_{0}$ e $k_{1}$ da malha $G$

$$
\begin{gathered}
\text { para } j=j_{0}, j_{1} \text { faça } \\
\text { para } k=k_{0}, k_{1} \text { faça } \\
\varphi_{i_{0}-1, j, k}=-\infty \\
\varphi_{i_{1}+1, j, k}=-\infty
\end{gathered}
$$

fim para

fim para

$$
\begin{gathered}
\text { para } i=i_{0}, i_{1} \text { faça } \\
\text { para } k=k_{0}, k_{1} \text { faça } \\
\varphi_{i, j_{0}-1, k}=-\infty \\
\varphi_{i, j_{1}+1, k}=-\infty
\end{gathered}
$$

fim para

fim para

$$
\begin{gathered}
\text { para } i=i_{0}-1, i_{1}+1 \text { faça } \\
\text { para } j=j_{0}-1, j_{1}+1 \text { faça } \\
\varphi_{i, j, k_{0}-1}=-\infty \\
\varphi_{i, j, k_{1}+1}=-\infty
\end{gathered}
$$

fim para

fim para

fim para

para cada malha $G$ do nível ltop faça

$$
\varphi_{i, j, k}=\text { índice da malha } G
$$

fim para 


$\overline{\underline{\text { Algoritmo } 6 \text { Mapa Euleriano 1.2 }}}$

para cada malha $G$ do nível ltop faça

determinar os índices $i_{0}, i_{1}, j_{0}, j_{1}, k_{0}$ e $k_{1}$ da malha $G$

$$
\begin{gathered}
\text { para } j=j_{0}-1, j_{1}+1 \text { faça } \\
\text { para } k=k_{0}-1, k_{1}+1 \text { faça } \\
\text { se } \varphi_{i_{0}-1, j, k}<0 \text { então } \\
\text { para } m=0, \text { mcell }-1 \\
\quad \varphi_{i_{0}+m, j, k}=-\left|\varphi_{i_{0}+m, j, k}\right|
\end{gathered}
$$

fim para

fim se

$$
\begin{aligned}
& \text { se } \varphi_{i_{1}+1, j, k}<0 \text { então } \\
& \text { para } m=0, \text { mcell }-1 \\
& \quad \varphi_{i_{1}-m, j, k}=-\left|\varphi_{i_{1}-m, j, k}\right|
\end{aligned}
$$

fim para

fim se

fim para

fim para

fim para 


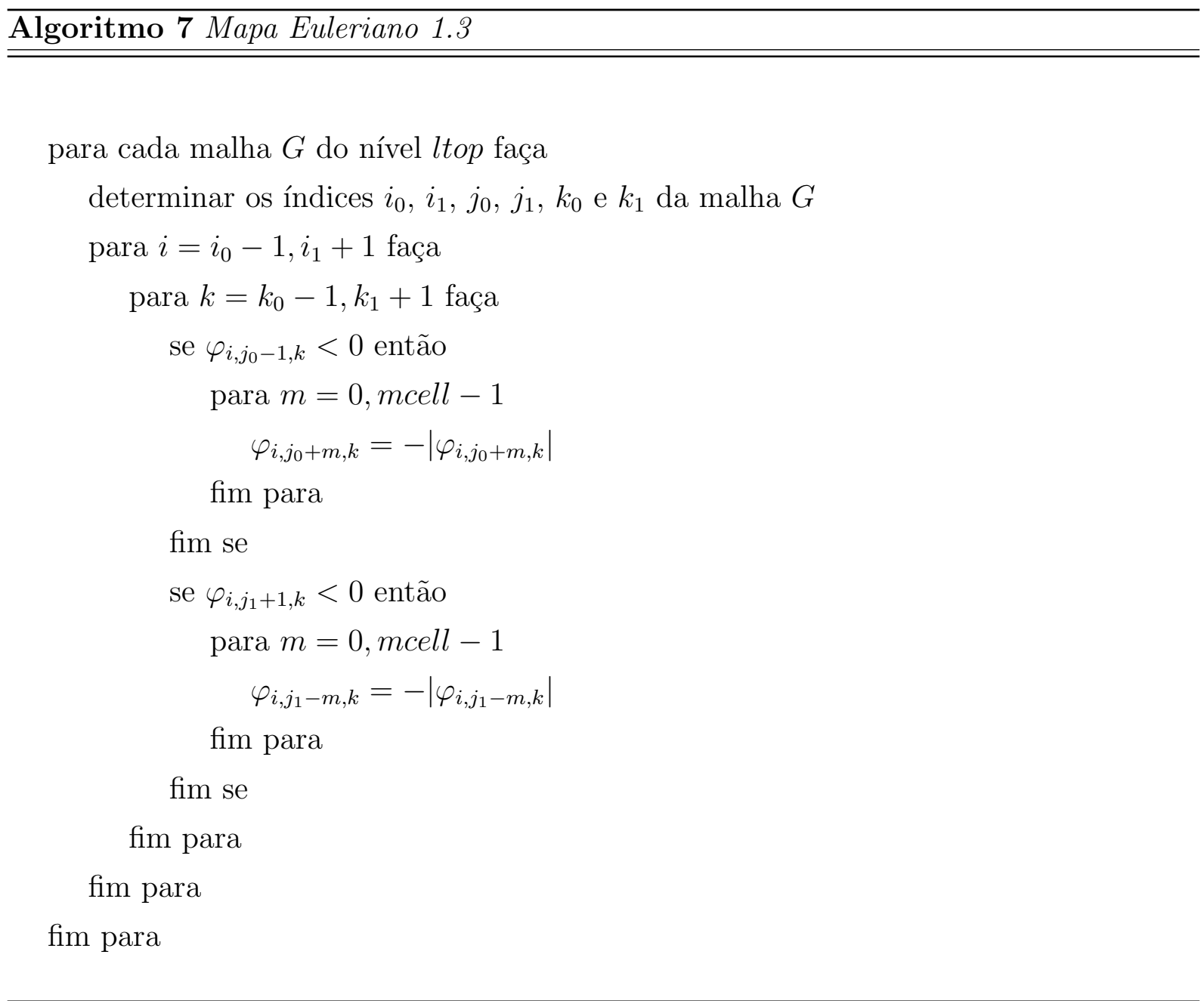




$\overline{\underline{\text { Algoritmo 8 Mapa Euleriano 1.4 }}}$

para cada malha $G$ do nível ltop faça

determinar os índices $i_{0}, i_{1}, j_{0}, j_{1}, k_{0}$ e $k_{1}$ da malha $G$

$$
\begin{gathered}
\text { para } i=i_{0}-1, i_{1}+1 \text { faça } \\
\text { para } j=j_{0}-1, j_{1}+1 \text { faça } \\
\text { se } \varphi_{i, j, k_{0}-1}<0 \text { então } \\
\text { para } m=0, \text { mcell }-1 \\
\quad \varphi_{i, j, k_{0}+m}=-\left|\varphi_{i, j, k_{0}+m}\right|
\end{gathered}
$$

fim para

fim se

$$
\begin{aligned}
& \text { se } \varphi_{i, j, k_{1}+1}<0 \text { então } \\
& \text { para } m=0, \text { mcell }-1 \\
& \quad \varphi_{i, j, k_{1}-m}=-\left|\varphi_{i, j, k_{1}-m}\right|
\end{aligned}
$$

fim para

fim se

fim para

fim para

fim para 


\section{Referências Bibliográficas}

[1] D. M. Anderson, G. B. McFadden e A. A. Wheeler. Diffuse-interface methods in fluid mechanics. Annu. Rev. Fluid Mech., vol. 30, pag. 139-165, 1998.

[2] J. Andreas Baerentzen e H. Aanaes. Signed distance computation using the angle weighted pseudonormal. IEEE Transactions on Visualization and Computer Graphics, Vol. 11, maio/junho 2005.

[3] V. E. Badalassi, H. D. Ceniceros e S. Banerjee. Computation of multiphase systems with phase field models. Journal of Computational Physics, vol. 190, pags. 371-397, 2003.

[4] V. E. Badalassi, H. D. Ceniceros e S. Banerjee. Gravitational effects on structural development in quenched complex fluids. Ann. NY. Acad. Sci., vol. 1027, pags. 371$382,2004$.

[5] J. Bakosi. Modeling of turbulent flows using a probabilistic approach. $\mathrm{PhD}$ thesis, George Mason University, 2005.

[6] J. Bell, M. J. Berger, J. Saltzman e M. Welcome Three-dimensional adaptive mesh refinement for hyperbolic conservation laws. SIAM J. Sci. Comput. vol. 15, n. 1, pags. 127-138, 1994.

[7] M. J. Berger e J. Oliger. Adaptive mesh refinement for hyperbolic partial differential equations. Journal of Computational Physics, vol. 53, pags. 484-512, 1984. 
[8] M. J. Berger e A. Jameson. Automatic adaptive grid refinement for the Euler equations. American Institute of Aeronautics and Astronautics Journal, vol. 23, n. 4, pags. 561-568, 1985.

[9] M. J. Berger. Data structures for adaptive grid generation. SIAM J. Sci. Stat. Comput., vol. 7, n. 3, pags. 904-916, 1986.

[10] M. J. Berger. On conservation at grid interfaces. SIAM J. Numer. Anal., vol. 24, n. 5, pags. 967-984, 1987.

[11] M. J. Berger. e P. Colella. Local adaptive mesh refinement for shock hydrodynamics. Journal of Computational Physics, vol. 82, pags. 64-84, 1989.

[12] M. J. Berger e I. Rigoutsos. An algorithm for point clustering and grid generation. IEEE Transaction on System, Man, and Cybernetics, vol. 21, n. 5, pags. 1278-1286, 1991.

[13] M. J. Berger e R. J. Le Veque. Adaptive mesh refinement using wave-propagation algorithms for hyperbolic systems. SIAM J. Numer. Anal., vol. 35, n. 6, pags. 22982316, 1998.

[14] F. Boyer, L. Chupin e P. Fabrie. Numerical study of viscoelastic mixtures through a Cahn-Hilliard flow model. European Journal of Mechanics B/Fluids, vol. 23, pags. 759-780, 2004.

[15] H. D. Ceniceros e A. M. Roma. A multi-phase flow method with a fast, geometrybased fluid indicator. Journal of computational Physics, vol. 205, pags. 391-400, 2005 .

[16] Y. C. Chang, T. Y. Hou, B. Merriman e S. Osher. A level set formulation of Eulerian interface capturing methods for incompressible fluid flows. Journal of Computational Physics, vol.124, pags. 449-464, 1996.

[17] R. Chella e J. Viñals. Mixing of a two-phase fluid by a cavity flow. Physical Review E, vol. 53, n. 4, pags. 3832-3840, 1996.

[18] B. CockBurn e B. Yenikaya. An adaptive method with rigorous error control for the Hamilton-Jacobi Equations. Journal of Computational Physics, vol. 209, Issue 2, pags. 391-405, 2005. 
[19] P. A. Durbin e G. Iaccarino. An approach to local refinament of structured grids. Journal of Computational Physics, vol. 181 , pags 639-653, 2002.

[20] D. Enright, S. Marschner e R. Fedkiw. Animation and rendering of complex water surfaces. ACM transactions on Graphics, vol. 21, 2002.

[21] A. E. Fabris e A. R. Forrest. Antialiasing of curves by discrete pre-filtering. Computer Graphics - Siggraph, vol. 31, n. 3 pags. 317-326, 1997.

[22] I. Ginzburg e G. Wittum. Two-phase flows on interface refined grids modeled with VOF, staggered finite volumes, and splines interpolants. Journal of Computational Physics, vol. 166, pags. 302-335, 2001.

[23] B. E. Griffith, R. D. Hornung, D. M. McQueen e C. S. Peskin. An adaptive, formally second order accurate version of the immersed boundary method. Journal of Computational Physics, vol. 223, pags. 10-49, 2007.

[24] Z. Haifei, L. Zhigang e L. Zhihang. Level-Set based 3D reconstruction algorithm from unorganized data cloud. Journal of Xi'an Jiaotong University, vol. 40 , n. 5 , 2006.

[25] F. H. Harlow e J. E. Welch. Numerical calculation of time-dependent viscous incompressible flow of fluid with free surface. Physics of Fluids, vol. 8, pags. 2182-2189, 1965.

[26] C. W. Hirt e B. D. Nichols. Volume of fluid (VOF) method for the dynamics of free boundaries. Journal of Computational Physics, vol. 39, pags. 201-225, 1981.

[27] D. Jacqmin. Calculation of two-phase Navier-Stokes flows using phase-field modeling. Journal of Computational Physics, vol. 155, pags. 96-127, 1999.

[28] A. J. James e J. Lowengrub. A surfactant-conserving volume-of-fluid method for interfacial flows with insoluble surfactant. Journal of Computational Physics, vol. 201, pags. 685-722, 2004.

[29] D. Jamet, O. Lebaigue, N. Coutris e J. M. Delhaye. The second gradient method for the direct numerical simulations of liquid-vapor flows with phase-change. Journal of Computational Physics, vol. 169, pags. 624-651, 2001. 
[30] D. Kemmler. O. Kolditz, A. Panagiotis e R. Rabenseifner. Application of high performance computing techniques (parallel processing) to the modeling of complex coupled geo-processes using a finite element approach. University of Tübingen, Center for Applied Geosciences, GeoSystemsResearch, 2005.

[31] J. Kim, K. Kang e J. S. Lowengrub. Conservative multigrid methods for CahnHilliard fluids. Journal of Computational Physics, vol. 193, pags. 511-543, 2004.

[32] J. Kim, K. Kang e J. S. Lowengrub. Conservative multigrid methods for ternary Cahn-Hilliard systems. Comm. Math. Sci., vol. 2, pags. 53-77, 2004.

[33] D. V. Le, B. C. Khao e J. Peraire. An immersed interface method for viscous incompressible flows involving rigid and flexible boundaries. Journal of Computational Physics, vol. 220, pags. 109-138, 2006.

[34] H. Liu, S. Krishman, S. Marella e H. S. Udaykumar. Sharp interface Cartesian grid method II: A technique for simulating with surface of arbitrary shape. Journal of Computational Physics, vol. 210, pags. 32-54, 2005.

[35] P. G. J. López, J. Hernández e F. Faura. A volume of fluid method based on multidimensional advection and spline interface reconstruction. Journal of Computational Physics, vol. 195, pags. 718-742, 2004.

[36] J. Lowengrub e L. Trusdinovsky. Quasi-incompressible Cahn-Hilliard fluids and topological transitions. Proceedings: Mathematical, Physical and Engineering Sciences, vol. 454, pags. 2617-2654, 1998.

[37] M. Mäntylä. An introduction to solid modelling. Computer Science Press, 1988.

[38] S. Marella, S. Krishman, H. Liu e H. S. Udaykumar. Sharp interface Cartesian grid method I: An easily implemented technique for $3 D$ moving boundary computations. Journal of Computational Physics, vol. 210, pags. 1-31, 2005.

[39] T. Masuda. Filling the signed distance field by fitting local quadrics. Proceedings 2nd International Symposium on 3D Data Processing, Visualization, and Transmission (3DPVT’04), 2004. 
[40] G. E. Marai, D. H. Laidlaw e J. J. Crisco. Super-resolution registration using tissueclassified distance fields. IEEE Transactions on Medical Imaging, vol. 25, n. 2, 2006.

[41] D. Marr e E. Hildreth. Theory of edge detection. Proc. Royal Soc. London, vol. 207, 1980.

[42] S. Mauch. Efficient algorithms for solving static Hamilton-Jacobi equations. PhD thesis, Caltech, Pasadena CA, abril 2003.

[43] S. J. Mosso, B. K. Swartz, D. B. Kothe e R. C. Ferrel. A parallel, volume-tracking algorithm for unstructured meshes. Parellel Computational Fluid Dynamics, Italy, 1996.

[44] E. P. Newren, A. L. Fogelson, R. D. Guy e R. M. Kirby. Unconditionally stable discretization of the immersed boundary equations. Journal of Computational Physics, vol. 222, pags. 702-719, 2007.

[45] B. D. Nichols, C. H. Hirt e R. S. Hotchkiss. SOLA-VOF: A solution algorithm for transient fluid flow with multiple free boundaries. Los Alamos National Lab Report LA-8355, 1980.

[46] R. L. Nós. Simulação de escoamentos tridimensionais bifásicos empregando métodos adaptativos e modelos de campo de fase. Tese de Doutorado, Universidade de São Paulo, 2007.

[47] S. Osher e J. A. Sethian. Fronts propagating with curvature-depedent speed: Algorithms based on Hamilton-Jacobi formulations. Journal of Computational Physics, vol. 79, pags. 12-49, 1988.

[48] S. Osher e R. P. Fedkiw. Level Set Methods: An overview and some recent results. Journal of Computational Physics, vol. 169, pags. 463-502, 2001.

[49] R. Peikert e C. Sigg. Optimized boundary polyhedra for GPU-based distance transform. Scientific Visualization: The Visual Extraction of Knowledge from Data, Springer, jan 2006.

[50] C. S. Peskin. Flow patterns around heart valves: A digital computer method for solving the equation of motion. PhD thesis, Albert Einstein College of Medicine Yeshiva University, julho 1972. 
[51] C. S. Peskin. Flow patterns around heart valves: A numerical methods. Journal of Computational Physics, vol. 10, pags. 252-271, 1972.

[52] C. S. Peskin. The immersed boundary method. Acta Numerica, pags. 479-517, 2002.

[53] G. R. Price, G. T. Reader, R. D. Rowe e J. D. Bugg. A piecewise parabolic interface calculation for volume tracking. Proceedings og the Sixth Annual Conference of the computational Fluid Dynamics Society of Canada, vol. VIII, pags. 71-77, 1998.

[54] Y. Renardy e M. Renardy. PROST: A parabolic reconstruction of surface tension for the volume-of-fluid method. Journal of Computational Physics, vol. 183, pags. 400-421, 2002.

[55] Y. Renardy, M. Renardy e V. Cristini. A new volume-of-fluid formulation for surfactants and simulations of drop deformation under shear at a low viscosity ratio. Eur. J. Mech. B 21, pags. 49-59, 2002.

[56] W. J. Rider e D. B. Kothe. Reconstructing volume tracking. Journal of Computational Physics, vol. 141, pags. 112-152, 1998.

[57] A. M. Roma. A multilevel self adaptive version of the immersed boundary method. PhD thesis, New York University, 1996.

[58] A. M. Roma, C. S. Peskin, e M. J. Berger. An adaptive version of the immersed boundary method. Journal of Computational Physics, vol. 153, pags. 509-534, 1999.

[59] R. Scardovelli e S. Zaleski. Direct numerical simulation of free-surface and interfacial flow. Annual Review of Fluid Mechanics, vol. 31, pags. 567-603, 1999.

[60] C. H. Séquin. Procedural spline interpolation in unicubix. Proc. Third USENIX Computer Graphics Workshop, pags. 63-83, 1986.

[61] J. A. Sethian. Level Set Methods. Cambridge University Press. Cambridge, 1996.

[62] J. A. Sethian. Level Set Methods and Fast Marching Methods. Cambridge University Press. Cambridge, 1999.

[63] J. A. Sethian. Evolution, implementation, and application of Level Set and Fast Marching Methods for advancing fronts. Journal of Computational Physics, vol. 169, pags. 503-555, 2001. 
[64] J. J. Shah e M. Mantyla. Parametric featture-based CAD/CAM concepts thechniques and applications, A Wiley-Interscience Publication, 1995.

[65] C. Sigg, R. Peikert e M. Gross. Signed distance field using graphics hardware. IEEE Graphics Visualization, outubro 2003.

[66] A. A. Silva. Implementação da estrutura de dados Halfedge visando aplicações em mecânica de fluidos computacional. Dissertação de mestrado em Matemática Aplicada, Universidade de São Paulo, 2006.

[67] L. Silva. Pertinência de pontos em objetos discretos de dimensão arbitrária. Tese de doutorado em Ciência da Computação, Universidade de São Paulo, 2004.

[68] M. Sussman, P. Smereka e S. J. Osher. A Level Set approach for computing solutions to imcompressible two-phase flows. Journal of Computational Physics, vol. 114, pags. 146-159, 1994.

[69] M. Sussman e P. Smereka. Axisymmetric free boundary problems. Journal of Fluid Mech. 341, pag. 269, 1997.

[70] M. Sussman, A. S. Almgren, J. B. Bell, P. Collela, L. H. Howell e M. L. Welcome. An adaptive Level Set approach for incompressible two-phase flows. Journal of Computational Physics, vol. 148, pags. 81-124, 1999.

[71] M. Sussman e E. Fatemi. An efficient, interface-preserving level set redistancing algorithm and its applications to interfacial incompressible fluid flow. SIAM J. Sci. Comp., vol. 20, pags. 1165-1191, 1999.

[72] H. Takewaki, A. Nishiguchi e T. Yabe. Cubic interpolation pseudo-particle method (CIP) for solving hyperbolic-type equations. Journal of Computational Physics, vol. 61, pag. 261, 1985.

[73] G. Thürmer e C. Wüthrich. Computing vertex normal from polygonal facets. Journal Graphics Tools, vol. 3, pags. 43-46, 1998.

[74] J. Yang e E. Balaras. An embedded-boundary formulation for large-eddy simulation of turbulent flows interating with moving boundaries. Journal of Computational Physics, vol. 215, pags. 12-40, 2006. 
[75] P. Yue, J. J. Feng, C. Liu e J. Shen. Viscoelastic effects on drop deformation in steady shear. Journal of Fluid Mech., vol. 540, pags. 427-437, 2005.

[76] P. Yue, J. J. Feng, C. Liu e J. Shen. Diffuse-interface simulations of drop-coalescence and retraction in viscoelastic fluids. J. non-Newtonian Fluid Dynamics, vol. 129, pags. 163-176, 2005.

[77] P. Yue, C. Zhou, J. J. Feng; C. F. Ollivier-Gooch e H. H. Hu. Phase-field simulations of interfacial dynamics in viscoelastic fluids using finite elements with adaptive meshing. Journal of Computational Physics, vol. 219, pags. 47-67, 2006.

[78] S. Xu e Z. J. Wang. An immmersed interface method for simulating the interaction of a fluid with moving boundaries. Journal of Computational Physics, vol. 216, pags. 454-493, 2006.

[79] W. Xunlei e F. Tendick. Multigrid integration for interactive deformable body simulation. Simuation Group, CIMIT / Harvard University, 2004.

[80] N. Zhang e Z. C. Zheng. An improved direct-forcing immersed boundary method for finite difference applications. Journal of Computational Physics, vol. 221, pags. 250-268, 2007.

[81] http://geuz.org/gmsh/\#Download

[82] http://www.geuz.org/gmsh/\#Documentation

[83] http://www.ltcm.mecanica.ufu.br/files/LTCM_file00106.pdf

[84] http://www.tecplot.com/ 